WALDEN

UNIVERSITY

A higher degree. $A$ higher purpose.

Walden University ScholarWorks

\title{
The relationship between religious and spiritual factors and the perpetration of intimate personal violence
}

Robbin G. Todhunter

Walden University

Follow this and additional works at: https://scholarworks.waldenu.edu/dissertations

Part of the Family, Life Course, and Society Commons, Psychology Commons, Religion Commons, and the Women's Studies Commons

This Dissertation is brought to you for free and open access by the Walden Dissertations and Doctoral Studies Collection at ScholarWorks. It has been accepted for inclusion in Walden Dissertations and Doctoral Studies by an authorized administrator of ScholarWorks. For more information, please contact ScholarWorks@waldenu.edu. 


\section{Walden University}

COLLEGE OF SOCIAL AND BEHAVIORAL SCIENCES

This is to certify that the doctoral dissertation by

Robbin G. Todhunter

has been found to be complete and satisfactory in all respects, and that any and all revisions required by the review committee have been made.

Review Committee

Dr. John Deaton, Committee Chairperson, Psychology Faculty

Dr. David Kriska, Committee Member, Psychology Faculty

Dr. Barry Trunk, Committee Member, Psychology Faculty

Chief Academic Officer

Denise DeZolt, Ph.D.

Walden University

2009 


\begin{abstract}
The Relationship Between Religious and Spiritual Factors and the

Perpetration of Intimate Personal Violence
\end{abstract}

By

Robbin G. Todhunter

Dissertation Submitted in Partial Fulfillment

of the Requirements for the Degree of

Doctor of Philosophy

Psychology

Walden University

May 2009 


\begin{abstract}
Intimate partner violence (IPV) is a multifaceted social issue that affects the Christian faith community as it does the secular community. Though the literature reflects some understanding of general correlates and possible antecedents to IPV within the Christian community, the impact of religious and spiritual factors tends to be homogenized and is often misjudged. Allport's theory of intrinsic and extrinsic religious orientation provided a platform for investigating Christian male-perpetrated IPV. This quantitative study utilized survey design and measured the impact of 10 select religious and spiritual factors on the probability of physical or sexual IPV perpetration. Archival data from Wave III of the National Longitudinal Study of Adolescent Health were used and included male participants ages 18 to 26 who nominally classified themselves as Catholic, Protestant, or Christian. Data were analyzed using binary logistic regression and results indicated that IPV perpetration could not be predicted from the 10 religious or spiritual factors. Given the geographic breadth and the size of the sample utilized, not finding a predictive model suggests there may be a lack of consistency in religious and spiritual orientation in these young males and elucidated analysis problems resulting from multicollinearity and the use of ordinal data. Though a predictive model for Christian male-perpetrated IPV was not found, the results of this study can contribute to social change by challenging existing ecclesiastical paradigms regarding which religious or spiritual factors, if any, impact Christian male-perpetrated IPV and which religious and spiritual factors should be addressed in faith-based batterers' programs targeting young adult males.
\end{abstract}



The Relationship Between Religious and Spiritual Factors and the Perpetration of Intimate Personal Violence

By

Robbin G. Todhunter

Dissertation Submitted in Partial Fulfillment of the Requirements for the Degree of

Doctor of Philosophy

Psychology

Walden University

June 2009 
UMI Number: 3366988

Copyright 2009 by

Todhunter, Robbin G.

All rights reserved

\title{
INFORMATION TO USERS
}

The quality of this reproduction is dependent upon the quality of the copy submitted. Broken or indistinct print, colored or poor quality illustrations and photographs, print bleed-through, substandard margins, and improper alignment can adversely affect reproduction.

In the unlikely event that the author did not send a complete manuscript and there are missing pages, these will be noted. Also, if unauthorized copyright material had to be removed, a note will indicate the deletion.

\section{UMI}

UMI Microform 3366988

Copyright 2009 by ProQuest LLC

All rights reserved. This microform edition is protected against unauthorized copying under Title 17, United States Code.

\author{
ProQuest LLC \\ 789 East Eisenhower Parkway \\ P.O. Box 1346 \\ Ann Arbor, Ml 48106-1346
}




\section{DEDICATION}

This dissertation is dedicated to those who have survived the tragedy of domestic violence and to those who have not. To those who daily choose to give back and labor on as wounded healers, I am inspired by your courage and humbled by your personal sacrifice. Your cries for help and for justice have not gone unheard. 


\section{ACKNOWLEDGMENTS}

Soli Deo Gloria! Non ut sibi ministretur sed ut ministret.

I want to gratefully acknowledge the boundless love and prayerful support of my

husband, Dr. Michael Todhunter, who never once failed in his encouragement of this work and who personally gave countless hours proofreading, editing, and reining me in. His own tireless efforts as an advocate for justice are admired more than I can say.

I would like to thank my mother, Rosemarie Guzowski, who began her sacrifice for my education many, many years ago; and my sister, Deborah Wood, who never stops cheering for me. This research has been as much a labor of their love as it was mine.

I would like to express my gratitude to my dissertation committee members: Dr. John Deaton, for his endless encouragement, keen insight, counsel, and enthusiasm; Drs. David Kriska and Barry Trunk, for their excellent instruction, feedback, and determination to stay the course with me. 


\section{SPECIAL ACKNOWLEDGMENT}

This research uses data from Add Health, a program project designed by J.

Richard Udry, Peter S. Bearman, and Kathleen Mullan Harris, and funded by a grant P01HD31921 from the Eunice Kennedy Shriver National Institute of Child Health and Human Development, with cooperative funding from 17 other agencies. Special acknowledgment is due Ronald R. Rindfuss and Barbara Entwisle for assistance in the original design. Persons interested in obtaining data files from Add Health should contact Add Health, Carolina Population Center, 123 W. Franklin Street, Chapel Hill, NC 275162524 (addhealth@unc.edu). No direct support was received from grant P01-HD31921 for this analysis. 
TABLE OF CONTENTS

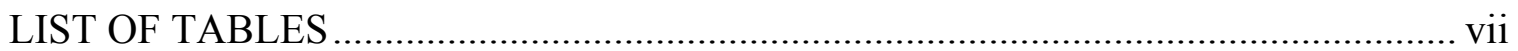

CHAPTER 1: INTRODUCTION TO THE STUDY .................................................

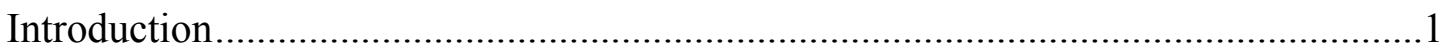

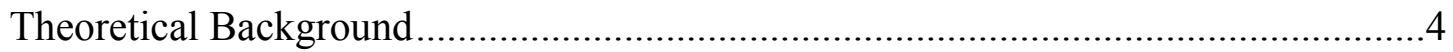

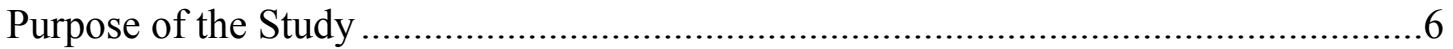

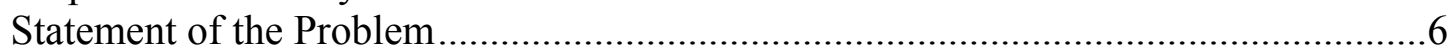

Research Questions ........................................................................................ 7

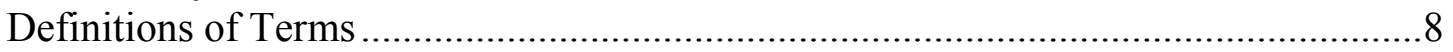

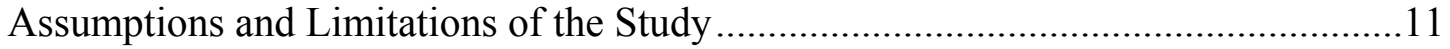

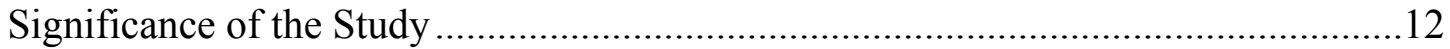

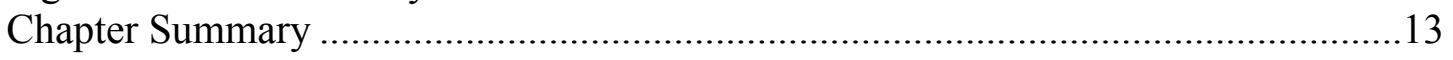

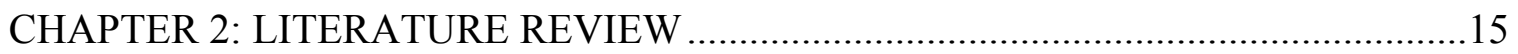

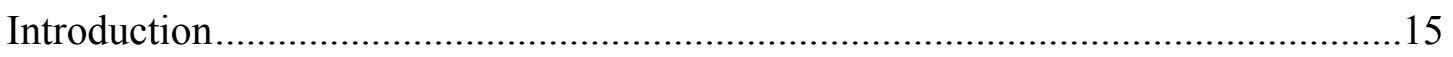

Suggested Antecedents to Domestic and Intimate Partner Violence.........................18

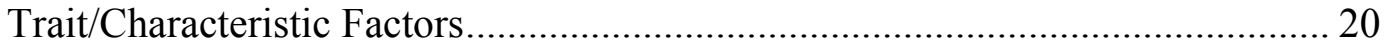

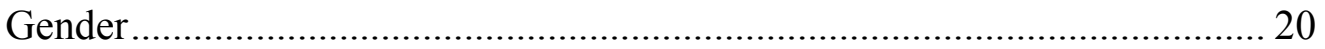

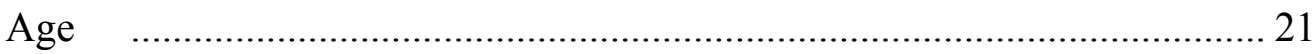

Income, Unemployment and Educational Attainment............................... 21

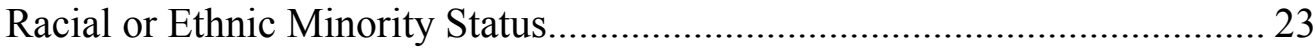

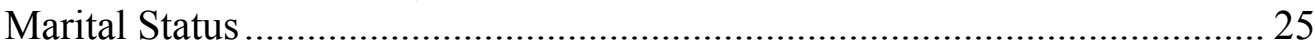

Substance Abuse .................................................................................. 25

Experiencing/Witnessing Violence during Childhood and Adolescence ....... 31

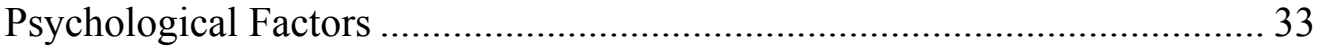

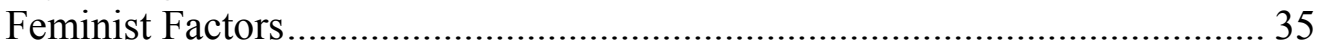

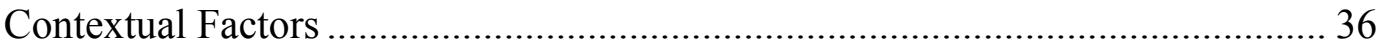

Relationship Satisfaction and Stress ...................................................... 36

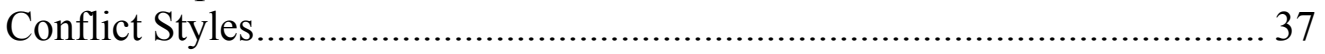

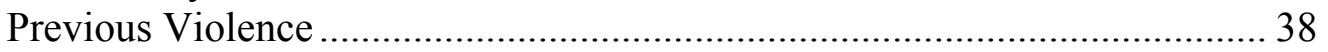

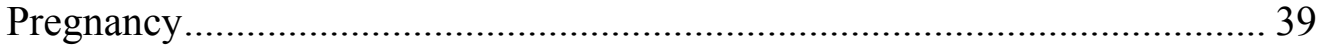

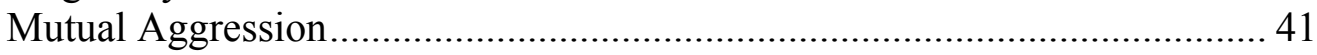

Availability of a Weapon ...................................................................... 42

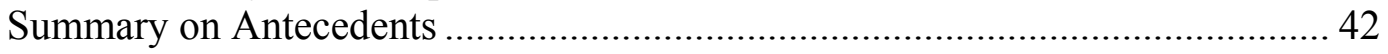

Religious Orientation: Intrinsic versus Extrinsic Motivation .................................44

Measuring the Constructs of Religious Orientation and Prejudice...................... 45

Criticisms to Allport's Theory and the ROS................................................... 49

Defining and Measuring Religious Orientation......................................... 49

Defining the Labels of Intrinsic and Extrinsic .......................................... 50

The Interrelationship between the I and E Factors .................................... 53

The Relationship between I and E and Other Variables ............................. 58 


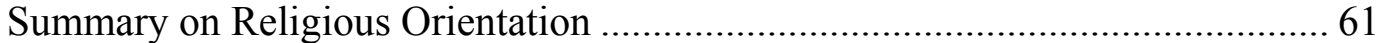

Exploration of Religious Antecedents to Domestic Violence ..................................62

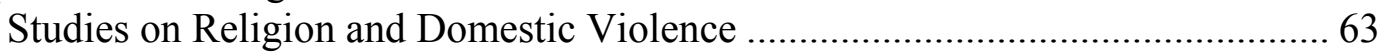

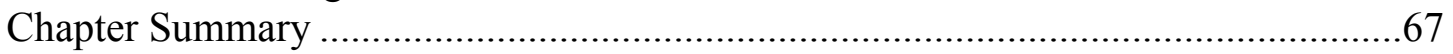

CHAPTER 3: RESEARCH METHOD ..................................................................69

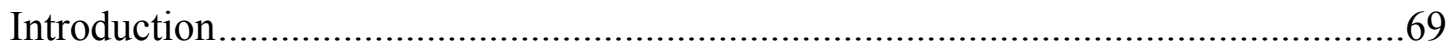

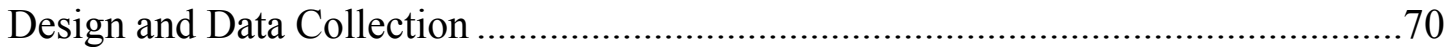

Summary of Wave I Design........................................................................... 70

Summary of Wave II Design ........................................................................ 71

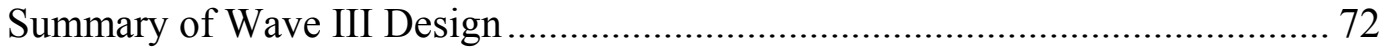

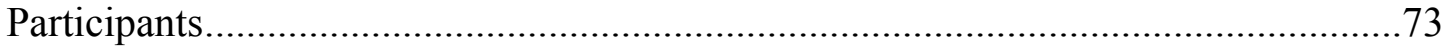

Summary of Wave I Participants ................................................................... 73

Summary of Wave II Participants .................................................................. 73

Summary of Wave III Participants ............................................................... 74

Measures To Protect Participants' Rights ......................................................... 74

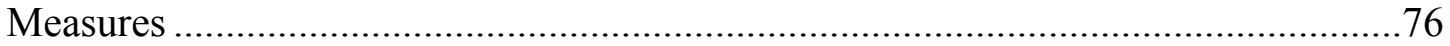

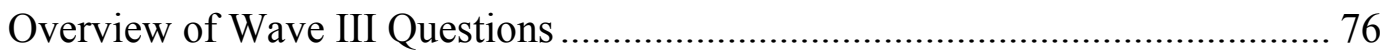

Question for Case Selection...................................................................... 77

Partner Violence Questions............................................................... 77

Religious and Spiritual Questions........................................................... 77

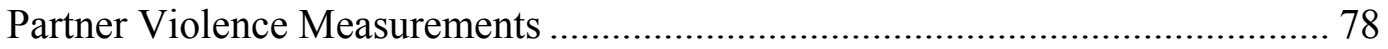

Religious and Spiritual Measurements ...................................................... 80

Frequency of Religious Attendance .................................................. 81

Other Corporate Religious Activities..................................................... 81

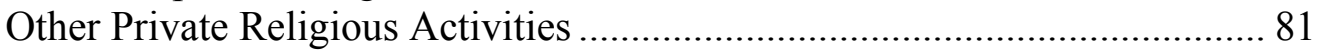

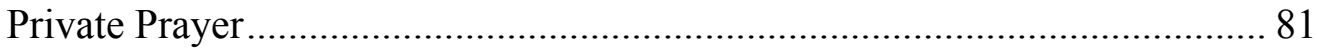

Importance of Spiritual Life........................................................... 82

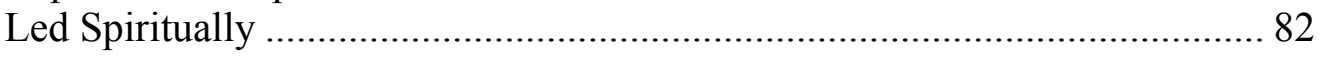

Integration Into Life ................................................................. 82

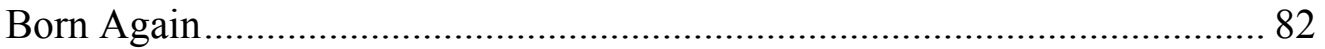

Degree of Religiousness ............................................................... 82

Degree of Spirituality......................................................................... 82

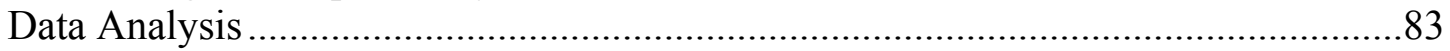

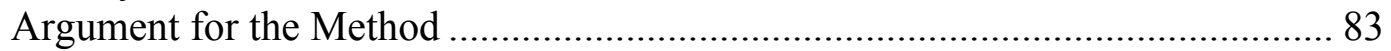

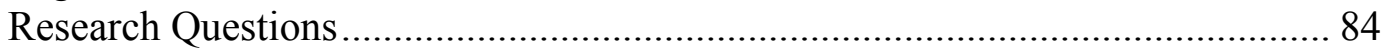

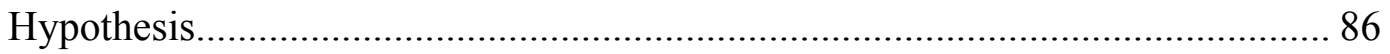

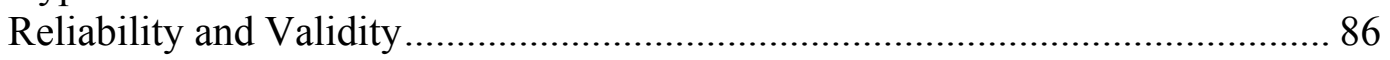

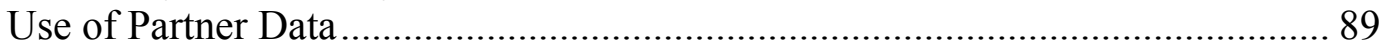

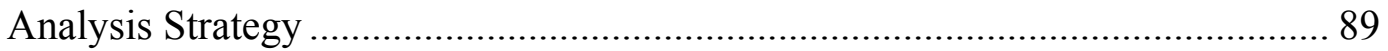

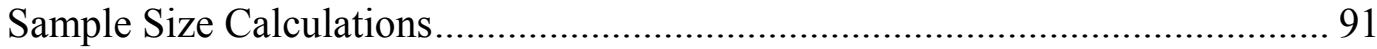

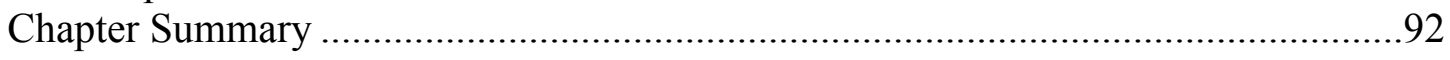

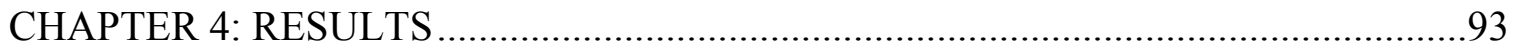




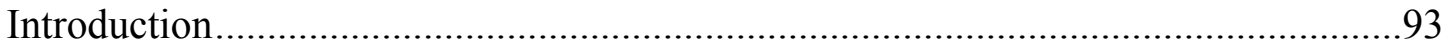

Reconstruction of the Add Health Data Sets ............................................................93

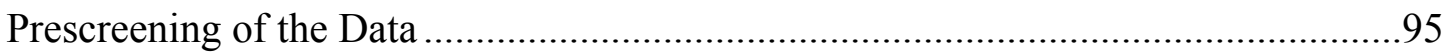

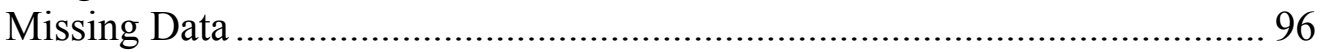

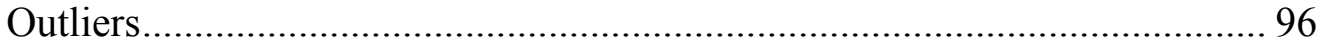

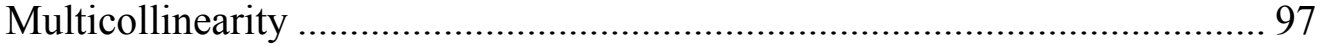

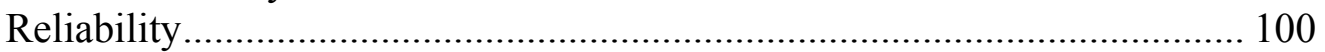

Analysis of Single Continuous Independent Variable .............................. 101

Demographic and Respondent Characteristics .................................................. 101

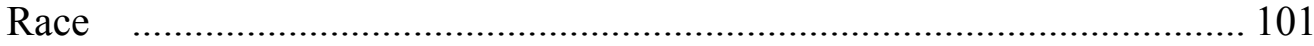

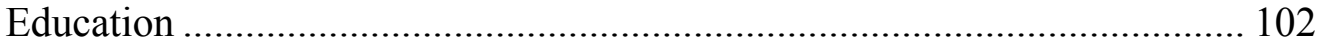

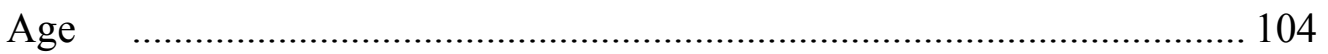

Religious and Spiritual Factors ........................................................... 105

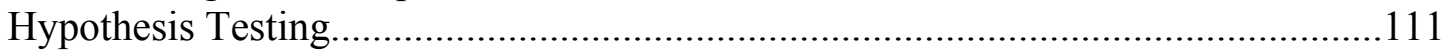

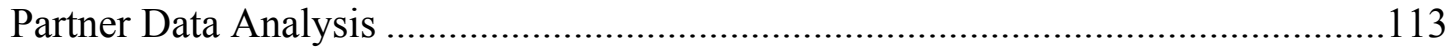

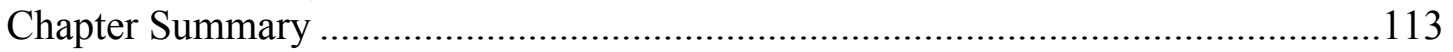

CHAPTER 5: SUMMARY, CONCLUSION, AND RECOMMENDATIONS .............114

Overview of the Study Problem and Methodology ..................................................114

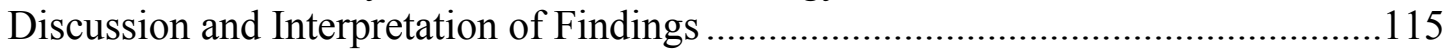

No Evidence of a Predictive Relationship ............................................. 115

Statistical Issues That May Mask the Relationship .................................. 117

Limitations of Ordinal Categorical Data.................................................. 119

Multicollinearity Issues.......................................................................... 119

Implications for Social Change and Recommended Actions ................................122

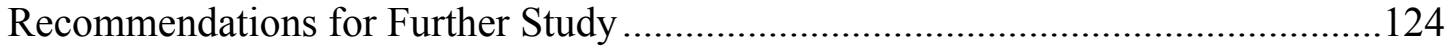

Further Examination the IPV-Religion Relationship................................. 124

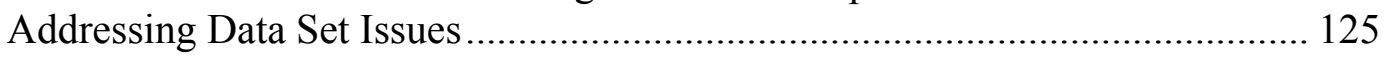

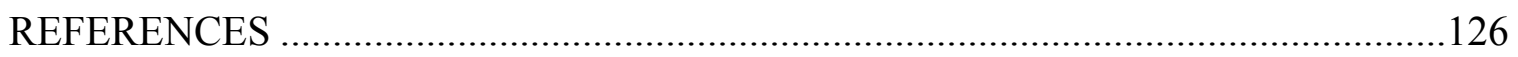

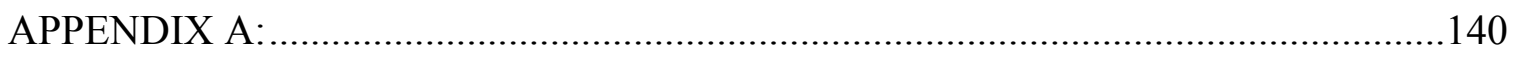

ALLPORT'S RELIGIOUS ORIENTATION SCALE QUESTIONS ......................140

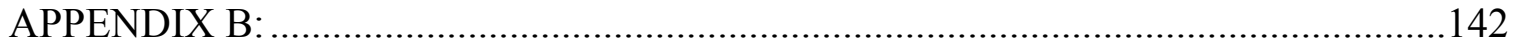

ADD HEALTH QUESTIONS: SECTION 1 - OVERVIEW AND

DEMOGRAPHICS ....................................................................... 142

APPENDIX C:

ADD HEALTH QUESTIONS: SECTION 7- EDUCATION .................................143

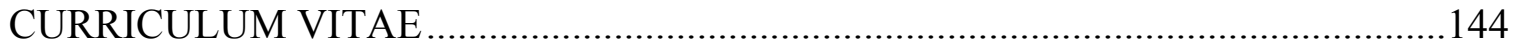




\section{LIST OF TABLES}

Table 1. Allport and Ross's 4 Category Model of Religious Orientation.......................... 48

Table 2. Example of General Construction Format of Merged Dataset ......................... 94

Table 3. Multicollinearity Statistics for Religious or Spiritual Factors ........................... 97

Table 4. Partial Correlations by Respondent Controlling for IPV Perpetration ............. 99

Table 5. Cronbach Alpha Item-Total Statistics............................................................. 100

Table 6. Racial Background .......................................................................................... 102

Table 7. Education Level of Respondents by Perpetration Occurrence ......................... 103

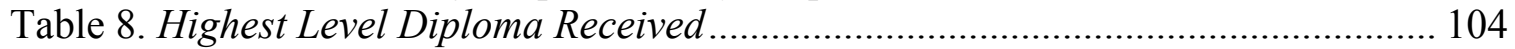

Table 9. Age Distribution by Respondent ................................................................... 105

Table 10. Religious or Spiritual Factor by Perpetration Occurrence - Part 1............. 107

Table 11. Religious or Spiritual Factor By Perpetration Occurrence - Part 2 ............. 108

Table 12. Religious or Spiritual Factor By Perpetration Occurrence - Part 3 ............. 109

Table 13. Percent of Respondents by Level of Religious or Spiritual Factors ............... 110 


\title{
CHAPTER 1:
}

\section{INTRODUCTION TO THE STUDY}

\author{
Introduction
}

In the literature there is much debate about the subject of domestic violence (DV) and more specifically, intimate partner violence (IPV). Reporting variations, differences in the definition of violence, disagreements about what constitutes an intimate relationship, and barriers to full and accurate disclosures of incidents make difficult the task of capturing the magnitude of IPV (Greenfeld et al. 1998). However, what is not debated is that IPV is a significant social problem in the United States.

The U.S. Department of Justice estimates that 3.9 million women have been victimized by current or previous intimate partners (Greenfeld et al., 1998). The World Health Organization (WHO) estimates the number of American women who have experienced at least one physical assault by an intimate partner from 1982 through 1999 at a staggering $22 \%$ of the female population (WHO, 2002). Figures from the National Center for Injury Prevention and Control indicate that in the United States 5.3 million occurrences of physical DV against women, over the age of 18 years, take place annually (Centers for Disease Control and Prevention [CDC], 2003). Collins et al. (1999) found that two out of five American women, over the age of 18, have been physically assaulted or sexually abused and/or were victims of DV.

Though the incident rate of overall violence against men exceeds that of women by $42 \%$, women were almost seven times more likely to be victimized by an intimate partner (Greenfeld et al., 1998; Rennison, 2003; Rennison \& Welchans, 2000). According 
to the Bureau of Justice Statistics (BJS), IPV accounted for $21.5 \%$ of nonfatal violence against women between 2001 and 2005 but only 3.6\% of such violence against men (BJS, 2005a). Perhaps even more staggering is the report that IPV accounts for $33 \%$ of femicide in this country but only 3 to $4 \%$ of male murders (BJS, 2005).

The economic toll of IPV includes expenses of victim injuries associated with 1.3 million occurrences of violence against women per year, as well as costs associated with the loss of victims' lives (BJS, 2005; Tjaden \& Thoennes, 2000). Annual expenses also reflect indirect costs associated with the emotional toll within households, detrimental developmental effects on children, lost productivity estimated at 8 million days of work, totaling $\$ 0.9$ billion, health costs estimated at $\$ 4.1$ billion, and burgeoning legal costs (CDC, 2003; Levendosky \& Graham-Bermann, 2001; Tjaden \& Thoennes, 2000).

Efforts to address this public health problem typically focus on victim safety and/or perpetrator accountability. For those who commit family violence, several types of prevention and intervention measures have been tried with mixed results and limited success (Bennett \& Williams, 2001; Dutton \& Corvo, 2006; Feder \& Forde, 2000; Gerlock, 2004; Holtzworth-Munroe, Meehan, Herron, Rehman, \& Stuart, 2000; Jones, Fowler, Farmer, Anderson, \& Richmond, 2005; Jones \& Gondolf, 2001; Kernsmith, 2005; National Institute of Justice [NIJ], 2002, 2003). Batterer's intervention programs (BIP) methodologies vary from the cognitive-behavioral to the merely psychoeducational but, across the board, appear to be woefully inadequate, with perpetrator recidivism rates of 39 to $86 \%$ or more (Bennett \& Williams, 2001; Dutton \& Corvo, 2006; Eckhardt, 
Murphy, Black, \& Shur, 2004; Feder \& Forde, 2000; Gerlock, 2004; Holtzworth-Munroe et al., 2000; Koss, Bachar, Hopkins, \& Carlson, 2004).

Despite faith doctrine and teachings to the contrary, the Christian community has not been spared the reality of family violence, with rates of occurrence that parallel the secular population (Annis \& Rice, 2001; Brinkerhoff, Grandin, \& Lupri, 1992; NasonClark, 2000, 2004). Faith-based batterer programs are similar in structure to secular programs; but are attended predominately by men who are Caucasian, employed, married, older, and more educated than men who populate the community programs (Nason-Clark, Murphy, Fisher-Townsend, \& Ruff, 2003). One argument frequently offered is that religious perpetrators of IPV may be helped more in a Church-based BIP because such programs might appeal to their conservative religious views, despite the fact that overt religious content often is not included in the faith programs (Nason-Clark et al.). However, according to Nason-Clark et al., $(2000,2003)$ there is no indication that faith-based batterers' programs yield any greater success in helping men who abuse their partners.

Exacerbating the problem of IPV in the Church, Nason-Clark (2004) observed that religious leaders may be reluctant to encourage members of their congregation to seek resources outside of the Church for fear that those outside their community will not be able to effectively deal with faith-based needs. In part this concern is warranted as many secular counselors think that religious beliefs are superfluous, extraneous or inappropriate as part of IPV intervention and treatment efforts (Foss \& Warnke, 2003; Pargament, Magyar-Russell, \& Murray-Swank, 2005). 
Given the family impact and social implications of DV, a steadily increasing number of studies have been undertaken to understand this type of abuse, though no one theoretical orientation drives the research. Salazar and Cook (2002) observed that studies addressing physical and sexual IPV have been limited in their scope and application with approximately half of the reported research considering only indirect or contributory factors, rather than substantive causes. Additionally, much of the research reflects the use of restricted, clinical, or convenience samples (Salazar \& Cook) or is unidirectional in nature, focusing exclusively on victims or on perpetrators (Michalski, 2005). Few studies have been conducted specifically examining the impact of religious variables on IPV (Ellison \& Anderson, 2001) and what research does exist frequently offers conflicting findings (Michalski, 2005; Nason-Clark, 2004).

In an attempt to improve batterer intervention strategies, researchers have suggested exploration into the use of multidisciplinary approaches as well as clientspecific methods (Michalski, 2005; Nason-Clark, 2004, 2000, 1997). Regarding faithbased intervention strategies, a logical next step may be to more closely examine individuals, who at least nominally label themselves as Christians, in order to better understand the phenomenon of violence by intimates within this community starting with an examination of the religious orientation of the religious batterer.

\section{Theoretical Background}

To more closely examine the phenomena of racial prejudice in the Christian Church, Allport and Ross (1967) developed the Religious Orientation Scale (ROS) as a way of capturing the maturity of one's faith, independent of the object of that faith. The 
ROS incorporates behavioral, attitudinal, and motivational elements to categorize a person's religious orientation in one of four ways: (a) as intrinsic, pertaining to those whose faith is core to their worldview, (b) as extrinsic, pertaining to those whose faith is seen as useful for some purpose (c) as indiscriminately proreligious, reflecting those who endorse both intrinsic and extrinsic elements equally, or (d) as indiscriminately antireligious, reflecting those who appear to be nonreligious (Allport \& Ross, 1967).

According to Allport (1966), the frequency and regularity of a person's participation in religious activities, such as weekly services and special Bible studies, was an indication of a kind of intrinsically oriented faith, which was more mature and deepseated. Allport and Ross (1967) reported that extrinsically oriented people who considered their faith as a means to an end were often sporadic churchgoers. In their analysis, Allport and Ross found that these sporadically attending churchgoers were more likely to be ethnically prejudiced than either nonchurchgoers or regular churchgoers. The difference between internalized versus externalized motivations surrounding one's religious commitment was linked to other negative social attributes, such as extreme ideological bias and dogmatism (Allport \& Ross; Donahue, 1985; Malony, 1971).

More recent research indicates that the degree and frequency of one's religious involvement may be inversely related to another antisocial behavior: IPV (Cunradi, Caetano, \& Schafer, 2002a; Ellison \& Anderson, 2001; Ellison, Bartkowski, \& Anderson, 1999). If a person's religious orientation is reflected in the degree to which he or she participates in religious activities, or holds to certain beliefs and attitudes, faith-based 
efforts to minimize or prevent DV within the Church could be tailored to be more clientspecific and perhaps greatly improved.

\section{Purpose of the Study}

Using data Wave III (i.e., the sixth follow-up year, conducted between 2001 and 2002) of The National Longitudinal Study of Adolescent Health (Add Health), this study explored the relationship between various religious and spiritual factors and the perpetration of IPV, by young male adults aged 18 to 26. Specifically, this research examined the impact of religious and spiritual factors on the risk of perpetrating, or threatening to perpetrate IPV. Also included was an assessment of the model predicting IPV and the factors that were essential to successful classification of cases by the model.

\section{Statement of the Problem}

Nason-Clark (2004) observed that if the church membership and its leadership ignored the existence of or the levels of IPV within the congregation, already unhealthy outcomes would be exacerbated within the religious community, making it more challenging to secure help as either a victim or a batterer. Problems with this "holy hush" (Nason-Clark, 1999, p. 357) have been intensified by confusing religious ideologies surrounding reconciliation, forgiveness, suffering, and submission. Treatment for both IPV survivors and batterers within the Church may require resources that secular counselors feel unqualified to provide. Alternatively, Nason-Clark (2004) observed that clergy may be reluctant to encourage congregational members to tap into resources outside of the Church for fear that those outside the Church will not be able to effectively deal with faith-based needs. 
To create relevant, effective, faith-based violence prevention or intervention programs it is necessary to better understand a person's religious orientation and more specifically, the degree to which his or her religious involvement in the faith community is associated with the perpetration or the suffering of intimate personal violence. While there have been studies that investigated religious antecedents and deterrents to DV, none have been found to specifically examine these elements in younger adults, aged 18 to 26 , who appear to be more at risk for both the IPV perpetration and victimization (CDC, 2007; Cunradi et al., 2002a; Ellison et al., 1999; Hedin \& Janson, 2000; Miller 2006; Pan, Neidig, \& O’Leary, 1994; Schmaling et al., 2006; Weir, 2000).

The purpose of this study was to investigate the relationship between IPV and religious and spiritual factors using data from Wave III of the National Longitudinal Study of Adolescent Health (Harris, 2008). Building on the work of Allport (1966) and others, the idea of intrinsic and extrinsic motivation, as expressed by various religious and spiritual factors was explored.

\section{Research Questions}

The research questions to be answered included:

1. To what extent do certain religious or spiritual factors (i.e., frequency of: religious attendance, corporate religious activities, private religious activities, private prayer, importance of spiritual life, belief of being led spiritually, integration of beliefs into life, being born again, degree of religiousness, and degree of spirituality) increase or decrease the odds of committing IPV 
2. If IPV occurrence can be correctly predicted, which religious and spiritual factors are essential to the prediction?

3. How good is the model developed at classifying cases for which the occurrence of IPV is unknown?

The hypotheses investigated followed this general format for each of religious or spiritual factors examined:

(Null Hypothesis): The probability of occurrence of [religious or spiritual factor] is not related to the frequency of perpetration of physical, sexual, injurious, and/or threatening violence toward an intimate partner.

(Alternative Hypothesis): The probability of occurrence of [religious or spiritual factor] is related to the frequency of perpetration of physical, sexual, injurious, and/or threatening violence toward an intimate partner.

\section{Definitions of Terms}

Aggression: any malicious act, with the intention of hurting another, including physical and nonphysical actions (Gelles \& Straus, 1979).

Church or Church community: In this study, the Christian church, its membership, or those who consider themselves to be members. Also referred to as the Christian community.

Church-based: In this study meaning associated with the Christian church (any denomination) or sponsored by ecclesiastical resources. Also used interchangeably with the term faith-based. 
Domestic violence $(D V)$ : in the literature, physical or sexual violence, threats of violence, verbal, emotional, psychological abuse committed by or against spouses, boyfriends/girlfriends, or same sex partner (CDC, 2003; WHO, 2002). Violence between family members was referred to as domestic violence in the literature. For the purposes of the analysis in this study, DV was considered to encompass intimate partner violence or more specifically, threats of violence, or actual physical violence of any degree, or sexual violence between intimate partners.

Extrinsic: originating from external factors; exoterically driven (Allport \& Ross, 1967; Batson, 1976).

Faith-based: In this study meaning associated with the Christian church (any denomination) or sponsored by ecclesiastical resources. Also used interchangeably with the term church-based.

Intimate: used as a noun to describe a current or former spouse, boyfriend/girlfriend, partner, date, or dating partner (Rennison, 2003). Intimate Partner Violence (IPV): Behavior within an intimate relationship intended to cause physical, sexual, psychological, or emotional harm to another (Rennison \& Welchans, 2000). In this study, it is considered synonymous with domestic violence (DV) as it occurs between intimate partners.

Intimate relationship: a relationship between current or former spouses, boyfriend, girlfriends, and/or same sex partners. Distinguished from relationships with other family members such as parents, siblings, cousins, grandparents, etc. 
Intrinsic: originating from the essential nature of a thing; internally driven (Allport \& Ross, 1967; Batson, 1976).

Perpetrator: the person presumed to have initiated the physical or sexual violence or the person who was the primary abuser.

Religious and/or spiritual factors: Ten religious or spiritual behaviors, beliefs, attitudes, and activities as derived from 10 Add Health Questions in Section 19: Religion and Spirituality. These factors comprised the 10 independent variables examined in this research.

Risk: the likelihood of experiencing or perpetrating violence in the future. Includes factors such as the type, degree, frequency, and immediacy of the violence (Kroop, 2008).

Risk factors: antecedents: factors that signal the likelihood of violence occurring in the proximate future. In some cases the type, frequency, and significance of the consequences are part of the consideration (Riggs \& Caulfield, 2000).

Social economic status (SES): In some literature SES reflects generally income level, but also at times includes the perceived social status of the individual including arrest records and criminal activity. In this study it is most directly tied to income level.

Substance abuse: The use or overuse of any substance that causes impairment, whether legal or illicit (Kroop, 2008).

Victim: the person who is subjected to violent behaviors and actions. 
Violence: a behavior carried out with the intention of causing physical, sexual, psychological, or emotional injury or harm to another (Gelles \& Straus, 1979). For example: rape, homicide, assault, and robbery, threats, and intimidation.

Assumptions and Limitations of the Study

As Allport and Ross (1967) suggested, one key assumption in this study was that membership and participation within a Church was stimulated by different cognitions and motivations. This assumption also was extended to the motivations and cognitions surrounding a respondent's classification of their present religion as Protestant, Catholic, or Christian.

This research used self-reported, behavioral incidents of IPV as well as selfreported religious or spiritual factors. The accuracy of a participant's admission of perpetrated violence, as well as the level of his or her religious or spiritual attitudes and behaviors, might have been seriously limited by a social desirability bias. It was this researcher's intention to use partner-report information to minimize threats to the internal validity of the study.

Though the use of 2001 to 2002 archival data likely presented some limitations to content and external validity, the demographical breadth of this longitudinal study outweighed these limitations. Retrospective answers to interview and survey questions may have been inaccurate due to the need to recall frequencies of IPV events and religious and spiritual activities and behaviors over a 12-month period. Such overdemanding recall might have resulted in exaggerations or minimizations in the frequency and time estimates given by the respondents. Also, there might have been some 
ambiguity in the interpretation of the response options because the questions were asked in a way that seemed like a single partner was presumed for the time frame in question.

The Add Health IPV data collected allowed for only limited distinction between the type and severity of violence experienced or perpetrated by the respondents and/or their partners. The 12-month timeframe Add Health, used for event recall, did not allow for the distinction between acute-only and chronic abuse. With only the inclusion of physical or sexual violence, the results of the Add health study did not sufficiently address other forms of violence (e.g., verbal, emotional, psychological) that often precede escalation to the physical or sexual assaults.

Perhaps the greatest limitation in this study was its construct validity. Answers to several questions from Section 31 of the Add Health study were used as proxy measures for the construct of religious orientation, and in particular intrinsic orientation. Convergent validity, or the degree to which Add Health Measures of religiosity and spirituality are correlated with Allport's ROS or other measures of religious orientation were not ascertained in this study. Generalizability of the findings regarding the relationship between religious and spiritual factors and incidents or threats of IPV was limited to the actual factors examined.

\section{Significance of the Study}

This study was expected to supplement existing knowledge and contribute to Walden University's mission of social change by: 
1. Closing the gap in the literature with the contribution of new and generalizable information regarding religious and spiritual factors that might be related to the perpetration of IPV among 18 to 26 year olds.

2. Raising Church and community awareness of IPV and shifting ecclesiastical and secular paradigms regarding partner violence in the Church with information that could help remove the stigma, shame, and silence that surround this crime.

3. Advocating for collaborative efforts between ecclesiastical and secular resources to provide more specific and client-tailored approaches in faithbased and secular batterer's intervention efforts in an attempt to decrease the levels of IPV perpetration.

4. Contributing to a better understanding by secular mental health professionals, clergy, and lay ministers of the unique motivations, attitudes, and beliefs of the batterer within the Church community and thereby open opportunities for improvements in counseling approaches of psychologists and clergy working with the faith community.

5. Spawning additional research in the area of IPV, especially among young adults.

\section{Chapter Summary}

Though the risk factors associated with IPV are varied and complicated, they warrant continued examination. Some research has indicated that a better understanding of the religious and spiritual factors among members of the Christian faith community 
may help us to better understand violent behaviors within this population. Knowing whether or not a batterer's religious or spiritual behaviors and beliefs are related to his perpetration of personal violence, counselors, clinicians, and ecclesiastical resources may be able to more specifically tailor and improve faith-based, and possibly secular, intervention and prevention approaches.

In chapter 2 a review of key research regarding antecedents of domestic violence is discussed. Factors suspected to impact the religiosity-violence relationship are also examined. The theoretical framework of Allport's theory of religious orientation, its criticisms, and its possible relationship to antisocial behaviors is offered. Recent research on religion-based antecedents to IPV will be evaluated. Chapter 3 explains the logistic regression analyses utilizing Add Health Wave III data, followed by the analyses findings in chapter 4 and conclusions in chapter 5. 


\section{CHAPTER 2:}

\section{LITERATURE REVIEW}

\section{Introduction}

As evidenced in the literature, there are numerous theoretical explanations for the development of abusive and violent relationships between intimates (Emery \& LaumannBillings, 1998; Riggs \& Caulfield, 2000; Tjaden \& Thoennes, 2000). For example, psychological theories address the impact of personality disorders and other psychopathic phenomena on violence perpetration (Dutton, Bodnarchuk, \& Cavanaugh, 2005). Feminist theories explore and center heavily upon the notion of male power and control over women, as well as the assertion of male privilege (Gelles \& Straus, 1979; Yllo, 2005). Under the umbrella of social structure theory, there are useful sub theories such as control theory, which examines why people are usually nonviolent and resource theory, which considers the ways in which money, property, or goods contextually affect family violence (Gelles \& Straus, 1979; Loseke, 2005). Though numerous and varied, within these theories there exist a number of overlapping elements that provide evidence for the existence of generalized DV risk factors.

The research does not support the existence of a single risk factor, or even a composite of several factors, that can be used to assess one's probability of being abusive or of being a victim of abuse. Nor can factors be used to predict specific incidents of abuse (Dobash, 2003; Riggs \& Caulfield, 2000). However, despite the inadequacies of various assessment methodologies, Kroop (2008) emphasized the need for some sort of violence risk assessment that can be used by mental health professionals, medical 
personnel, law enforcement, and community workers. In his opinion, understanding and communicating information about overall risk allows potential victims to take safety measures and help field workers and professionals educate communities, while creating or improving violence prevention and intervention efforts.

Contributory factors in the onset, protraction, and termination of domestic, family, and IPV have been researched extensively in the literature, but few studies have been found to specifically examine the relationship between religious or spiritual attitudes, beliefs, and behaviors and these types of violence (Ellison \& Anderson, 2001; Ellison, et al., 1999; Nason-Clark, 2004). While not discounting the usefulness of insights garnered by general DV research, the paradox of partner violence within the Christian Church might be more fruitfully examined from not only a straightforward risk-marker perspective but also from a cognitive-motivational point of view. If membership and participation within a church are stimulated by different cognitions and motivations, an explanation of doctrinally inconsistent behaviors like partner abuse within the Church may be possible. By probing for explanations for the occurrence of behaviors and attitudes that contradict Christian values and beliefs, prevention and intervention efforts marshaled by the Church may be enhanced.

This critical literature review includes an examination of the general research, which investigates risk factors and correlates to domestic and intimate partner violence, including traits, characteristics, and contextual circumstances. To frame the concept of mature religiousness or spirituality, a review of Allport's theory of religiosity is completed, as well as the primary criticisms of the theory including (a) its operational 
definition and measurement of the construct of religious orientation, (b) objections to the application of intrinsic and extrinsic labeling, (c) the relationship between intrinsicness and extrinsicness, and (d) the relationship between intrinsicness/extrinsicness and other variables. Suggested changes and improvements to Allport's approach to examining the relationship between religion and negative social behaviors and attitudes are included within the critiques. A review of the limited research available in the area of religious correlates and DV is reviewed. This literature survey will lay the groundwork for the use of Allport's religious orientation theory as a foundation for examining more closely the paradox of DV within the Christian Church.

Literature gathered for this review includes articles printed in English only obtained primarily via electronic databases such as PsycINFO, PsycARTICLES, PsycBOOKS, SocINDEX, and Academic Search Premier. Additional articles were obtained through IU-Bloomington's Document Delivery Service, the University of Minnesota library and journal search, and various U.S. government websites. Key journals searched included The Journal for the Scientific Study of Religion The Journal of Family Violence, The Journal of Interpersonal Violence, Trauma, Violence \& Abuse, Violence Against Women, Violence and Victims, Journal of the American Academy of Religion, Bulletin of the Colloquium on Violence and Religion, Journal of Consulting and Clinical Psychology, and key reports completed on behalf of the National Institute of Justice and the CDC. Key search words included intimate partner violence, domestic violence, family violence, dating violence, religious orientation, religiosity, as well as key author and specific article searches. 
Suggested Antecedents to Domestic and Intimate Partner Violence

In his review, Kropp (2008) emphasized that health and community workers dealing with domestic violence and, in particular, IPV, often make risk assessments even though there is no clear, agreed-upon methodology for completing such an evaluation. In his view, even the very concept of what constitutes a risk is debatable. Nonetheless, by striking a balance between an unstructured, somewhat unreliable clinician assessment and a more rigid, "actuarial” (2008, p. 206) approach, Kroop advocated an assessment that blends the judgment of professionals with empirical knowledge about violence.

There is also concern expressed in the literature about whether the discussion of risk factors or antecedents to IPV is tantamount to blaming the victim for the violence experienced. However, the journal literature generally supports investigations into any factors that enhance or directly impact victimization, in as much as the findings are useful for IPV intervention and prevention efforts (Koss \& Dinero, 1989; Siegel \& Williams, 2001).

Key to the knowledge base is a better understanding of the antecedents to family violence from both the perpetrator and victim's perspective. IPV markers have been suggested from sociological, demographical, feminist, psychological, and biological arenas, and most researchers imply there is a dynamic component that includes a variety of situational factors. Characteristics thought to be linked together differ depending on whether the study focused narrowly (e.g., using women from a clinical or shelter settings, men from a batterer's group), or more broadly examined. It was not uncommon to find that the research literature did not distinguish well between severe abuse, moderate 
aggression, maltreatment, or minor offenses and as such may be limited in its applicability across situations (Dobash, 2003; Emery \& Laumann-Billings, 1998; Kantor \& Jasinski, 1998).

However, despite all the research caveats, several studies reveal or affirm characteristic themes for those who experience IPV and for those who perpetrate this abuse. Correlates generally considered in the literature were divided into individual trait or characteristic categories which included: gender, age, socioeconomic status (SES), education, race/ethnic background, marital status, alcohol/drug usage, violence in the natal family; and various psycho-social factors and feminist elements, such as power and control disparities, gender norms, and social norms about violence (Coker, Smith, McKeown, \& King, 2000; Cunradi et al., 2002a; Ellison \& Anderson, 2001, Ellison et al., 1999; Heise \& Garcia-Moreno, 2002; Nason-Clark, 2004; Tjaden \& Thoennes, 2000, WHO, 2002).

Rather than viewing IPV in terms of its severity or the reasons for its onset, Aldarondo and Sugarman (1996) examined DV in terms of stable and malleable factors. These researchers pointed out that stable elements have been found useful in assessing the risk for the onset of domestic abuse, while malleable factors (i.e., those that vary with the situation or developmentally shift) were shown to correlate with both the onset of violence and its cessation or continuation. In this vein, intimate violence has also been investigated from the angle of contextual and relationship circumstances such as with marital conflict, pregnancy, the occurrence of previous violence, and economic stress (Aldarondo \& Sugarman, 1996; WHO, 2002). 
Important findings in the trait, characteristic, and contextual arenas will be reviewed in the following section.

\section{Trait/Characteristic Factors}

\section{Gender}

IPV is not exclusively a heterosexual, male-on-female perpetrated crime, and research has been conducted to better understand female aggression against their intimate partners (Busch \& Rosenberg, 2004; Leonard \& Senchak, 1996, Melton \& Belknap, 2003; Reed, 2008), as well as violence within same-sex relationships (Greenwood et al., 2002; Miller, Bobner, \& Zarski, 2000; O’Leary, Barling, Arias, Rosenbaum, Malone, \& Tyree, 1989). Nonetheless, national statistics generally have indicated that physical and sexual abuse remains predominately a crime against women, with $25 \%$ of women (33\% for African American women) having been physically or sexually attacked versus 7 to 14\% of men (Breiding, Black, \& Ryan, 2008; Tjaden \& Thoennes, 2000). According to the Bureau of Justice (2005) crime characteristics intimate partners committed $70 \%$ of female rape/sexual assaults. Similarly, $18 \%$ of all female assaults were committed by their male partners as compared to $3 \%$ of male assaults.

Seeking to clarify the notion of gender asymmetry in violence, Melton and Belknap (2003) examined official police reports and legal records and found the most serious IPV threats and actions were perpetrated by males and that reports of female perpetrated violence frequently were in conjunction with episodes of dual reporting and appeared to be defensive in nature. 
Age

Younger women, especially in the 18-to-24-year-old bracket, appear to experience IPV more often than older women (CDC, 2007; Cunradi et al., 2002a; Ellison et al., 1999; Hedin \& Janson, 2000; Miller 2006; Schmaling et al., 2006; Weir, 2000). Felson and Burchfield (2004) found that young women appeared to be more at risk of victimization while drinking and speculate that this was possibly due to increased risktaking while under the influence of alcohol. In their longitudinal study of 391 New York couples, O’Leary et al. (1989) found the occurrence of physical violence before and after marriage was higher in the under-30 age group (16\%) versus the 31-to-50-year age group (5\%). Pan et al. (1994) found that for perpetrators, with every 10 -year increase in age there was a $29 \%$ decrease in the odds of committing mild violence and a $19 \%$ decrease in odds of committing severe violence. However, Pan et al. also reported that though aggression diminishes with age, age itself does not allow for a differentiation between mild and severely abusive men.

Income, Unemployment and Educational Attainment

Though the occurrence of violence between intimates domestic violence has been reported at all economic and educational levels, low socioeconomic (SES) factors have been shown to be strong correlates to at least initial violence perpetration between intimates (Hedin \& Janson, 2000) and in some cases, are able to forecast batterer recidivism (Cattaneo \& Goodman, 2003). The WHO (2002) found that worldwide having a higher SES affords women an element of protection, though it is not clear if this is because of the specific financial resources available or because of improvements in 
various emotional and psychological factors such as personal stress, frustration, a sense of culturally defined success, and life satisfaction.

Interestingly, Ellison et al. (1999) noted that unemployed women engaged in higher levels of IPV, though their overall rate of perpetration was less than males. In their investigation into recurrent partner violence, Cattaneo and Goodman (2003) found that unemployed men in particular had higher rates of repeat abuse. Other studies revealed that lower SES batterers perpetrated not only severe violence, but also were inclined to extend their assaults without a break (Pan et al, 1994; Riggs \& Caulfield, 2000).

Similarly, Aldarondo and Sugarman (1996) concluded that batterers, who did not suspend their violent behaviors, reported more unemployment, lower income, and more intense and harmful physical conflict with their partner.

Mean annual household income was found to exert the most influence on reports of the occurrence of male to female violence with both Black and Hispanic couples, but not with White couples (Cunradi et al., 2002b) and in female-to-male violence in Black couples. Pan et al. (1994) concluded that for every $\$ 1000$ of income earned the risk of perpetrating mild physical violence decreased by $3 \%$ and of severe violence by $5 \%$. Using data from the 2005 Behavioral Risk Factor Surveillance System Survey, Breiding et al. (2008) discovered that the percentage of men or women with annual earnings greater than $\$ 50,000$, who experienced IPV at some point in their lifetime, was $13.9 \%$ and $24.2 \%$, respectively. For those with annual incomes under $\$ 15,000$ the percentages were higher at $20.7 \%$ for men and $35.5 \%$ for women. 
The literature also suggested that domestic abuse cut across all educational levels (Riggs \& Caulfield, 2000). However, some research and statistics showed that batterers had generally lower educational levels (e.g., less than high school) and that the risk of experiencing violence for a women was inversely related to the level of education of her partner (Coker et al., 2000; Ellison et al., 1999; Hedin \& Janson, 2000; Schmaling et al., 2006). Riggs and Caulfield noted that batterers with less education commit more severe violence. Ellison et al. reported that educational differences between partners, as opposed to absolute educational levels, correlated with the occurrence of DV. Interestingly, Breiding et al. (2008) found that for both men and women, those who were college graduates reported less IPV (i.e., 22.9\% for women, 13.6\% for men), but that the highest percentages of IPV were experienced by those who had some college education, but did not graduate (i.e., $31.7 \%$ for women and $18.5 \%$ for men).

\section{Racial or Ethnic Minority Status}

The significance of the relationship between IPV and ethnicity or race in the United States is not clear in the literature. Worldwide the statistics reported vary widely by country (WHO, 2002). Also, research conclusions have been complicated by evidence that strength of the relationship between culture grouping and IPV varied and may reflect disparity in the willingness to report IPV as much as differences in the occurrence of DV (Tjaden \& Thoennes, 2000).

Notwithstanding the differences in the research findings, several researchers have reported that domestic violence perpetration frequently involves men and women minorities (Cunradi et al., 2002a; Ellison et al., 1999; Riggs \& Caulfield, 2000). In their 
review of the 1995 to 1996 NVAW survey data, Tjaden and Thoennes (2000) found that female minorities experienced IPV more frequently, with the highest levels of lifetime occurrence of victimization among Native American and Alaskan women (37.5\%). Tjaden and Thoennes found the prevalence level for Caucasian women to be lower at 24.8\%. Using different reporting, Breiding et al. (2008) found levels of lifetime IPV experienced as high as $43.1 \%$ for multiracial non-Hispanic women. Campbell, Greeson, Bybee, and Raja (2008) found in their study with African American female veterans that the prevalence of their physical and sexual violence experiences was higher (74\%) than reported in the literature for other ethnic groups, but was in line with previous studies on civilian African American women. Overall, Asian/Pacific Islander women exhibited much lower levels of violence at $9.7 \%$ to $15 \%$ (Breiding et al., 2008; Tjaden \& Thoennes, 2000). Breiding et al. found that the lifetime occurrence of IPV was lower for men overall with the lowest percentages found for Asian men (8.1\%) and highest for multiracial, non-Hispanic men (26\%).

It is important to note that the nature of specific violence within different groups has not been consistent. For example, Coker et al. (2000) found that physical battery was associated with Caucasians, but sexual and nonphysical abuse was not. Likewise, in their meta review of the literature, Lee, Thompson, and Mechanic (2002) found that women of color did not experience nonfatal violence at levels higher than Caucasian women but that African American women are murdered by intimates at a rate twice that of Caucasian women. 


\section{Marital Status}

The journal literature was perhaps most evenly divided on the impact of marital status and IPV. Tjaden and Thoennes (2000) reported that those most frequently victimized by an intimate were unmarried: either divorced, separated, or cohabitating. The WHO (2002) and the CDC (2007) concurred with reports that divorce and separation were significantly linked to the occurrence of IPV. Yet, in their review NSFH data, Ellison et al. (1999) reported no differences in violence experienced by married versus cohabitating women. Greenfield et al. (1998) reported that the marital status of men did not correlate significantly with the perpetration of IPV. However, Cattaneo and Goodman (2003) noted that unmarried men have higher rates of repeat abuse than married batterers.

Regardless of marital status, researchers reported that the period, which women were at the highest risk for injury, was at any time of separation in the relationship (Riggs \& Caulfield, 2000). Greenfeld et al. (1998) reported that women who were separated from their husbands were three times more likely than divorced women, and a shockingly 25 times more likely than married women, to be a victim of IPV.

\section{Substance Abuse}

Of the potential factors investigated in conjunction with IPV, alcohol and drug use appeared frequently in the literature and were examined from a variety of perspectives. Yet, although a good deal of research has suggested that drug and alcohol abuse is strongly correlated with aggression and violence between intimate partners, there remains no conclusive evidence that substance abuse is a specific risk factor for either IPV victimization or perpetration (Bevan \& Higgans, 2002; Brecklin, 2002; Cano \& 
Vivian, 2001; Coker et al., 2000; Fals-Stewart, 2003; Field, Caetano, \& Nelson, 2004; Galvani, 2004; Gelles \& Straus, 1979; Leonard, 2002; Pan et al., 1994). At one end of the spectrum, reported statistics suggested that drugs and alcohol were involved in more than $50 \%$ of homicides by intimates (Sharps et al., 2003). However, in another study alcohol usage did not correlate at all with the occurrence of violence between intimates (Torres \& Han, 2003). There have been far fewer studies considering the association between drug abuse and partner violence, but the results have been similar and equally mixed (Feingold, Kerr, \& Capaldi, 2008; Stuart, 2007).

Complicating the study of IPV and alcohol and drug usage has been the likelihood that any observed connections did not reflect direct causal elements, but were related to other psychological, biological, and situational factors (Brecklin, 2002; Cano \& Vivian, 2001; Cattaneo \& Goodman, 2003; Chartas \& Culbreth 2001; Leonard \& Senchak, 1996). Given that many people use alcohol yet only some of them exhibit aggressive behavior, researchers continue to look in particular for physiological elements that characterize drug and alcohol heightened aggression (Chermack, Walton, Fuller \& Blow, 2001; Fish, Faccidomo, DeBold, \& Miczek, 2001; WHO, 2002).

Whatever the mechanism, in light of the significant number of findings regarding alcohol and violence, Riggs and Caulfield (2000) have suggested health and community workers exercise the most prudent course and consider the presence of heavy or binge drinking, especially associated with past violence or increased conflict, as a strong risk factor for DV. Despite the lack of direct cause and effect linkages between substance 
abuse and IPV, there are several ways that drugs and alcohol have been considered to be associated with the perpetration of partner violence

Effect on perpetration of violence. In the United States Riggs and Caulfield (2000) observed that alcohol and drug use plays a greater role in the perpetration of DV than it does in victimization. Leonard and Senchak (1996) observed that alcohol consumption by men correlates strongly with male-to-female abuse both during dating and in marriage. Other studies affirmed this finding on a more global level (Jeyaseelan et al., 2004, WHO, 2002). Some studies have shown alcohol consumption by the perpetrator to occur in approximately $21 \%$ to $55 \%$ of domestic violence cases, with overall estimates widely varying from $6 \%$ to $92 \%$ of DV cases (Chartas \& Culbreth, 2001; Sharps, Campbell, Campbell, Gary, \& Webster, 2003). Interestingly, Cattaneo and Goodman (2003) found that while alcohol usage was predictive of the perpetration of DV it was not predictive of subsequent abuse.

Stuart et al. (2008) reported on earlier research which directly and indirectly linked problems with alcohol to the perpetration of physical violence, by both men and women, even after factoring trait, contextual, and psychological factors. Additionally, in their study of arrested batterers, these researchers found that the use of marijuana and stimulants (e.g., cocaine and amphetamines) was a stronger predictor of male perpetration of physical violence than alcohol related problems. Stuart (2007) specifically noted that stimulant abuse was grimly and alarmingly associated with batterer recidivation.

Effect on victimization. Women experiencing IPV evidenced less of a drinking problem than their perpetrators, but nonetheless, $13 \%$ of the victims of threatened or real 
partner homicide were found to be heavy drinkers themselves (Sharps et al., 2003). Not unlike their study findings with perpetrators, Chermack et al. (2001) reported that victims of violence, especially severe violence, engaged in more frequent cocaine use. Testa, Livingston and Leonard (2003) found that illicit drug usage was related to a higher probability of experiencing IPV in a current relationship, as well as in any new relationship. Interestingly, El-Bassell, Gilbert, Wu, Go and Hill (2005) found that not only did frequent users of crack and marijuana experience an increased likelihood of intimate violence, but they also found a reciprocal relationship in that the experience of IPV increased the likelihood for the victim's use of heroin and possibly for crack, marijuana, and cocaine.

Felson and Burchfield's (2004) examination drinking and violence revealed that alcohol usage might indirectly cause IPV injuries because of the risky behavior or lack of precautions a victim was willing to take with her partner. They reasoned that inebriation created a vulnerability or incapacitation on the part of the victim. Testa et al. (2003) considered that a victim who drinks or uses illicit drugs may induce physical abuse by her own provocative behaviors or by contributing to the conflict situation by being more vocal (Galvani, 2004), or irritable and hot-tempered (Testa et al., 2003). National Violence Against Women Survey data from 1995 to 1996 showed that the more frequently a potential female victim drinks, the higher her risk of experiencing violence both while sober and when intoxicated (Felson \& Burchfield, 2004). Additionally, researchers found that IPV victims were more likely to be drinking than those who suffered an assault by a stranger (Felson \& Burchfield, 2004). In their longitudinal study, 
Testa et al. (2003) found that a woman's risk of experiencing physical violence both in current and new relationships was greater if she used illicit drugs. Some research has revealed that women who abuse alcohol may also have suffered high levels of sexual and/or physical victimization during childhood and because of such findings, some researchers have speculated that alcohol usage among IPV victims is more of a coping mechanism than a causal factor (Riggs \& Caulfield, 2000). Relatedly, Chartas \& Culbreth (2001) speculate that women who engage in substance abuse may simply become involve with men who share their same drug or alcohol dependencies.

Effect on the severity of violence. Using the 1992 to 1996 National Crime Victimization Survey data, Brecklin (2002) found that by considering the degree of their alcohol abuse it was possible to differentiate nonviolent men from violent men and to distinguish moderately violent men from brutally violent men. Fals-Stewart (2003) reported that the overall IPV risk to women was 8 times greater on days when their partner was drinking versus when her partner was not with the risk of severe IPV 11 times greater when the male partner was drinking. Considering cases involving severe violence, Sharps et al. (2003) found that $80 \%$ of the men who murdered their partners were found to be heavy drinkers. Similarly, drug usage was found to increase the risk of severe physical abuse (Pan et al., 1994). One study examining escalating factors in the severity of violence found that drug use by perpetrators who were moderately abusive to be at $6.7 \%$ vs. $12.6 \%$ for those who commit homicide (Sharps et al., 2003). In their study Chermack et al. (2001) reported that victims who perpetrated more severe partner violence also engaged in marijuana and cocaine use. 
However, not all studies evidenced these dramatic findings. With study participants from both alcohol and DV treatment programs, Fals-Stewart, Leonard and Birchler (2005) found that alcohol usage correlated with severe IPV only with men who also had a diagnosis of antisocial personality disorder (ASPD). Only moderate IPV was correlated with alcohol usage in non-ASPD men. Interestingly, Fals-Stewart et al. (2005) found that men diagnosed with ASPD would engage in moderately abusive behaviors regardless of alcohol consumption.

Effect of alcohol expectancies. Though a good deal of research has been focused on the exploration of the biosocial and psychopharmacological effects of alcohol as related to violence perpetration and victimization, some investigators and theorists considered alcohol use merely to be an excuse for committing IPV (Leonard, 2002; Stuart et al., 2008). In this light, more integrative violence perpetration models have included motivations associated with alcohol aggression expectancies (Leonard, 2002). In examining the views that people hold regarding drinking and violence, researchers found that alcohol usage was considered a direct causal factor in violence perpetration because of the belief that there exists an addictive component that incites aggression, vulgarity, and combativeness (Galvani, 2004). However, even early research has shown that there is very much a cultural and societal element to the notion of disinhibition associated with alcohol (Critchlow, 1985; Quigley, Corbett, \& Tedeschi, 2002). Leonard observed that in earlier studies both victims and perpetrators were considered by others to have less of a responsible role in the IPV incident if the perpetrator alone had been drinking. Later studies have shown though that while alcohol was thought to have played a causal role in 
IPV it did not make the victim believe the perpetrator was less culpable (Felson \& Burchfield, 2004; Leonard, 2002).

Eckhardt (2007) further explored the effects of alcohol on both maritally violent and nonviolent men. The assessment of the participants' personal ratings of the anger they experienced during simulated marital conflict situations as well as the anger expressions (e.g., threats, insults, hostile statements) revealed that men with already high dispositional anger were more inclined to express anger while intoxicated, though their personal sense of the anger experienced was no different than nonviolent men. Eckhardt's findings indicate that an abuser's level of intoxication may have little impact on his feelings of anger during an altercation but may at least temporarily affect his anger expression. Eckhardt conjectured that the intensified anger expression observed in already violent men might be due to a real physiological interference of related emotional and behavioral regulatory mechanisms. However, the apparent lack of connectedness between feelings of anger, expressions of anger, and alcohol consumption raises the specter of the impact of alcohol expectancies.

\section{Experiencing/Witnessing Violence during Childhood and Adolescence}

Several investigators have noted that the direct experience of or the witnessing of violence in a women's natal family was strongly correlated with her violence victimization as an adult (Cunradi et al., 2002a; Tjaden \& Thoennes, 2000). Though many of these studies are limited to narrow populations (e.g., college students, patients) and do largely rely on the anecdotal recall, the patterns that have emerged are compelling and worth considering in light of preventative measures. For example, Coker et al. (2000) 
found that previous sexual violence was a strong correlate for sexual violence in adulthood. Campbell et al. (2008) found in their veteran research that for the cluster of African American females who experienced the highest levels of adult IPV, $67 \%$ had been sexually assaulted as a child. Siegel and Williams (2001) found in their longitudinal study that only women who experienced sexual abuse as both a child and an adolescent reported higher levels of IPV. Similarly, White and Smith (2001) found in their five-year longitudinal study of 2,269 college students that college women who had experienced either physical or sexual abuse during childhood evidenced a higher incidence of such abuse as an adult.

Some studies in the literature countered these findings and suggested that the experience of only witnessing of violence earlier in life was not enough to create a higher level of vulnerability of victimization in the absence of other risk factors (Riggs \& Caulfield, 2000). Additionally, there is much speculation about the reason for the reported correlations between experiencing violence during childhood and subsequent IPV experiences. For example, a woman's acceptance of violence within a relationship, presumed to be developed in response to the experience of violence during childhood or adolescence, appeared to contribute to the risk of IPV in her lifetime (Cano \& Vivian, 2001). Conversely, some researchers found that the woman's acceptance of violence was only a contributing or exacerbating factor (Field, Caetano, \& Nelson 2004). However, it is important to note that whether related to learned behavior, developmental issues, selfesteem, or changes in attitudes and beliefs, there does appear to be some IPV risk for 
women associated with their experience or witnessing of violence during childhood and adolescence (Seigel \& Williams, 2001).

For male perpetrators, researchers found that the direct experience of violence or the witnessing of family violence was a risk factor for the committing of physical or sexual violence toward an intimate, especially if the man experienced corporal punishment as a child (Cano \& Vivian, 2001; Grann \& Wedin, 2002, White \& Smith, 2001).

Psychological Factors

Research regarding psychological factors associated with violence victimization was often conducted in context of studies about other factors. Several studies showed that women who experience DV exhibit low self-esteem, high levels of post traumatic stress disorder (PTSD) associated with the current or previous abuse, depression, anxiety, as well as, eating, mood, and obsessive compulsive disorders, but it was unclear in these studies whether or not these were causal factors, risk markers or merely byproducts of intimate violence (Cascardi, O’Leary, \& Schlee, 1999; Riggs \& Caulfield, 2000). In their study, Howard, Wang, and Yan (2007) discovered that adolescent girls were at greatest risk to experience dating violence if they were emotionally sad, had expressed feelings of hopelessness, had attempted or considered suicide, had recent sexual experiences with multiple partners, had engaged in unprotected sex, or had engaged in physical violence themselves (especially if it involved the use of a weapon or substance use). In specifically looking at depression as an adolescent, Keenan-Miller, Hammen and Brennan (2007) found that women, who experienced depression by age 15, were at the highest risk for 
victimization by severe IPV over a 5-year period. Interestingly, these researchers found that women, but not men, whose mothers' had severe depressive episodes during their adolescence were more likely to perpetuate severe violence.

More specific psychological investigations found in the literature attempted to understand the mental factors, associated with the perpetration of violence. Riggs and Caulfield (2000) observed that mood disorders, anger/hostility, and antisocial personality as measured on clinical scales all have been associated with the perpetration of DV. Murphy, Meyer, and O’Leary (1994) found that batterers evidenced higher dependency needs and lower self-esteem, as well as lower levels of competence and self-sufficiency, as compared to their nonviolent counterparts. In a study of IPV perpetrators who experienced PTSD symptoms related to their military experience or other events, Gerlock (2004) concluded that combat exposure and the development of PTSD resulted in a higher risk for perpetrating IPV. Gerlock's study also revealed that the severity of PTSD correlated significantly with the severity of the DV perpetrated.

Holtzworth-Munroe and Stuart (1994) used a compound approach to evaluate 15 batterer typologies in order to develop a cohesive typology of batterers. The complexities of this interpersonal crime were revealed in their 1994 and later research as they were able to identify three components of marital violence:(a) its rate of recurrence and severity, (b) the degree to which it involved people beyond the family unit, and (c) specific psychological factors of the perpetrator (Holtzworth-Munroe et al., 2000; Holtzworth-Munroe \& Stuart, 1994). The research of Holtzworth-Munroe (2000) and others confirmed three hypothesized and one unanticipated category of batterer. 
Though difficult to distinguish from martially dissatisfied and stressed men, the least violent and exhibiting the least amount of psychopathology of the four batterer groups were classified as family-only (FO) batterers (Holtzworth-Munroe et al., 2000). These researchers also noted a group labeled low-level antisocial (LLA), who exhibit some low level antisocial characteristics in addition to the characteristics of the FO batterer. These authors characterized borderline dysphoric (BD) abusers as ones who engaged in mild to severe IPV, primarily within the family only, and who exhibited several symptoms of depression and/or anxiety. The generally violent-antisocial (GVA) batterers were observed to perpetrate the most severe violence, both within and outside of the family unit, to display criminal behavior, to abuse alcohol and/or drugs, and who also were expected to exhibit serious personality disorders. The GVA-type batterers also exhibited the most serious sexual coercion with their victims (Marshall \& HoltzworthMunroe, 2002). Further research found that, as expected, GVA and BD were more prone to moderate to severe violence over a longer period of time than men who were FO batterers (Grann \& Wedin, 2002; Holtzworth-Munroe, Meehan, Herron, Rehman, \& Stuart, 2003).

\section{Feminist Factors}

Researchers postulating correlates and causes of IPV from a feminist perspective have offered that IPV finds its roots in gender bias, misogynic beliefs, patriarchal thinking, occupational and status disparities, and male/female power struggles (Cano \& Vivian, 2001; Gelles \& Straus, 1979). 
Leonard and Senchak (1996) found that a husband's views about power within the relationship were correlated to his perpetration of spousal abuse. Interestingly, a wife's view regarding the power was not found to be predictive of violence. In their longitudinal study, these researchers found that a high desire to engage in problem solving, coupled with low levels of conflict avoidance, were observed among aggressive husbands. In addition to issues of control, male combativeness also plays a role in violence that occurs during partner conflict. These researchers also found using the F subscale of the Personal Attributes Questionnaire (PAQ) that femininity was inversely related to aggression. These authors speculated that the construct of femininity, as measured by the PAQ subscale, was similar to constructs for tenderness and concern for others.

\section{Contextual Factors}

\section{Relationship Satisfaction and Stress}

Gelles and Straus (1979) noted that the greater the level of marital distress and the more areas of dispute that exist, the more likely an intimate pair would experience volatile encounters. These authors also note that the greater the opportunity for a negative exchange, the greater the risk for violence, as compared with martially satisfied couples. Inversely, men who perpetrated IPV also reported lower levels of satisfaction within that intimate relationship (Riggs \& Caulfield, 2000).

Taking a slightly different stand, Pan et al. (1994) offered that marital discord (i.e., as measured by Spanier's (1976) Dyadic Adjustment Scale) was the most influential factor in predicting IPV and that marital satisfaction was more of a mediating variable. Pan and colleagues also concluded that for every $20 \%$ increase in stress level (i.e., as 
measured as a combination of marital discord and the magnitude of concern for one's partner) there was a $30 \%$ increase in the odds of mild violence and $74 \%$ increase in the odds for severe violence. Relatedly, Cano and Vivian (2001) argued that not only does the presence of situational stressors increase the risk for violence, but also the frequency of those life stressors. In a more recent study, Schmaling et al. (2006) found that decreased relationship satisfaction and increase personal stress (from all sources) both significantly influenced the occurrence of partner violence, especially severe violence. In most of the literature reviewed, researchers were quick to point out the problems with evaluating the constructs of stress and of marital/relationship satisfaction. Stress was seen as arising from a myriad of sources such as employment, financial, lifestyle, and personal interactions (Cano \& Vivian, 2001; Pan et al., 1994; Schmaling et al., 2006). With satisfaction, there was no clear cut-off level to distinguish potentially violent discord from the more ordinary types of marital distress or dissatisfaction (Riggs \& Caulfield, 2000).

\section{Conflict Styles}

The degree of conflict and its effect on the escalation of violence has not been very well understood. Leonard and Senchak (1996) found that poor conflict resolution abilities on the part of both husbands and wives were correlated with marital violence. Riggs and Caulfield (2000) noted that escalating verbal aggression during couple's attempt to resolve a conflict often preceded physical violence. They also have noted that physical violence occurred along with verbal arguments as either (a) an attempt to deescalate the conflict, or (b) a deliberate act of escalation of the abuse. Leonard and 
Senchak concluded that in situations where husbands were nonconflict avoiding, already verbally aggressive, and highly focused on problem solving, the risk for marital violence to occur was greater.

Riggs and Caulfield (2000) pointedly observed that much of what has been published reflects measurements and questions about conflict only in the context of an argument (e.g., the Conflict Tactics Scale (Straus, 1979)), and reminded readers and researchers that little is known about the level of abuse that occurs in the absence of an ongoing argument.

\section{Previous Violence}

Some studies revealed that the experience of past abuse was one of the best risk indicators of future violence (Leonard \& Senchak, 1996) and of continual violence (Cattaneo \& Goodman, 2003). Riggs and Caulfield (2000) observed that physical partner violence that occurred early in a relationship (i.e., during dating or premarital) often continued and, in some cases, even worsened over time. Using the findings of the 199 to 1999 National Crime Victimization Survey (NCVS) researchers found women were frequently assaulted multiple times within a 6 month period by an intimate partner (Rand and Saltzman, 2003). In more closely examining victim patterns of IPV, investigators found that women who experienced high levels of stalking and high levels of physical and psychological abuse, and low levels of sexual abuse, were at greater risk of experiencing IPV revictimization during the 12 months following the first interviews than were women who experienced moderate levels of all types of abuse (Dutton, Kaltman, Goodman, Weinfurt, \& Vankos, 2005). Interestingly, these same women had three times 
greater odds of revictimization than the women who also experienced the same high levels of stalking, physical/psychological abuse, but who also experienced sexual violence. Dutton et al. observed that this finding might reflect the idea the women who experience high physical/psychological/stalking abuse and sexual assault are more likely to separate themselves from the perpetrator, thereby decreasing their risk of re-assault.

Some studies overlap in their findings regarding IPV risk factors. For example, in their study of DV during pregnancy, Hedin and Janson (2000) found that $95 \%$ of the women who suffered IPV during their pregnancy also experienced abuse from their partner prior to pregnancy. Other studies show that verbal abuse by one's partner was linked to subsequent physical violence by that partner (Tjaden \& Thoennes, 2000).

Riggs and Caulfield (2000) opined that recent studies indicated that men who generally were more aggressive also presented more of a risk of become increasingly violent toward an intimate partner. However, in one longitudinal study, researchers found that not all violent men escalated in their abuse over time, with the exception of those men who were categorized as extremely violent at the outset of the relationship (Holtzworth-Munroe et al., 2003). According to these researchers, these extraordinarily violent men did tend to increase their level of partner maltreatment and rarely had periods of cessation.

\section{Pregnancy}

Though not conclusive, some research suggested that the risk of experiencing violence was greatly increased for a woman during pregnancy than in her general lifetime, with estimates ranging from $1 \%$ to $40 \%$ or more of pregnant women 
experiencing IPV (Amaro, Fried, Cabral, \& Zukerman, 1990; Gazmararian et al., 2000; McFarlane, Soeken, et al., 1998). According to Ballard et al. (1998) the wide variety of findings among researchers was perhaps due in part to a lack of clarity in measurement. Some studies did not differentiate between abuse that started during pregnancy and abuse that merely continued during pregnancy, nor did some studies clarify the type or severity of abuse (Ballard et al.). For example in a more recent study, Saltzman, Johnson, Gilbert and Goodwin (2003), found in their study across 16 states that women were not at any greater risk for IPV after they were pregnant than they were before they were pregnant. Other researchers have found that part of the difficulty in assessing this particular risk factor lies in the various venues used for collecting the data. For example, Fried, Aschengrau, Cabral and Amaro (2006) found a substantial discrepancy between selfreports of violence $(60.2 \%)$ and those appearing in formal medical reports $(11.8 \%)$.

However, in spite of measurement concerns, many studies over the last two decades have strongly supported the conclusion that a woman's pregnancy can contribute to the onset or escalation of IPV (Amaro et al., 1990; Campbell et al., 2003; Fried et al., 2006; Gelles, 1987; McFarlane, Soeken, et al., 1998; McFarlane, Wist, \& Watson, 1998). Paralleling these findings, researchers conducting a CDC study reported that from 1991 to 1999 homicide was the second leading cause of death in pregnant women (Chang, Berg, Saltzman, \& Herndon, 2005).

Gelles (1987) proposed five factors to explain the phenomenon of assault on a pregnant partner: (a) sexual frustration of the perpetrator, (b) family stresses associated with the upcoming changes in the household, (c) biological changes in the female, (d) 
extensions of prenatal child abuse, and (e) the diminished ability of the female to defend herself. Burch and Gallup (1990) offered an evolutionary theory of sexual jealousy to explain the doubling of severity and frequency of IPV during pregnancy. Gazmararian et al. (2000) found that violence during pregnancy was most highly associated with sporadic contraceptive use and unplanned pregnancies. One study revealed that the risk of IPV and the severity of abuse during pregnancy were heightened in the presence of a weapon such as a gun (McFarlane, Soeken, et al., 1998).

\section{Mutual Aggression}

In their examination of female aggression, Feld and Straus (1989) indicated that hostility on the part of a woman made her seven times more likely to experience abuse by an intimate partner. However, these authors did not discern whether or not her aggressiveness was self-defensive rather than part of a pattern of mutual violence. Similarly, Leonard and Senchak (1996) showed that a wife's score on the assault subscale of the Buss-Durkee Hostility Scale was predictive of marital aggression. Though possibly still provocative in nature, these researchers noted that a wife's aggression might be exhibited in response to her husband's aggression (Leonard \& Senchak, 1996).

Research by Feld and Straus (1989) indicated that violence between partners was not a continuous behavior within a marriage. They observed that violence between husbands and wives ebbed and flowed over the course of a relationship. However, when a wife contributed to the abusive situation with violence of her own (regardless if offensive or defensive in nature), the risk for escalation in violence by the husband was higher. Feld and Straus concluded that the increase in the severity of abuse of the primary 
perpetrator was related to: (a) the acceptance of the current level of violence as normal within the relationship, (b) the need to escalate to achieve the perpetrator's desired effect, (c) the presence of more and/or different violence inducements (e.g., stressors), and (d) violent behavior by the other partner.

Availability of a Weapon

Campbell et al. (2003) concluded that if a woman's life was threatened, the risk of her actually being murdered was 15 times greater than for women in general. Additionally, these researchers concluded that that if a woman was threatened with a gun, her risk of being killed was 20 times greater than other women. In their review of previous studies, Campbell et al. also found that IPV victims had a six times greater chance of being killed if there was a firearm in the house, as compared to other abused women. Interestingly, abuse with a weapon also was associated with alcohol abuse (Brecklin, 2002).

\section{Summary on Antecedents}

In reviewing the literature it has become clear that research in the area of domestic violence is burgeoning. However, the wide range of theoretical perspectives, coupled with the narrow focus of much of the research, makes it difficult to grasp the direct and indirect relationship of various factors to IPV. The literature does not support the prediction of IPV victimization or perpetration by any one risk factor, or even a combination of markers. However, as several investigators have noted, it is imprudent, and perhaps even unethical, to not deliberate, investigate, and communicate even potential antecedents, even if further research shows many of the correlates discussed to 
be comorbid with other factors (Breiding et al. 2008; Campbell, et al., 2003; Kroop, 2008; Riggs \& Caulfield, 2000). Riggs and Caulfield contend that it is still possible to use potential factors to at least create a "syndrome" of risk markers for partner abuse and argue that best use of the information regarding IPV victim and perpetrator "profiles" is to guide DV interventions and prevention measures, rather than to determine any single individual's risk or situational threat.

Though mixed, the existing research did suggest IPV correlates might prove insightful for the development and execution of prevention and intervention efforts within the Christian faith community. However, much of the literature dealing with potential antecedents did not provide the necessary insight to understand the incongruity of DV within the Church community. To more fully understand the motivation to perpetrate IPV in general, it is reasonable to also explore a perpetrator's motivation to be part of a Church community. In the next section Allport's concept of religious orientation and its theoretical derivatives are explored in order to better frame solutions to family violence within the Christian Church. 


\section{Religious Orientation: Intrinsic versus Extrinsic Motivation}

Building on the earlier findings and suppositions of sociologists Lenski and Fichter, Allport developed a cognitive-motivational approach to understand what he considered to be paradoxically high levels of racial bias among Christian churchgoers. From this early work Allport (1954) dissected Christianity into two types of religion, and later (1966) assigned the axiological labels of "intrinsic" and "extrinsic" to characterize the different motivations of churchgoers.

In his consideration of religious maturity and prejudice, Allport (1966) identified church members' religious orientation (RO) along a bipolar continuum of extrinsic (E) to intrinsic (I) qualities. At one extreme he described congregational members who had a strong need to belong to a community and who found satisfaction in being affiliated with the Church. Allport and Ross (1967) posited that these exoterically oriented members were motivated to come to church primarily for reasons such as to build up their social status, to network with business contacts, to entertain themselves, or find company to combat their loneliness. In Allport's view, the extrinsics' motives for membership and church attendance were mostly pragmatic, self-serving, and, at times, exploitative.

At the intrinsic extreme, Allport posited church members were internally motivated to be involved with the Church as a natural extension of their religious beliefs. Allport observed that the religious attitudes and behaviors of these members were more obviously reflected in their lifestyle, manifested in both their minor and major life choices. The intrinsics were far less self-serving and were more concerned with providing service and support to others. Participation in regular church fellowship was considered 
vital to this type of member because of the high value he or she believed God placed on communal worship. They regarded church attendance and other forms of religious activity as integral to one's spiritual growth. Allport (1966) noted a significant distinction between infrequent and frequent churchgoers, characterizing as intrinsic the habits of more regular church attendance. He also observed that these attendance habits were deeply personal and not readily altered by situational factors (e.g., inclement weather).

Allport and Ross devised a Religious Orientation Scale (ROS) to investigate their general observation that religious persons were more prejudice than nonreligious persons. Using the construct of religious orientation, Allport and Ross (1967) discovered that both nonreligious and intrinsically religious persons were significantly less prejudiced than those churchgoers who appeared to be extrinsically motivated.

\section{Measuring the Constructs of Religious Orientation and Prejudice}

In their examination Allport and Ross (1967) used five accepted measures of racial and ethnic prejudice, including Harding and Schuman's Social Problems questionnaire. As part of the study these researchers directly measured racial intolerance where participants overtly mentioned the group against whom the prejudice was targeted. Allport and Ross also created indirect measures of racial bias using items from Gilbert and Levinson's Custodial Mental Illness Ideology Scale, including items that addressed attitudes toward the mentally ill, and one's general level of skepticism or mistrust. Allport and Ross examined response bias using these instruments and concluded that (a) racial bigotry correlated with a variety of personality traits and (b) that indirect measures 
of racial bias were not better than direct measures in understanding racial and ethnic intolerance.

Using the ROS, Allport and Ross (1967) measured the religious tendencies of the participants from 309 different denominations across five states. Imbedded in their early description of the construct of religious orientation was Allport's belief that a person's spiritual stance was motivated by drivers that could be characterized along a bipolar continuum of internal to external drivers.

The early ROS consisted of 11 extrinsic and 9 intrinsic items rated on a Likerttype scale (Allport \& Ross, 1967). Details of the complete battery of the 1967 ROS questions can be found in Appendix A. An example of an extrinsic item on the ROS follows:

"What religion offers me most is comfort when sorrows and misfortune strike.

1) I definitely disagree,

2) I tend to disagree,

3) I tend to agree,

4) I definitely agree"

An example of an intrinsic question follows:

"My religious beliefs are what really lie behind my whole approach to life:

1) this is definitely not so,

2) this is probably not so,

3) probably so,

4) definitely so" 
As compared to similar examinations, Allport and Ross (1967) found that the correlation between religious orientation and prejudice was less than expected. They speculated that the differences between their study and others (e.g., Wilson, 1960, as cited in Allport \& Ross, 1967) lie in the differences among the test instruments, a few of which had been shown to also reflect the participant's education level, as well as his or her prejudices. Allport and Ross also found that individual subscale RO-prejudice correlations were smaller. With these unexpected findings, Allport and Ross concluded that the I-E scale did not reflect a one dimensional, bi-polar continuum, but likely included other independent dimensions. At the conclusion of this study, these researchers also no longer believed that it was wholly inconsistent for someone to endorse both intrinsically and extrinsically worded statements.

Despite some unexpected findings, Allport and Ross (1967) found that two thirds of their sample consistently responded either intrinsically or extrinsically. Additionally, a third, more indecisive group emerged that readily endorsed both I and E elements. Allport and Ross labeled this group "Indiscriminately Proreligious" (p. 437). This finding prompted Allport and Ross to create a new four category RO Model (shown in Table 1) and to suggest that their previous bipolar continuum model warranted reexamination. They affirmed their belief that the I and E orientations were interconnected, but not necessarily in a linear fashion. In the new RO model a fourth group, labeled “Antireligious" (p. 438), was only hypothetically presupposed because individuals not involved with a church were excluded from the Allport and Ross study. 
Table 1

Allport and Ross's 4 Category Model of Religious Orientation

Agrees with intrinsic items Disagrees with intrinsic items

$\begin{array}{ccc}\begin{array}{c}\text { Agrees with } \\ \text { extrinsic items }\end{array} & \text { Indiscriminately Proreligious } & \text { Consistently Extrinsic } \\ \begin{array}{l}\text { Disagrees with } \\ \text { extrinsic items }\end{array} & \text { Consistently Intrinsic } & \text { Indiscriminately Nonreligious }\end{array}$

Note: Adapted from Personal Religious Orientation and Prejudice by G. W. Allport and J. Ross (1967). Journal of Personality and Social Psychology, 5(4), p. 438.

Of the three types of participants included in the study, Allport and Ross (1967) reported that the churchgoers who answered in a consistently intrinsic fashion were the least biased of the three groups. They also found that the consistently extrinsic churchgoers were less biased than the indiscriminately proreligious (IPR) group. However, Allport and Ross expressed difficulty in fully interpreting the IPR results which did not differentiate among various religious endorsements and seemed to reflect an attitude that "all religion is good" (p. 441). ). For example, someone in the IPR group might indicate that he or she strongly agreed with the intrinsic statement: "I try hard to carry over my religion into all my other dealings in life" and the extrinsic statement: “although I am a religious person I refuse to let my religious considerations influence my everyday affairs".

Offering a cognitive style rather than a motivational explanation, Allport and Ross surmised that if someone was undifferentiated in their thinking about religion it 
followed that they would also not readily distinguish among individuals within an ethnic or racial group and therefore might be more likely to generalize their prejudice.

\section{Criticisms to Allport's Theory and the ROS}

Since its construction over a half century ago and despite many criticisms, Allport's theory of intrinsically and extrinsically-rooted religious orientation has spawned many studies (Donahue, 1985; Gorsuch \& McPherson, 1989). Most of the critical discourse found in the literature was related to: (a) the definition of the construct of religious orientation and its various measurement instruments, (b) the usage of the valueladen labels of intrinsic and extrinsic, (c) the nature of the relationship between I and E factors, and (d) the relationship of I and E motivations to other personality traits, attitudes, or behaviors. Not surprisingly, many of the objections and suggested improvements have generated their own round of criticism.

\section{Defining and Measuring Religious Orientation}

According to Kirkpatrick and Hood (1990) those critical of Allport's operational definition of religious orientation usually labeled RO as vague, or untidy, or categorically misleading. Hunt and King (1971) argued that it was not clear whether Allport originally intended to measure a person's religious perspective, a personal attitude, or a type of religion. Allport and Ross (1967) fueled the RO construct debate themselves when they shifted from using motivational and value-laden language to expressions that reflected more cognitive styles. Kirkpatrick and Hood affirmed that researchers have agreed that $\mathrm{RO}$ represents some aspect of religious behavior coupled with motivation, but that whatever the RO concept reflects, it is likely multidimensional and probably not linear. 
Though acknowledged as a betterment of his earlier methods, Allport's ROS has been derided for its mix of self-report questions about attitudes, conduct, practices, personality traits, and theological positions (Gorsuch, 1984; Gorsuch \& McPherson, 1989). Kirkpatrick and Hood (1990) believed that regardless of whether or not the ROS was intended to measure motivations, personality traits, or cognitive styles, there were better instruments available in all of these categories.

In an attempt to make both construct of RO and the ROS instrument more operational, Feagin (1964) modified and extended Allport's base theory. One of the more significant improvements to the I/E subscales was made by Feagin using factor analysis. More specifically, Feagin improved the subscales by straightforwardly measuring the degree to which someone was internally driven in their religious behavior. Allport and Ross (1967) agreed that this improvement was significant because linearity no longer had to be presumed and intrinsic motivation did not have to be inferred by low scores on the extrinsic scales.

\section{Defining the Labels of Intrinsic and Extrinsic}

Some of Allport's critics decried his use of the axiological terms intrinsic and extrinsic, believing that those labels lacked meaning in the context of assessing a person's disposition or outlook (Hunt \& King, 1971; Kirkpatrick \& Hood, 1990).

Hunt and King (1971) noted that though Wilson and others attempted to make more understandable the I-E polar extremes of religious orientation, they in turn failed to capture many of the salient elements in Allport's original descriptions. In their meta review of Allport's research and publications, Hunt and King codified into 11 categories 
the various I/E descriptors used by Allport. Their I-E descriptor pairs offered were (pp.342-343):

1. "Reflective" versus "Uncritical"

2. "Differentiated" versus "Undifferentiated"

3. "Personal" versus "Institutional” (i.e., internalized versus externalized)

4. "Universal" versus "Parochial” (i.e., inclusive versus exclusive)

5. "Unselfish" versus "Selfish"

6. "Relevance for all of Life" (i.e., comprehensively orientated versus isolated and nonintegrated)

7. "Salience" (i.e., a sincere and fully followed faith versus more casually held beliefs)

8. "Ultimate" versus "Instrumental" (i.e., religion as an end goal or purpose in itself versus religion as means or method to a goal)

9. "Associational" versus "Communal" (i.e., involved with others in order to find deeper meaning versus socially involved)

10. "Humility" versus "Dogmatism"

11. "Regularity of Church Attendance" (i.e., consistent versus sporadic participation)

Hunt and King (1971) noted that Allport's research and publications predominately reflected areas $4,5,6,7$, and 9 . Taking into account the frequency of occurrence of the references, Hunt and King concluded that Allport's I/E labels attempted to capture more of a personality trait than a behavior pattern, and certainly not a type of religion. When they factored in the subsequent research they also concluded that the categories of descriptors might be better operationalized with other scales. 
In their review, Kirkpatrick and Hood (1990) concluded that Allport's intrinsic elements reflected something akin to dedication or obligation, while the extrinsic elements measured types of motivation (e.g., selfishness). These authors argued that though the idea of measuring one's commitment to religion could be useful, the specific substance of the beliefs also should be examined. Kirkpatrick and Hood maintained that the Allport-Ross measurement of religious orientation was not as illuminating with a religiously diverse group, where members held deep levels of commitment but also very different beliefs. Similarly, Maltby (2002) suggested that the measurement of religious orientation was useful only when made on religious persons.

In order to extend the applicability of the Allport-Ross scales to include children as well as adults, Batson (1976), Gorsuch and Venable (1983), and later Gorsuch and McPherson (1989) incorporated age appropriate terminology into their revisions of the ROS. Additionally, they compensated for factors thought to possibly influence the ROS results such as educational differences. Maltby (2002) pointed out that since its introduction many researchers have tailored the ROS' wording, number of items, and scaling in order to improve its psychometric properties and usefulness. As significant as these changes have been, more important has been the research conducted in order to better understand the interrelationship between the I and E factors. 


\section{The Interrelationship between the I and E Factors}

For some researchers the core debate is not about the usefulness of the intrinsic and extrinsic elements of religious orientation, but rather about whether (a) the relationship between the two was linear, curvilinear or uncorrelated, or (b) whether or not these two elements were one-dimensional or multidimensional.

(a) The IPR dilemma: The fourfold typology debate. Allport's (1967) original model expressed the I and E elements as inversely related extremes of a bipolar continuum. One of the biggest detractors in this original model had been the appearance of, and the explanation for, the indiscriminately proreligious group of churchgoers. The lack of correspondence of this third category to the Allport model caused some researchers to theorize that the IPR results represented an unintended assessment of another concept, separate from that of religious orientation (Kirkpatrick \& Hood, 1990). Pargament et al. (1992) speculated that the IPR phenomena might represent a type of coping style and be more reflective of one's general responses to particular life events.

Though he showed early support of the revised four category model, Hood (1978) and later with Kirkpatrick (Hood \& Kirkpatrick, 1990), suggested the explanation that IPR-type participants had merely offered inconsistent or perhaps illogical responses, detracted from Allport's theory. Kahoe (1976) suggested researchers use the preferred practice of considering and incorporating additional, independent factors into Allport's model rather than typifying study participants into arbitrary categories. Later Kahoe (1985) argued further that there was no substantive research to show a significant 
interaction between the I and E elements and therefore felt that Allport and Ross had no sound basis on which to construct this new model.

Donahue (1985) mentioned that in later studies there was statistical support for the presence of interactions at high and low levels of I and $\mathrm{E}$ and reconsidered giving some credence to Allport's fourfold typology. Later researchers generously offered that the originally conceived bi-polar continuum between intrinsic and extrinsic motivations should not be abandoned just because the measurement instrument needed improvement (Kirkpatrick \& Hood, 1990). Kahoe (1985) partially allowed that Allport may have been correct in his original thinking and suggested further research to better understand the development of I and E tendencies.

Believing that the new fourfold typology was merely a rationalization, Kirkpatrick and Hood (1990) suggested that Allport and Ross model had integrated a cognitive assessment into what was originally a motivational evaluation. These researchers also submitted that the use of discrete categories to estimate continuous variables was misleading. In their view, even using contrived groupings to facilitate statistical analysis presented too great a risk of loss of information (e.g., statistical power, the presence of relationships).

Where the use of the fourfold model was used, there was still debate in the literature about where to assign the cutoffs between sections. Kirkpatrick and Hood (1990) argued that the median split approach would not work for comparisons between studies. Donahue (1985) suggested using "theoretical midpoints" to allow for standardization between studies. Furthermore Donahue noted that research using the four 
categories was noticeably lacking without much advancement in the previous decades. Though generally critical of the Allport-Ross model, Kirkpatrick and Hood (1990) offered a meager defense of Allport's four-category model noting that it should not be completely abandoned before it had been more fully and practically tested. These researchers reasoned that it was conceivable that people could behave with varied, and at times, conflicting motives, and allowed that the number and type of questions used to estimate I and E may have been too limited.

In his review of 35 research studies, Donahue (1985) concluded that the makeup of the participant sample likely had a significant impact on the correlational findings of any single study. Not unexpectedly, respondents, like those from a conservative religious college, who answered strongly on the intrinsic questions, evidenced the most significant correlations between I and E items. Because correlations among other types of respondents were weaker than this predominately religious sample, Donahue suggested that it was possible that the correlation within the population was zero and conjectured there was reason to conclude that I and E represented orthogonal constructs.

(b) The one-dimensional versus multidimensional debate. Some researchers have been satisfied with the fourfold typology and its refinements, but others have insisted that constructs of intrinsicness and extrinsicness be considered as two separate entities, whether studied together or with other variables. Still yet others have preferred supplementing the I and E scales with other factors.

In examining the Allport-Ross and Feagin scales, Gorsuch and McPherson (1989) and Kirkpatrick and Hood (1990) concluded that three, rather than two, factors 
exist: (a) Intrinsic, (b) Extrinsic-social (Es), and (c) Extrinsic-personal (Ep). Kirkpatrick and Hood observed that extrinsic items that did not fit into the Ep and Es categories were actually negatively worded intrinsic items. While these investigators considered this discovery enough reason to discount the usefulness of the original I/E metrics, others saw it as an opportunity to improve the metric by using a three-dimensional scale (Gorsuch \& McPherson, 1989; Maltby, 2002; Maltby, 1999). Gorsuch and McPherson further pointed out that the scales would be improved even more if response biases associated with selfreport data were minimized.

Batson (1976) offered that I-religiosity, as measured by the Allport and Ross instrument, might represent a mature faith, but strongly suggested that more than likely the intrinsic elements corresponded to the rigid belief system of a religious conformist or of someone who exhibited behaviors and expressed values as part of a religious dogma. Batson compensated for what he considered to be deficiencies in the I-E Model with the addition of a third element he called interactional or Quest (Q). Batson argued that one of the hallmarks of a truly mature religiosity was the desire of the believer to deeply examine his/her life, to ask questions, to voice doubt, and ultimately, to be willing to shift his or her religious paradigm. Batson supposed, for example, that a Christian would manifest the Q element by wrestling with the paradox between a loving God and the presence of pain, suffering, and tragedy in the world. According to Donahue (1985), Batson's assertion came under its own rain of criticism because it differed greatly with: (a) both Allport's original and revised positions, (b) religious traditions which contend that when the faithful mature they become less doubtful, not more doubtful, and (c) the 
essence of religiousness itself in that $\mathrm{Q}$ did not correlate with other measures of religiousness.

Batson (1976) measured intrinsicness using a consolidation of the ROS Isubscale, the internal subscale of the Religious Life Inventory (RLS) instrument, and the Doctrinal Orthodoxy Scale. Extrinsicness was measured by combining the ROS Esubscale and the external subscale of the RLS. Batson (1976) and Batson and Ventis (1982) measured Quest elements with the remaining interactional subscale of the RLS, targeting responses to personal and social situations. For example: the Quest subscale contained questions such as: "My life experiences have led me to rethink my religious convictions", "Questions are far more central to my religious experience than are answers", and "As I grow and change, I expect my religion to also grow and change" (Batson \& Schoenrade, 1991a).

In subsequent work Batson confirmed the Quest scale's convergent and discriminant validity, as well as its repeatability, expanded the scale from 6 to 12 items to improve internal consistency, converted from a discrete to continuous type of measurement, and generalized the use of the new scales to measure religious orientation (Batson \& Schoenrade, 1991a; Batson \& Schoenrade, 1991b; Batson, 1976).

Based on his meta-review and his own study of I-E correlations, Donahue (1985) posited that the relationship between I and E was curvilinear in nature. Burris (1994) confirmed this supposition when in one study he showed the curvilinear relationship between I and Q, further confirming that I-type persons, who score highly on the measure of devoutness were not likely to be Q-types (i.e., questioning, tentative persons). 
However, Burris did find more of a linear relationship between $\mathrm{E}$ and $\mathrm{Q}$, indicating that the orientations of these persons did not necessarily clash.

The Relationship between I and E and Other Variables

Lastly, if and how I and E relate to other variables was explored in several serious examinations on religious motivation, attitude, and behavior. Studies spawned by Allport's theory of religious orientation generally indicated that extrinsically motivated religion correlated with dysfunctional personal attributes such as ethnic and ideological prejudice and nonhumanitarian behaviors (Allport \& Ross, 1967; Burris, 1994, Donahue, 1985).

Relationship to prejudice. Allport (1966) noted that other research revealed that when the frequency of church attendance was taken into account as an indicator of intrinsicness, the relationship between church membership and racial prejudice was curvilinear, with the greatest racial bias exhibited by infrequent attendees (i.e., those who attended 1 to 3 times/month) and the greatest tolerance shown by both regular weekly attendees and non attendees. Batson (1976) also observed this inverse relationship between prejudice and church attendance, but discounted it, concluding that it was likely a result of social desirability bias. In his nine-study meta-review on Allport's theory Donahue (1985) reported the correlation between intrinsicness and all measures of prejudice -.05 and with extrinsicness to be .34 . He concluded that the relationship between each orientation and racial prejudice was significant, but weaker than predicted by Allport's original model. 
Feagin (1964) found a similar inverse relationship between racial prejudice and theological orthodoxy as measured by Dynes' Fundamentalism scale. He further speculated that it was this orthodoxy bias, which accounted for the inverse relationship Allport observed between intrinsic orientation and prejudice. Other researchers have drawn opposite conclusions. For example, Altemeyer and Hunsberger $(1993,1992)$ found evidence that religious persons, defined by their degree of fundamentalism, were not less biased, but actually quite the contrary.

Relationship to religiousness. Batson (1976) reported that Allport's intrinsic subscale correlated highly with the internal scale of his Religious Life Inventory and other measures of orthodoxy. He contended that intrinsicness might reflect sincere and deep religious commitment, but that it also might be a sign of attitudes and behaviors that are conventional, risk-averted, and gullible. In their examination whether or not religion fosters prosocial actions, Batson (1976) and others (Batson, Oleson, Weeks, Healy, Reeves, Jennings, et al., 1989) observed that helping behavior of intrinsics manifested without hesitation and was not suspended even if, for example, the supposed victim indicated he or she did not need assistance. Batson and others suggested the actions of the intrinsics might be evidence of the social desirability bias and not of a particularly deep or mature faith. Watson, Morris, Foster and Hood (1986) argued that Batson incorrectly charged intrinsics with having mistaken motives simply because they happened to hold as part of their faith more pro-social beliefs. Furthermore they observed that Batson would not have observed the linkage between intrinsic religiousness and prosocial behavior if he had not included religious content in his study. 
Donahue's (1985) meta-analysis included four significant studies that showed that intrinsicness correlated highly with measures of religious dedication (.76) and that extrinsicness did not (.03). However, he cautioned readers not to discount the usefulness of extrinsicness as a legitimate measure of religiousness noting that the E-subscale measured attitudes not religiousness per se. Kirkpatrick and Hood (1990) reported the same observations, but indicated that because religiosity permeated both the measures of dedication and orientation, this finding at best, was a measure of the ROS' concurrent validity.

Relationship to social desirability. As noted earlier Batson (1976) discounted the inverse relationship between intrinsic orientation and the prejudice as a byproduct of the social desirability bias commonly occurring with self-report data. Similar research by Watson, Hood, Morris and Hall (1984) confirmed the observed positive-I and an negative-E correlational relationship with a measure of empathy, but it was not clear if this finding was motivated by the participant's desire to be perceived as selfless. Watson, Morris, Foster and Hood (1986) showed in later studies that though the measure of intrinsic religious orientation was highly correlated with the Crowne Marlowe Social Desirability Scale. However, these authors allow for the fact that an intrinsically motivated person could also live their lives upholding more socially desirable values.

Relationship to other variables. Donahue (1985) concluded that E-religiosity was not strongly related to measures of religious importance but was positively correlated with various ignoble behaviors and attitudes. Alternatively, I-religiosity was positively correlated with measures of religious commitment, but not related to antisocial behaviors 
and attitudes. Alker and Gawin (1978) established that participants who were highly intrinsic also had a greater sense of well-being and were happier. Sturgeon and Hamley (1979) examined the results of the ROS, as well as anxiety and locus of control instruments, and concluded that intrinsically-typed Christians were less anxious, more self-assured secure, and more self-supporting than extrinsically-typed ones. Comparing intrinsically motivated religious students and nonreligious students McClain (1978) reasoned that the religious students were better able to consider the needs, concerns, and wishes of others while fulfilling their own needs and that they also had a higher level of psychological harmony.

\section{Summary on Religious Orientation}

Regardless of how many times the RO concept has been derided, it appears that researchers have agreed on the essence of what Allport was attempting to measure, even if they cannot agree on its specific aspects. Though labeled in the extreme as antiquated or embryonic, Allport's approach to looking at a person's motivation for belonging to a faith community has established a useful platform from which to examine negative social behaviors, like IPV, within the Church.

Gorsuch (1984) noted that the correlations between the ROS and other variables were attention grabbing and that the relationships uncovered between religious attitudes, values, and behaviors warranted examination rather than arbitrary dismissal. Even if the construct of RO and the usefulness of ROS is ultimately deemed limited for the general population, studies within the faith community have highlighted significant and useful correlations between I, E, and other variables (Kahoe, 1985). 
Though several attempts have been made to improve, modify, or supplant Allport's theory of religious orientation, none have been clearly found to be superior. Therefore, even as a limited measure of religious motivation, Allport's intrinsic/extrinsic distinction may have implications for improving batterer intervention efforts within the faith community by allowing for a more tailored approaches.

\section{Exploration of Religious Antecedents to Domestic Violence}

The journal literature reflected varied, albeit limited, research interest about the influence of religion on both the committing and the suffering of partner violence. One more common, but inconclusive area of exploration has been centered around the influence of religious conservatism on the perpetration of partner violence. Driving this research has been the notion: (a) that patriarchal views on male-female role legitimizes physical abuse by husbands (Cunradi, Caetano, \& Schafer, 2002a; Ellison et al., 1999) and (b) that the Church leadership sanctions the dismissal of such abuse (Nason-Clark, 2000). Relatedly, some research has explored the IPV vulnerability of women who hold strong religious views about forgiveness and who also believe such violence is allowable according to the Bible (Nason-Clark, 2004), or is required because of mankind's "sinful nature" (Ellison, et al., 1999).

Some research reflects the assumption that the Christian theology of love and respect coupled with the social support systems available in the Church, made women less, not more vulnerable to IPV and made men less likely to be violent toward their partners (Ellison \& Anderson, 2001). Still others have asserted that that decreased levels of partner violence exist within a Church community because of the moderating effect of 
religion in improving marital satisfaction, life adjustments, and relationship commitment (Cunradi et al., 2002a; Ellison \& Anderson, 2001).

Allport's theory of religious orientation and its many derivatives have spawned a tremendous amount of research, despite the ongoing debate about the usefulness, of the construct and its measurement. This theory along with its various refinements has provided an avenue for researchers to better understand theologically un-Christian behaviors such as racial and ethnic prejudice within the Church community. By extension, it also may hold that an examination of intrinsic and extrinsic motivation behind religious participation will help researchers understand the paradoxical existence of partner violence within the Church. The following research was reviewed in light of the observations of Allport and others concerning religion and socially negative behaviors. The reader is reminded that one characteristic Allport used to differentiate between intrinsic and extrinsic orientations was the frequency of religious participation (Allport \& Ross, 1967; Genia, 1993). He found that, people who attended church consistently (i.e., at least once a week or more) expressed higher intrinsic scores and in his view, were more mature in their faith (Allport \& Ross, 1967).

\section{Studies on Religion and Domestic Violence}

One larger study was completed by Ellison et al. (1999) using logistic regression analysis on the Wave I data from the National Survey of Families and Household (NSFH) to test the relationship between the frequency of participation in weekly religious services and the occurrence of DV, as measured with the responses of the NSFH's primary respondents. According to Sweet, Bumpass and Call (1988) the primary respondents to 
the NSFH were selected at random and participated in the survey by completing both a self-report questionnaire and a personal interview. The person cohabitating with the primary respondent was classified as the secondary respondent and completed only a selfadministered questionnaire. The NSFH questions addressed religious affiliation and allowed answers with category options that were nominally Christian, as well as nonChristian (Sweet et al., 1988). The frequency categories of attendance used were: (a) once per year or less, (b) several times per year, (c) one to three times a month, and (d) at least once per week (Ellison et al., 1999). Ellison et al. created an index they called theological conservatism based on two NSFH questions considering the subjects': (a) use of, and (b) feelings about the authority of the Bible in their lives. This index was used in combination with denominational grouping to establish if the similarities and differences in the fundamentalism of their religious beliefs between the partners regarding the altered the risk of perpetuating DV.

Ellison et al. (1999) concluded that there were no denominational differences in the frequency of domestic abuse perpetrated and thus refuting at least the patriarchal argument for violence based on denominational conservatism. The researchers also found the level of violence was less within denominationally homogenous couples, except when both partners were not affiliated with any denomination. The theological conservativeness, nor the homogeneity of the couple's views did not factor into the risk of perpetrating IPV, except in cases where the man held much more conservative views than his partner. Later, when partner reports were used to triangulate the data and explore 
the effect of the social desirability bias researchers found the same, though weaker relationships (Ellison \& Anderson, 2001).

As they hypothesized, Ellison et al. (1999) found the perpetration of partner violence was inversely related to the frequency of religious participation for both men and women. The percentage of men committing domestic violence was $1.8 \%$ for men who attended church at least once a week versus $6 \%$ for those who attended less than once a year. Interestingly, the percentage of women committing abuse was $3.3 \%$ for women who attended church at least once a week, $3.8 \%$ for women who attended 1 to 3 times a month and $\sim 8 \%$ for those who attended less than once a year. For men who participated in religious services at least once a week, the odds of committing IPV were half that of men who attended once a year or less.

Broadening their earlier work, Ellison and Anderson (2001) explored further the inverse relationship between church attendance and the perpetration of IPV. Again using data from the first wave of the NSFH, the researchers explored in addition to religious attendance the influence of social support systems, substance abuse, and psychological problems (e.g., low self-esteem, depression) on the perpetration of IPV. Ellison and Anderson found that the seemingly constructive impact that church attendance had on lowering the risk of IPV perpetration stood above the generally positive benefits of the social support systems. Low self-esteem did not appear to influence the partner abuse, but high levels of depressive symptoms and high levels of drug or alcohol abuse did.

Using participants who completed the National Alcohol Survey and answered DV questions as part of the 1995 National Study of Couples, Cunradi et al., (2002a) 
evaluated: (a) various aspects of family violence and religious affiliation, including the effect of religious attendance on the occurrence of domestic abuse, and (b) the potentially mediating effect of religion on the use of alcohol. The 1-hour one-to-one interviews included direct questions about violent behaviors taken from the Straus' Conflict Tactics Scale Form $\mathrm{R}$ that measures physical violence and other aggressive behaviors. Additional questions were included addressed alcohol dependency, denominational homogeneity, the importance of religion, and frequency of church attendance. Analysis of the data from 1,635 married or cohabitating men and women over the age of 18 , revealed that men who frequently attended religious services showed lower rates of perpetrating interpersonal violence then did men who attend less frequently (Cunradi et al., 2002a). Similar to other studies, these researchers concluded that sharing or not sharing the same denominational beliefs had little effect on the level of abuse perpetrated. Also, women who more highly valued religion showed a slightly higher risk for victimization, but the reasons for this finding were not clear. The authors observed regular church attendees who felt that their faith was important had lower levels of alcohol usage. The authors conjectured that religion's effect on alcohol usage possibly mediated the correlation found between religious attendance and intimate violence.

In a Canadian study Brinkerhoff, Grandin and Lupri (1992) conducted personal interviews with 1,123 adults, as well as administered an 18-element modified Conflict Tactics Scale questionnaire. In addition to religious affiliation the researchers made additional inquires into the fundamentalism of the person's religious beliefs. Countering the common finding of higher male to female violence, Brinkerhoff et al. found that the 
incidence of IPV perpetration was higher for women $(29.5 \%)$ than for men (17.8\%), but acknowledge the motivation for the violence (e.g., self-defense) and the severity of the abuse was different between the sexes. Abusive behavior was the highest for males and females not associated with a denomination. They also observed that within religiously conservative couples it was the female, not the male, who perpetrated violence most often. Other findings included: (a) one's denomination was not linked to the occurrence of IPV, (b) those who attended church most frequently engaged in the lowest levels of DV, (c) higher levels of reported abuse were found in men and women attending one to three times a month and with women with not attending at all. These findings in the Brinkerhoff et al. study paralleled the curvilinear findings of Allport and others and suggest Allport's intrinsic/extrinsic model still may be useful in better understanding of these observations.

\section{Chapter Summary}

Despite passionate investigations searching for definitive antecedents to partner violence in general, and in particular within the Christian Church, research in this area has not yielded clear and practical conclusions. Individual trait patterns, contextual elements, and situational factors have been noted, but this information has not been able to be effectively incorporated into faith-based IPV prevention and batterer's intervention efforts (Nason-Clark, 2004). As confirmed by the inconclusiveness among research findings, the differences between batterers, victims, and situational characteristics complicate as much as illuminate matters. Bringing an end to intimate violence might require more specific, batterer-specific approaches. 
Domestic violence of all kinds, like racial prejudice, is considered to be a contrasocial phenomenon. Perpetrator motivations for such social ills have been difficult to unravel. To specifically address racial prejudice within the Church Allport and Ross (1967) closely examined the attitudes and behaviors of the specific members, not only regarding racial prejudice, but also concerning their reasons for participating in the Church community. Allport and Ross pointed out that though one's level of intolerance was related to the frequency of their church participation, this observation itself was not an explanation of the curvilinear phenomena they detected. These researchers believed a more substantive explanation was required beyond observable behaviors into the commitment level of the churchgoer. Their premise led them to an investigation into intrinsic and extrinsic motivation and attitudes associated with church participation.

Admittedly, an investigation into self-reported church attendance, religious activities, personal attitudes, beliefs, and self-evaluations offers a limited measure of a man or woman's commitment to his or her faith. However, as a place to begin to better understand domestic violence and its relationship to religious variables a quantitative investigation using data from the Add Health study will be conducted.

In chapter 3 more background about the Add Health study is provided. Additionally, details are given about the specific domestic violence and religious measures that will be used in the logistics regression analysis to determine which religious or spiritual factors or combinations of religious or factors affect the odds of occurrence of: (a) threats of violence, (b) physical violence, (c) injurious violence, and (d) sexual violence. 


\title{
CHAPTER 3:
}

\section{RESEARCH METHOD}

\author{
Introduction
}

As a national longitudinal study, the first three waves of the Add Health study (Harris et al., 2008) include both in-school and in-home survey information gathered from adolescents and young adults over approximately a 7.5-year period. Generally, the questionnaires and interviews used in these waves were designed to gather information about the impact and consequences of behavioral choices made by individuals, within the context of various social, familial, and educational environments. To date this longitudinal study includes three completed survey waves (September 1994 to December 1995; April 1996 to August 1996; August 2001 to April 2002). A fourth wave (in 2007 and 2008) is ongoing.

In order to examine the relationship between partner violence and selected religious and spiritual factors this research included a multivariate logistic regression assessment of the Wave III archival research survey test data. Because of the mixed categorical and quantitative nature of these violence, religious, and spiritual factors, logistic regression was deemed the most suitable analysis method to evaluate the likelihood that certain religious and spiritual factors that had an impact on the probability of occurrence of IPV and to build a predictive model for IPV occurrence. Because of the inability to clearly differentiate between the categories of violence perpetrated in the Add Health dataset, a binary, rather than multinomial, logistic regression analysis was selected. 
A total of 15,197 out of an original 20,745 students were included from the inhome administration portion of the Wave III interviews. Wave I and Wave II data were not utilized, as they did not contain the needed violence and religious or spiritual factors.

Chapter 3 further details the background of each of the completed waves of the Add Health study and provides an overview of the participants in each of the interview waves. The violence, religious and spiritual questions from which the study variables were constructed are reviewed. Later in the chapter, the design of this quantitative study using archival data is discussed including the research questions surrounding all factor relationships, the specific hypothesis tested, the reliability of the archival data set, and the projected use of partner data. The specific analyses to be performed are outlined and the expectations regarding the power of the analyses are discussed.

\section{Design and Data Collection}

\section{Summary of Wave I Design}

The Wave I design utilized cluster sampling to determine the in-school core group for the study (Harris et al., 2008). A high school met the criteria for selection if more than 30 students were enrolled and it included at least the $11^{\text {th }}$ grade. Feeder schools that included a seventh grade and sent at least five students to a high school were solicited in communities where the high school did not include a seventh grade. Schools that declined to participate were replaced with others such that the appropriate geographic region, ethnic, urban/rural, size, type, and curriculum representation were maintained. The recruitment selection process resulted in a sample of 132 schools, representing 80 clusters nationwide. 
During September 1994 to April 1995, a 45- to 60-minute in-school questionnaire was administered to over 90,000 students participating in the first wave (Harris, 2008). Included on this self-administered instrument were questions addressing household demographics, friend and family relationships, extracurricular activities, unsafe behaviors, and a few psychosocial elements.

Recruitment for the in-home interviews included students who were listed on the school roster, even if they did not complete the in-school survey. From April to December 1995, 1- to 2-hour in-home interviews were conducted with 20,745 students. The in-home evaluation included both direct interviewer and audiotaped, age-appropriate questioning in areas such as health and nutrition, peer groups, family makeup and functioning, employment, romantic and sexual relationships, criminal activities, tobacco/drug/alcohol use, and future educational expectations. In-home participants also were given the Add Health Picture Vocabulary Test to screen for verbal ability and to test for receptive vocabulary for standard English. School administration (164 interviews) and parental data $(17,700$ interviews) also were collected in this wave.

\section{Summary of Wave II Design}

Wave II of the study was conducted April through August 1996 (Harris et al., 2008). Repeating the in-home interview design of the first wave, the second wave of the study was completed with 14,738 student interviews from the same participant pool as Wave I, excluding most of the previous 12 th grade participants and the disabled participants. Sixty-five students who were part of the genetic sample, but not interviewed in Wave I, were included in Wave II. Pertinent school, community, and neighborhood 
information was updated in phone interviews with administrators and/or published databases. Parental interviews were not completed during this phase.

\section{Summary of Wave III Design}

Conducted between August 2001 and April 2002, Wave III of the Add Health study was the $6^{\text {th }}$ year follow-up of the in-home student survey (Harris et al., 2008). Participating in the Wave III survey were 15,197 of the Wave I participants. Incarcerated participants were interviewed when possible, though those who were not in the United States at the time of this survey were excluded. A total of 1,507 interviews with the partners of the primary respondents were conducted. The in-home interviews for Wave III averaged 134 minutes and while some questions were unchanged from Wave I, other inquires were made to more deeply explore the current peer groups and romantic relationships of these young adults. As in earlier waves, interviewers asked the more general questions directly and the more sensitive questions were queried in a written format. In order to maintain confidentiality, interviewee responses were recorded only by direct computer entry, with no hardcopies. Biological specimens of saliva and urine to test for sexually transmitted diseases were collected as part of the Wave III study and added approximately 44 minutes to the data collection time. Of particular interest in this wave are the questions on religion and spirituality and those addressing violence within in intimate relationships. 


\section{Participants}

\section{Summary of Wave I Participants}

The Add Health research was focused on the study of behaviors and attitudes of adolescents in Grades 7 through 12. The sample was drawn from a national population and from both rural and urban school settings. During the 1994 to 1995 school year, 90,118 students in Grades 7 through 12 completed the in-school portion of the study (Harris et al, 2008). With parental permission, students completed the 45 to 60 minute questionnaire during a regular class period. Students absent on the day the questionnaires were administered were not included in the school study, but were included in the potential sample for the in-home study. Completed in-home interviews included a nationally stratified core sample of 12,105 students, supplemented with oversampling from four ethnic populations: Blacks with at least one parent with a college degree (1,068), Chinese (334), Cuban (450), and Puerto Rican (437). Also included were a sample of students (589) who classified themselves as disabled, a genetic sample consisting of related and nonrelated pairs of siblings, and a saturation sample including all students enrolled in 16 schools. Participants could qualify for more than one oversampled group.

\section{Summary of Wave II Participants}

Wave II included approximately 15,000 of the Wave I participants (Harris et al., 2008). Twelfth graders were generally excluded from the sample except when they were part of a genetic pair. 


\section{Summary of Wave III Participants}

For Wave III a total of 15,197 in-home interviews were completed with participants aged 18 to 26 (Carolina Population Center [CPC], 2004). A partner interview was designated if the main respondent currently had a partner with whom they had been involved with for at least 3 months prior to the study, and if the partner was of the opposite sex, and was at least 18 years of age. The sampling was designed to include married, cohabitating and dating couples in equal proportions. The final partner sample included 1,507 participants. For this study, all of the Wave III participants were included in the initial data set. The specific criteria for participant case selection in this study are described in Religious and Spiritual Measurements section of this chapter.

\section{Measures To Protect Participants' Rights}

All data considered in this study were publicly available or available as a restricted-use contractual dataset. During the collection of the Add Health Wave III data, precautions were taken to protect the participant's privacy and rights.

All Wave III respondents were between the ages of 18 and 26 years old, and personally read and signed informed consent forms (CPC, 2004). The Add Health researchers collected information using identification numbers and other identifiers. The identification numbers themselves were not used in data distribution. Additionally, the sociometrics agreement entered into with the Carolina Population Center ([CPC], 2003) to obtain use of the dataset required that: 
1. The data are not to be used for purposes other than the intended research, or aggregate reporting, including but not limited to commercial purposes.

2. The data can be used only by authorized (and named) members of the research team.

3. The release of identifying information is not permitted.

4. The dataset is not to be linked with or used in combination with any other dataset with identifiers.

5. No attempt will be made to identify the participants and if an identification is inadvertently made, no use of the data will be made, the Carolina Population Center will be informed, no one will be told of the discovery, and the identifying information will either be safeguarded or destroyed.

To further safeguard the use of the dataset, restrictions have been placed on the statistics from the study (CPC, 2003). Specifically:

1. In no table should all cases in any row or column be found in a single cell;

2. In no case should the total figure of a row or column of a crosstabulation be less than 50;

3. In no case should a quantity figure based on a count of 10 or less be presented for an age-sex category for a community with a total population of 200 or less; 
4. In no case should an age-sex quantity figure be based upon fewer than 10 cases;

5. In no case should a quantity figure be published if one case contributes more than 60 percent of the amount;

6. In no case should data on an identifiable case, nor any of the kinds of data listed in preceding items A-D, be derivable through subtraction or other calculation from the combination of tables released on a given study; and,

7. Data released should never permit disclosure when used in combination with other known data.

Measures

\section{Overview of Wave III Questions}

Wave III interview topics were similar to those included in Wave I, with changes made to reflect anticipated changes in the participant's physical and social environment, relationships and health. Thirty-five topic sections were included in the Wave III study (see Appendix A for a complete section listing for both Wave I and Wave III question sections). This research used the Add Health Wave III measures of IPV, religious and spiritual behaviors and beliefs. Wave III of the Add Health interviews also included 1,507 partner responses that could be used to triangulate the violence perpetrated 
responses of the main respondent. The self-report and partner-report survey questions used quantitative, Likert, nominal, and ordinal rating systems.

\section{Question for Case Selection}

Questions reflecting the category of religious denomination were used for selection of cases for analysis. Selection was made for those cases answering $1=$ Protestant, 2 = Catholic, or $8=$ Christian on Question 1: "What is your present religion?" Additionally, since the majority of reported IPV in the literature reflects male-on-female perpetrated crime, only cases where the primary respondent was male were selected.

\section{Partner Violence Questions}

The dependent (violence) variables in the study were extracted from eight Add Health questions reflecting the frequency counts or estimations by the participants regarding their experience of, or perpetration of: physical violence, sexual violence, threats, and/or injurious violence. Wave III questions of interest were asked in 1,507 cases of both primary participants and their partners. Responses in the partner interviews to questions regarding the frequency of their experiences of physical violence, sexual violence, threats, and/or injurious violence were to be used to triangulate the primary participant's violence perpetration findings.

\section{Religious and Spiritual Questions}

The independent (religious) variables were derived from 10 religious and spiritual questions. One independent variable examined was the frequency of attendance at weekly worship services. Other independent variables included were: the frequency of 
participation in corporate or individual religious activities other than weekly services, the frequency of private prayer/meditation, and the ratings given on various religious or spiritual "importance" questions (\#33, \#37, \#38, \#40,\#41, and \#42 noted in the following section).

\section{Partner Violence Measurements}

The occurrence of physical, threatening, injurious, and sexual IPV was assessed using the information gathered in Section 19: Relationships in Detail of the Add Health, Wave III questionnaire. The Section 19, Wave III questions used to determine threatened physical violence, pushing, and shoving were:

109. How often have you threatened $<$ PARTNER $>$ with violence, pushed or shoved $\{$ HIM/HER $\}$, or thrown something at $\{$ HIM/HER $\}$ that could hurt? $0="$ never"; $1=$ "once"; $2=$ "twice"; $3=" 3$ to 5 times"; $4=" 6$ to 10 times"; $5=" 11$ to 20 times"; 6="more than 20 times"; $7=$ "this hasn't happened in the past year, but did happen before then"; 95="question not asked of this respondent"; 96="refused"; 98="don't know"; 99="not applicable"; •="missing"

110. How often has $<$ PARTNER $>$ threatened you with violence, pushed or shoved you, or thrown something at you that could hurt?

$0="$ never"; $1=$ "once"; $2=$ "twice"; $3=" 3$ to 5 times"; $4=" 6$ to 10 times"; $5=" 11$ to

20 times"; 6="more than 20 times"; $7=$ "this hasn't happened in the past year, but did happen before then"; 95="question not asked of this respondent"; 96="refused"; 98="don't know"; 99="not applicable"; •="missing"'

The Section 19, Wave III questions used to determine physical violence were:

111. How often have you slapped, hit, or kicked $<$ PARTNER>? $0="$ never"; $1=$ "once"; $2=$ "twice"; $3=$ " 3 to 5 times"; $4=$ " 6 to 10 times"; $5=" 11$ to 20 times"; $6=$ "more than 20 times"; $7=$ "this hasn't happened in the past year, but did happen before then"; 95="question not asked of this respondent"; 96="refused"; 98="don't know"; 99="not applicable"; •="missing"

112. How often has $<$ PARTNER $>$ slapped, hit, or kicked you? $0="$ never"; $1=$ "once"; $2=$ "twice"; $3=$ " 3 to 5 times"; $4=" 6$ to 10 times"; $5=" 11$ to 20 times"; $6="$ more than 20 times"; $7=$ "this hasn't happened in the past year, but 
did happen before then"; 95="question not asked of this respondent"; 96="refused"; 98="don't know"; 99="not applicable"; •="missing"

The Section 19, Wave III questions used to evaluate sexual violence were:

113. How often have you insisted on or made $<$ PARTNER $>$ have sexual relations with you when $\{\mathrm{HE} / \mathrm{SHE}\}$ didn't want to?

$0="$ never"; $1=$ "once"; $2=$ "twice"; $3=" 3$ to 5 times"; $4=" 6$ to 10 times"; $5=" 11$ to

20 times"; $6=$ "more than 20 times"; $7=$ "this hasn't happened in the past year, but did happen before then"; 95="question not asked of this respondent"; 96="refused"; 98="don't know"; 99="not applicable"; •="missing"

114. How often has $<$ PARTNER $>$ insisted on or made you have sexual relations with $\{$ HIM/HER $\}$ when you didn't want to?

$0="$ never"; $1=$ "once"; $2=$ "twice"; $3=" 3$ to 5 times"; $4=" 6$ to 10 times"; $5=" 11$ to 20 times"; 6="more than 20 times"; $7=$ "this hasn't happened in the past year, but did happen before then"; $95=$ "question not asked of this respondent"; 96="refused"; 98="don't know"; 99="not applicable"; •="missing"

The Section 19, Wave III questions used to evaluate injurious violence were:

115. How often have you had an injury, such as a sprain, bruise, or cut because of a fight with $<$ PARTNER $>$ ?

$0="$ never"; $1=$ "once"; $2=$ "twice"; $3=$ " 3 to 5 times"; 4=" 6 to 10 times"; $5=" 11$ to 20 times"; $6="$ "more than 20 times"; $7=$ "this hasn't happened in the past year, but did happen before then"; 95="question not asked of this respondent"; 96="refused"; 98="don't know"; 99="not applicable"; •="missing"'

116. How often has $<$ PARTNER $>$ had an injury, such as a sprain, bruise, or cut because of a fight with you?

$0=$ "never"; $1=$ "once"; $2="$ twice"; $3=" 3$ to 5 times"; $4=" 6$ to 10 times"; $5=" 11$ to 20 times"; 6="more than 20 times"; $7=$ "this hasn't happened in the past year, but did happen before then"; 95="question not asked of this respondent"; 96="refused"; 98="don't know"; 99="not applicable"; •="missing"'

Because of the wide variation in opinion about what constitutes mild, moderate,

and severe violence, no attempt was made to re-categorize or collapse the ratings within the violence questions. Also due to the anticipated likelihood of correlations among the four types of violent behaviors measured, the violence perpetration variable (dperp) was 
coded as dichotomous (i.e., any type of violence committed and no violence committed). There was no attempt in this study to characterize the degree or frequency of violence perpetrated. Any count responses (e.g., $1=$ once, $2=$ twice, $3=3$ to 5 times, $4=6$ to 10 times, 5 = 11to 20 times, $6=$ more than 20 times) to the violence questions $109,111,113$, and 116 were coded as "violence committed." A response of " $0=$ never" was coded as "no violence committed." All other responses were coded as missing. In this study, the violence data were analyzed for primary male respondents only.

\section{Religious and Spiritual Measurements}

Proxy elements of religious orientation were assessed using questions from Section 31: Religion and Spirituality of the Add Health, Wave III questionnaire. One general religious question from this section was used for selection of the cases for analysis is:

\section{What is your present religion?}

$0=$ "none/ atheist/ agnostic"; 1="Protestant"; $2=$ "Catholic"; 3="Jewish"; 4="Buddhist"; 5="Hindu"; 6="Moslem"; 7="other*"; 8="Christian*"; 96="refused"; 98="don't know"; 99="not applicable"; •="missing"

Case selection was made for those cases of males only, answering " $1=$ Protestant"; "2=Catholic", or "8=Christian" on Question 1: "What is your present religion?"

The remaining religious/spiritual questions included from Add Health were considered by this student to parallel other religious orientation questions in Allport's ROS (Allport \& Ross, 1999), and to be indicative of the participants' intrinsic or extrinsic approach to religion/spirituality. Response format to the Add Health questions dictated 
the nature of the variables generated. Nine out of the 10 questions were used to generate categorical religious/spiritual variables. One question was used to generate a single continuous variable. The interview questions taken from Section 31 of Wave III of the Add Health study comprising the 10 religious or spiritual factors were:

Frequency of Religious Attendance (freqattend - categorical variable):

24. How often have you attended \{CHURCH/SYNAGOGUE/TEMPLE/ MOSQUE/RELIGIOUS $\}$ services in the past 12 months?

$0=$ "never"; 1="a few times"; 2="several times"; 3="once a month"; 4="2 or 3 times a month"; 5="once a week"; 6="more than once a week"; 96="refused"; 98="don't know"; 99="not applicable"; •="missing"

Other Corporate Religious Activities (othercorp - categorical variable):

25. Many churches, synagogues, and other places of worship have special activities or young adults - such as Bible classes, retreats, youth groups, or choir. In the past 12 months, how often have you taken part in such activities?

0 = "never"; 1="a few times"; 2="several times"; 3="once a month"; 4="2 or 3 times a month"; 5="once a week"; 6="more than once a week"; 96="refused"; 98="don't know"; 99="not applicable"; •="missing"

Other Private Religious Activities (otherpriv-continuous variable):

31. In an average week, about how many hours do you spend in religious activities in your home (such as praying, meditating, or reading religious books)?

0="0 hours"; hours range 1 to 90; 96="refused"; 98="don't know"; 99="not applicable"; • ="missing"

Private Prayer (prayer - categorical variable):

32. How often do you pray privately, that is, when you're alone, in places other than a \{CHURCH/SYNAGOGUE/TEMPLE/MOSQUE/RELIGIOUS ASSEMBLY\}?

$0=$ "never"; $1=$ less than once a month"; $2=$ "once a month"; $3=$ "a few times a month"; 4="once a week"; 5="a few times a week"; 6="once a day"; 7="more than once a day"; 96="refused"; 98="don't know"; 99="not applicable" 
Importance of Spiritual Life (imptspirit - categorical variable):

33. How important is your spiritual life to you?

$0=$ "not important"; $1=$ "somewhat important"; $2=$ "very important"; $3=$ =more important than anything else"; 6="refused'; 8="don't know";9="not applicable"; •="missing"

Led Spiritually (ledspirit - categorical variable):

37. What seem to be coincidences in my life are not really coincidences; I am being led spiritually.

1="strongly agree"; $2=$ "agree'; $3=$ "neither agree or disagree"; 4="disagree";

5="strongly disagree"; 96="refused"; 98="don't know"; 99="not applicable";

$\bullet=$ "missing"

Integration Into Life (integlife - categorical variable):

38. I employ my religious or spiritual beliefs as a basis for how to act and live on a daily basis.

1="strongly agree"; $2=$ "agree'; $3=$ "neither agree or disagree"; 4="disagree";

5="strongly disagree"; 96="refused"; 98="don't know"; 99="not applicable";

$\bullet=$ "missing"

Born Again (bornagain - categorical variable):

40. Would you say you have been born again or have had a born again experience - that is, a turning point in your life when you committed yourself to Jesus Christ?

0="no"; 1="yes"; 6="refused"; 7="legitimate skip"; 8="don't know"; 9="not applicable"; •"missing"

Degree of Religiousness (degrel - categorical variable):

41. To what extent are you a religious person?

$0=$ "not religious at all"; $1=$ "slightly religious"; $2=$ "moderately religious"; $3=$ "very religious"; 6="refused"; 8="don't know"; 9="not applicable"; •="missing"

Degree of Spirituality (degspirit - categorical variable):

42. To what extent are you a spiritual person? 
0="not spiritual at all"; 1="slightly spiritual; 2="moderately spiritual"; 3="very spiritual"; 6="refused"; 8="don’t know"; 9="not applicable"; •="missing"

The Add Health data set was made available to this researcher only for the purposes of completing this specific research. In accordance with the contractual agreement made with the University of North Carolina's Carolina Population Center, the original data $\mathrm{CD}$ must be returned and all hard and electronic copies of all raw data must be destroyed.

\section{Data Analysis}

\section{Argument for the Method}

As reviewed in chapter 2, many of the studies on domestic violence have been aimed at better understanding of IPV by testing both the degree of relationship among several demographic and contextual factors, as well as the significance of these variable differences between those who have been victimized by IPV or not. Many of the findings of these studies have application within the Christian Church community as well as within the secular community. However, perhaps the most helpful to faith-based intervention efforts, but less often undertaken, are those studies focused on examining likely religious antecedents to IPV. The literature is particularly lean in the area of religious research targeting younger adults, who are at greater risk for the perpetration of such violence.

In the United States, the perpetration of IPV still induces a degree of shame and social disgrace, and as such can greatly influence the accuracy with which study participants reveal such behaviors (Ellison \& Anderson, 2001; Ellsberg \& Heise, 2005). 
Similarly, the reporting of one's involvements in religious or spiritual activities (e.g., church attendance), is also influenced by social desirability bias, and thus is often exaggerated (Hadaway, Marler \& Chaves, 1993). The use of secondary data, carefully collected as part of Wave III of The National Longitudinal Study of Adolescent Health, provides a more cost-effective way to study sensitive topics like religious, spiritual, or violent behaviors/attitudes. Exploration of the relationship between religious and spiritual factors and the perpetration of IPV using the Add Health database, which targets a large number of individuals in a high-risk age category, offered a unique opportunity to discover more generalizable research findings in the area of religion and IPV.

Due to the categorical nature of the dependent violence variable and the mixed qualitative and quantitative nature of the 10 independent variables included in the Add Health study, a logistic regression analysis was selected as the best method to assess the odds of perpetrating violence as the values among independent religious and spiritual factors changed. Because of the inability to clearly differentiate between the categories of violence perpetrated in the Add Health dataset, a binary, rather than multinomial, logistic regression analysis was selected.

\section{Research Questions}

The research questions to be answered in this study were:

1. Can the occurrence of IPV perpetration (dperp) be correctly predicted from our knowledge of the following religious or spiritual factors?

a. The frequency of attendance in religious services (freqattend) - Add Health Wave III Section 31, Q24) 
b. The frequency of participation in corporate religious activities other than a weekly church service (othercorp - Add Health Wave III Section 31, Q25)

c. The frequency of participation in private religious activities (otherprivAdd Health Wave III Section 31, Q31)

d. The frequency of prayer/meditation (prayer - Add Health Wave III Section 31, Q32)

e. The degree of importance placed on one's spiritual life (imptspirit - Add Health Wave III Section 31, Q33)

f. The degree to which one is led spiritually (ledspirit-Add Health Wave III Section 31, Q37)

g. The degree to which religious beliefs are integrated into one's life (integlife - Add Health Wave III Section 31, Q38)

h. Whether or not one considers himself/herself to be "born again" (bornagain - Add Health Wave III Section 31, Q40)

i. The extent to which one views himself/herself as a religious person (degrel - Add Health Wave III Section 31, Q41)

j. The extent to which one views himself/herself as a spiritual person (degspirit - Add Health Wave III Section 31, Q42)

2. If IPV occurrence can be correctly predicted, which religious or spiritual factors are essential to the prediction?

3. How good is the model developed at classifying cases for which the occurrence of IPV is unknown? 


\section{Hypothesis}

Null Hypothesis: The perpetration of physical or sexual IPV is not related to religious attendance, participation in corporate religious activities, participation in private religious activities, participation in private prayer/meditation, the importance placed on one's spiritual life, the degree to which one is led spiritually, the degree to which religious beliefs are integrated into one's life, being born again or not, one's sense of religiousness, and one's sense of spirituality.

Alternative Hypothesis: The perpetration of physical or sexual IPV is related to religious attendance, participation in corporate religious activities, participation in private religious activities, participation in private prayer/meditation, the importance placed on one's spiritual life, the degree to which one is led spiritually, the degree to which religious beliefs are integrated into one's life, being born again or not, one's sense of religiousness, and one's sense of spirituality.

\section{Reliability and Validity}

No specific information about the validity and reliability of the Add Health survey and interview instruments could be found in the literature, outside of those measures where the Add Health researchers utilized methods or questions from already established procedures or instruments. In particular, no reports have been found regarding the validity or reliability for the specific questions of interest in this study in Sections 19 and 31 from Wave III of the Add Health study. Inquiries made to the Add Health Research 
Contact did not yield further information about reliability or validity testing of the questions used in Wave III, Sections 19 and 31.

Though documentation about the construction of specific Wave III questions could not be found, it is useful to consider the standards by which Add Health researchers developed the questionnaires used in earlier research waves. For example, Sieving et al. (2001) noted that the developers of the Add Health Wave I questionnaires used a deductive approach to build the instruments, based on known aspects of the areas to be investigated rather than on inductive/factor analysis. After the development of the multiscale items, pretest sample data were randomly split in order to cross-validate internal scale consistency (Sieving et al.). Using exploratory samples, Cronbach coefficients were calculated for the each scale item when compared to total scale data. An item was removed from the scale (a) if there was an increase in $\alpha>.02$ when the item was removed and (b) if the item was less correlated than the other items with the scale total. Sieving et al. reported that Cronbach alphas reported for the various multi-item scales were at acceptable levels, between .70 and .87 . It may be reasonable to assume that similar levels or rigor were employed when developing questions for Wave III.

It is important to note that with interview data, in addition to random measurement error, there was the potential for inaccuracies to be introduced into the study due to query biases of the researchers and response biases of the participants. The need for over demanding recall of violent occurrences and religious activities that have occurred within the last 12 months might have seriously contributed to interview inaccuracies. In this study, social desirability biases associated with sensitive topics, like 
violence perpetration and religious or spiritual attitudes and behaviors, might have limited the internal validity of the Add Health interviews. Precautions were taken by the Add Health researchers to minimize such biases by employing techniques that allowed participants to privately enter sensitive topic information directly into a computer. An outside organization, RTI International, collected Wave III field data for this University of North Carolina study.

Strengths of the Add Health dataset came from its longitudinal design and from its nationally broad sampling base. The external validity or generalizability of the analysis and findings was expected to be strong for 18- to 26-year-olds living in the United States. The interview questions utilized in this study were not categorized as a construct per se, beyond "violence perpetrated" and "religious or spiritual factors." The violence measures reflected the perpetration of violence only in the forms of pushing, shoving, throwing, slapping, hitting, kicking, forced sexual relations, sprains, bruises, cuts, and threats of violence. While these actions of violence are typically included under IPV actions, the Add Health survey does not include violence in other forms such as economic distress, neglect, threats regarding the children, psychological abuse, and emotional abuse. The religious or spiritual factors reflected a broad spectrum of behaviors and attitudes that paralleled the intrinsic questions on Allport's Religious Orientation Scale. However, there was no attempt to correlate the two scales in terms of their measurement of religiosity and therefore, concurrent validity, predictive validity, and discriminant validity of the Add Health measures is unknown. 


\section{Use of Partner Data}

If there were enough pairs of Wave III partner interviews selected from the original 1,507 interviews, logistic regression modeling was to be utilized to verify the primary respondent model and the results for the odds of threatening or actually committing an assault. A general comparison between the logistics regression findings using partner data and the primary respondent data can be used to assess the potential for social desirability bias on the part of the primary (male) respondent. These Wave III romantic partner data were among the most sensitive data available from Add Health and required approval of a contract and a security plan that was significantly more rigorous than the general restricted-use datasets.

\section{Analysis Strategy}

Ten religious and spiritual questions from Section 31 of the Add Health interviews were used to create the independent variables in the analysis. No collapsing of the scale measurements was expected at the start of the study. Though conceptually the religious/spiritual questions served as a proxy for the general religious orientation assessment of the participants, no comparison of the Add Health scales and Allport's ROS was made in this study.

The single dichotomous violence measure was derived from questions in Section 19 of the Wave III Add Health interviews. Logistical regression analysis was used to evaluate the odds of the occurrence of any of the four types of violence: (a) threatening violence, (b) physical violence, (c) physical violence that results in injury, and (d) sexual violence as compared to no violence of any type occurring. Due to the likely correlation 
among the violence variables, no attempt to differentiate among the types of violence or the level of violence was completed in this study. Participants who answer never to the violence questions became part of the reference group. To evaluate the odds of the occurrence of violence, the group of participants answering affirmatively to any type of violent questions was compared to the reference group.

Previous studies have indicated that some religious and spiritual factors may be related to the perpetration of IPV, but the degree and the direction of the effects were not clear (Brinkerhoff et al., 1992; Cunradi et al., 2002a; Ellison \& Anderson, 2001; Ellison et al., 1999). With this knowledge and because this study was exploratory in nature rather than theory based, the Forward LR entry method was selected (Mertler \& Vannatta, 2005). The overall fit of the model was assessed using the -2 Log Likelihood statistic (2LL). Examination was also made of the partial correlations (controlling for the violence variable), Cox \& Snell's $R^{2}$ and Nagelkerke's $R^{2}$ (Mertler \& Vannatta, 2005). If the answer to the first research question resulted in a good model for prediction, then the second research question would be addressed considered by assessing the individual contribution of each predictor variable in a significant model with the Wald statistic (Mertler \& Vannatta, 2005). Additionally, if the overall model evidenced goodness of fit, significant Exp $b$ values, indicating the change in odds of IPV perpetration per one unit change in the predictor variables, were to be reviewed. In order to assess if the model is successful in predicting group membership the SPSS classification table was examined. The SPSS classification table would be the primary source of for answering the third research question. If the overall model was significant, the regression coefficients and the 
odds ratios were to be reported. All analyses were completed using SPSS 16.0 software. The stated significance level in the study was set at $p<0.05$.

The degree of multicollinearity among the predictor (religious or spiritual) factors was not known therefore, the research included a correlational analysis to determine if there were any potentially troublesome linear relationships among the 10 religious and spiritual factors (i.e., represented in Section 31, questions numbered: 24 (Frequency of Religious Attendance), 25 (Other Corporate Religious Activities), 31 (Other Private Religious Activities), 32 (Private Prayer/Meditation), 33 (Importance of Spiritual Life), 37 (Led Spiritually), 38 (Integration Into Life), 40 (Born Again), 41 (Degree of Religiousness), and 42 (Degree of Spirituality). To assess for multicollinearity, tolerance and variance inflation factors (VIF) were evaluated for the 10 religious and spiritual variables (Mertler \& Vannatta, 2005). Factors that exhibited high intercorrelations were to be dropped from the study. Also, the means of the batterer and nonbatterers responses for the single continuous religious variable were compared using a standard $t$ test. Frequency differences between batterers and nonbatterers were examined for the categorical variables. Though a factor analysis was not included in this study, a Cronbach's analysis was performed to gain insight into the internal reliability of the Add Health religious and spiritual questions.

\section{Sample Size Calculations}

Preliminary sample size calculations were completed using NCSS' PASS Software 8.0.8 (Hintze, 2008). Noting there have been wide variations in the estimates for the occurrence of IPV in the population, for the purposes of sample size calculation an 
event rate for IPV was assumed to be $33 \%$ occurrence (i.e., one in three women experience some form of IPV). A general estimate for the detection of an odds ratio of 1.5 was selected for its similarity to the detection level experienced in another study (Ellison et al., 1999). The correlation among the independent variables is assumed to be zero. Estimates for the frequency of occurrence of each of the independent variables was assumed to be .50 . To capture the worst-case scenario, the covariates of interest were assumed to be binary. The sample size necessary to achieve $80 \%$ power was calculated to be $N=816$. Though the population variability is unknown, the power of this analysis was expected to be higher because case selection was made from a starting population of 15,197 participants.

\section{Chapter Summary}

The purpose of this study was to better understand the relationship between religious and spiritual factors and the perpetration of IPV by 18- to 26-year-old men, who consider themselves to be Catholic, Protestant, or Christian. Violence and religious/spiritual variables were constructed using archival data from Wave III of National Longitudinal Study of Adolescent Health. IRB-approved multivariate logistic regression analyses were performed, and the statistical results and other findings are presented in chapter 4 (IRB approval \# 01-27-09-0170831). 


\section{CHAPTER 4:}

\section{RESULTS}

\section{Introduction}

The primary analysis in this study was a binary logistic regression analysis, performed to determine if IPV perpetration by males, 18 to 26 years old, who classify themselves as Christian, Protestant, or Catholic, could be reliably predicted from knowledge of the frequency of their attendance at religious service (freqattend), the frequency of their participation in corporate religious activities other than a weekly church service (othercorp), the frequency of their participation in private religious activities (otherpriv), the frequency of time they spent in prayer/meditation (prayer), the degree of importance they placed on their spiritual life (imptspirit), the degree to which they felt they were led spiritually (ledspirit), the degree to which their religious beliefs were integrated into their life (integlife), whether or not they considered themselves to be "born again" (bornagain), the extent to which they viewed themselves as religious persons (degrel), and the extent to which they viewed themselves as a spiritual persons (degspirit). Other questions included: (a) if IPV was correctly predicted, which religious or spiritual factors were essential to the prediction, and (b) how good was the model overall at classifying cases for which the outcome was unknown?

\section{Reconstruction of the Add Health Data Sets}

The Wave III Add Health Section 19 violence questions included multiple responses for several individual participants, depending upon how many relationships the 
respondent had been engaged in, within the 12 months prior to the in-home interview. The Add Health religious and spiritual questions from Section 31 included only a single individual participant response for each question. When the data were merged for analysis, the religious and spiritual factors were treated as fixed variables in each of the respondent's individual relationships. For the reader's reference the general format of the reconstruction of the combined dataset is noted in Table 2.

Table 2

Example of General Construction Format of Merged Dataset

\begin{tabular}{ccccc}
$\begin{array}{c}\text { Respondent } \\
\text { ID }\end{array}$ & $\begin{array}{c}\text { Relationship } \\
\text { Number }\end{array}$ & $\begin{array}{c}\text { Violence } \\
\text { Perpetrated } \\
0=\text { No } \\
1=\text { Yes }\end{array}$ & $\begin{array}{c}\text { Religious } \\
\text { or } \\
\text { Spiritual } \\
\text { Factor A }\end{array}$ & $\begin{array}{c}\text { Religious } \\
\text { or } \\
\text { Spiritual } \\
\text { Factor B }\end{array}$ \\
\hline AB & 1 & 0 & 5 & 8 \\
CD & 1 & 1 & 6 & 1 \\
CD & 2 & 0 & 6 & 1 \\
EF & 1 & 1 & 1 & 4 \\
EF & 2 & 0 & 1 & 4 \\
EF & 3 & 1 & 1 & 4 \\
\hline
\end{tabular}

For example in Table 2, respondent EF has three relationships noted. The respondent ID, in combination with the relationship number, uniquely identified each case: EF-1, EF-2, and EF-3. In each case the corresponding religious or spiritual factors for the respondents were fixed and repeated for each case. The data set that included all 
of the multiple response cases is referred to by this researcher as "by cases" or BC $(n=$ 6013).

Some analyses and examinations were performed with a data set where a single case represented only one individual participant. Multiple relationships were restructured into variable groups. This researcher refers to this data set as "by respondent" or BR ( $n=$ 3652). The records for the BR data set were a subset of the larger BC data set. In the BR data set, a new violence variable (anyperp) was coded $1=$ yes if any of the four types of perpetration occurred, during any of the relationships that occurred within the 12 months prior to the interview. Similar to $d p e r p$, this new violence variable was coded $0=$ no, only if no violence occurred in any of the relationships referenced.

Two independent variables (ledspirit, integlife) were derived from questions that utilized Likert scale ratings: 1 - strongly agree to 5 - strongly disagree. For the purpose of analysis and to aid in interpretation, the scales for these two variables were reversed and recoded to scales in which the higher number reflected more intrinsic behavior and the lower number reflected less intrinsic behavior.

\section{Prescreening of the Data}

Though logistic regression is robust against deviations from normality, linearity, and homoscedasticity a few visual checks of scatter plots and normality plots were conducted, but no transformations were made (Mertler \& Vannatta, 2005). The data set was screened for missing values, cell frequencies, and outliers. 
Missing Data

Even after selection for males, 18 to 26 years of age, who classified themselves as Christian, Protestant, or Catholic, the number of Wave III Add Health records was large $(n=6282)$. Though the data set evidenced several missing values, there was sufficient data to run an 11-variable (1 DV, $10 \mathrm{IV})$ binary logistic regression. One independent variable, bornagain, derived from Section 31 Question 40, showed 38.8\% missing data and was dropped from the study as recommended by Mertler and Vannatta (2005) and by agreement with the dissertation committee. Potential reasons for this unusual finding will be discussed in chapter 5 . The other nine independent variables had less than $1 \%$ missing data. After reviewing the cross tabulations of the categorical independent variables using the guidelines in Mertler and Vannatta (2005), the discrete variables appear to have sufficient cell frequencies to complete the analysis (i.e., no empty cells and fewer than $20 \%$ of cells with expected frequencies of less than 5).

\section{Outliers}

Multivariate outliers were examined using Mahalanobis' distances calculated using the nine remaining independent variables (Mertler \& Vannatta, 2005). A total of 269 cases that exceeded the critical $X^{2}$ of $26.125(p<.001, d f=8)$ were visually examined. No unusual reasons for the outliers was noted and because the cases came from a broad number of variable levels the chosen action was to remove them from the analysis, leaving a total of 6013 cases. 


\section{Multicollinearity}

Assessments for multicollinearity were made using tolerance statistics, variance inflation factor results (VIF), and a partial correlation matrix, controlling for the violence perpetration variable (Mertler \& Vannatta, 2005). This assessment was made using both the $\mathrm{BC}$ and BR datasets. As shown in Table 3, the tolerance results were all above the recommended 0.1 cutoff and all VIF values were less than 10 (Mertler \& Vannatta, 2005).

Table 3

Multicollinearity Statistics for Religious or Spiritual Factors

\begin{tabular}{ccc} 
Variable & Tolerance & VIF \\
\hline freqattend & .569 & 1.758 \\
othercorp & .661 & 1.512 \\
otherpriv & .693 & 1.442 \\
prayer & .570 & 1.756 \\
imptspirit & .455 & 2.198 \\
ledspirit & .607 & 1.647 \\
integlife & .530 & 1.887 \\
degrel & .412 & 2.425 \\
degspirit & .404 & 2.475 \\
\hline
\end{tabular}

Note: Data analysis represented was performed on the BR data set. 
However, the partial correlation matrix, shown in Table 4, revealed significant correlations between all variables. Several of the medium to large correlations $(>.5)$ were discovered among variables that reflected the respondents' attitudes and beliefs about their religiosity or spirituality, rather than their actions or behaviors. The reason for this finding is not clear, but is discussed in chapter 5. For example, as shown in Table 4 correlations greater than .5 were found between several factors and (a) the participant's response regarding the importance of his spiritual life (imptspirit), (b) the extent to which the participant believed himself to be a religious person (degrel), (c) the extent to which the participant believed himself to be spiritual person (degspirit), and (d) the degree to which religious or spiritual beliefs are employed in daily living (integlife). Because all correlations were significant there was little justification for collapsing any of the independent variables. Therefore, all of the religious or spiritual factors, except for the previously excluded bornagain, were included in the analysis. 
Table 4

Partial Correlations by Respondent Controlling for IPV Perpetration

\begin{tabular}{|c|c|c|c|c|c|c|c|c|c|}
\hline \multicolumn{2}{|c|}{ Control Variables } & $\begin{array}{l}\text { Frequency } \\
\text { of } \\
\text { Attendance }\end{array}$ & $\begin{array}{l}\text { How Often } \\
\text { Other } \\
\text { Corporate } \\
\text { Activities }\end{array}$ & $\begin{array}{l}\text { How } \\
\text { Often } \\
\text { Prayer }\end{array}$ & $\begin{array}{l}\text { Importance } \\
\text { of Spiritual } \\
\text { Life }\end{array}$ & $\begin{array}{l}\text { Am Being } \\
\text { Led } \\
\text { Spiritually* }\end{array}$ & $\begin{array}{l}\text { Beliefs } \\
\text { Integrated } \\
\text { Into Life* }\end{array}$ & $\begin{array}{l}\text { Extent a } \\
\text { Religious } \\
\text { Person }\end{array}$ & $\begin{array}{c}\text { Extent a } \\
\text { Spiritual } \\
\text { Person }\end{array}$ \\
\hline \multirow[t]{8}{*}{$\begin{array}{l}\text { Violence } \\
\text { Perpetrated }\end{array}$} & $\begin{array}{l}\text { Frequency of } \\
\text { Attendance }\end{array}$ & 1.000 & .534 & .409 & .454 & .295 & .414 & .499 & .407 \\
\hline & $\begin{array}{l}\text { How Often } \\
\text { Other } \\
\text { Corporate } \\
\text { Activities }\end{array}$ & .534 & 1.000 & .296 & .343 & .278 & .332 & .342 & .324 \\
\hline & $\begin{array}{l}\text { How Often } \\
\text { Prayer }\end{array}$ & .409 & .296 & 1.000 & .571 & .388 & .459 & .513 & .507 \\
\hline & $\begin{array}{l}\text { Importance of } \\
\text { Spiritual Life }\end{array}$ & .454 & .343 & .571 & 1.000 & .486 & .539 & .578 & .639 \\
\hline & $\begin{array}{l}\text { Am Being Led } \\
\text { Spiritually* }\end{array}$ & .295 & .278 & .388 & .486 & 1.000 & .570 & .442 & .477 \\
\hline & $\begin{array}{c}\text { Beliefs } \\
\text { Integrated Into } \\
\text { Life* }\end{array}$ & .414 & .332 & .459 & .539 & .570 & 1.000 & .526 & .509 \\
\hline & $\begin{array}{l}\text { Extent a } \\
\text { Religious } \\
\text { Person }\end{array}$ & .499 & .342 & .513 & .578 & .442 & .526 & 1.000 & .709 \\
\hline & $\begin{array}{l}\text { Extent a } \\
\text { Spiritual } \\
\text { Person }\end{array}$ & .407 & .324 & .507 & .639 & .477 & .509 & .709 & 1.000 \\
\hline
\end{tabular}

Note: All Correlations are highly significant $p<.001 ; d f=3649$

*Correlation coefficients represented are on recoded Likert-scale variables. 


\section{Reliability}

An abbreviated reliability assessment was made using Cronbach's alpha. In the absence of a factor analysis it was not known if the nine religious and spiritual factors examined in this study represented a single or multiple, related constructs. Therefore, for the Cronbach analysis all religious and spiritual factors were examined in total. The overall alpha was .812 indicating a satisfactory level of scale reliability (Pallant, 1993). As shown in Table 5 the correlations of the individual religious and spiritual factors all exceeded .3 indicating that they correlated well with the overall Cronbach score (Field, 2005). Additionally, as shown in Table 5 the changes in Cronbach's alpha if the religious or spiritual factor was deleted were minimal $(<.028)$, indicating that no one factor's deletion would improve reliability (Field, 2005).

\section{Table 5}

Cronbach Alpha Item-Total Statistics

\begin{tabular}{ccc}
\hline & $\begin{array}{c}\text { Corrected } \\
\text { Item-Total } \\
\text { Correlation }\end{array}$ & $\begin{array}{c}\text { Cronbach's } \\
\text { Alpha if Item } \\
\text { Deleted }\end{array}$ \\
\hline freqattend & .578 & .784 \\
othercorp & .508 & .794 \\
otherpriv & .544 & .813 \\
prayer & .614 & .787 \\
imptspirit & .683 & .793 \\
ledspirit & .525 & .797 \\
integlife & .614 & .791 \\
degrel & .675 & .792 \\
degspirit & .646 & .791 \\
\hline
\end{tabular}




\section{Analysis of Single Continuous Independent Variable}

An independent $t$ test was performed on the one continuous independent variable: otherpriv, which measured the hours each respondent spent weekly in religious activities in his/her home. Assuming equality of variances, the $t$ test indicated that there was a significant difference between the hours spent by IPV perpetrators and nonperpetrators $(t=2.101, d f=3650, p=.036)$. However, the mean difference was very small at .236 hours, with a Cohen's $d$ of .0876 .

\section{Demographic and Respondent Characteristics}

Though not evaluated specifically in this study, several demographic and personal characteristics were captured in the review of the Wave III data set. General demographic information about the respondents included in the analysis can be found in Table 6 through Table 9. The Add Health interview questions are included in Appendix B for the reader's reference.

\section{Race}

Wave III of the Add Health in-home interviews included questions regarding the respondent's racial background and the breakdown is shown in Table 6. A visual survey of the BR data tabulations indicated that each racial category likely received adequate representation in the analysis. Also, the distribution of the data revealed that within each racial class, the majority $(\sim 72 \%$ to $83 \%)$ of these males did not perpetuate IPV. However, because respondents were allowed to classify themselves in more than one race category, 
racial group representation could not be validated, nor could differences in IPV perpetration by racial groups be assessed statistically.

Table 6

Racial Background

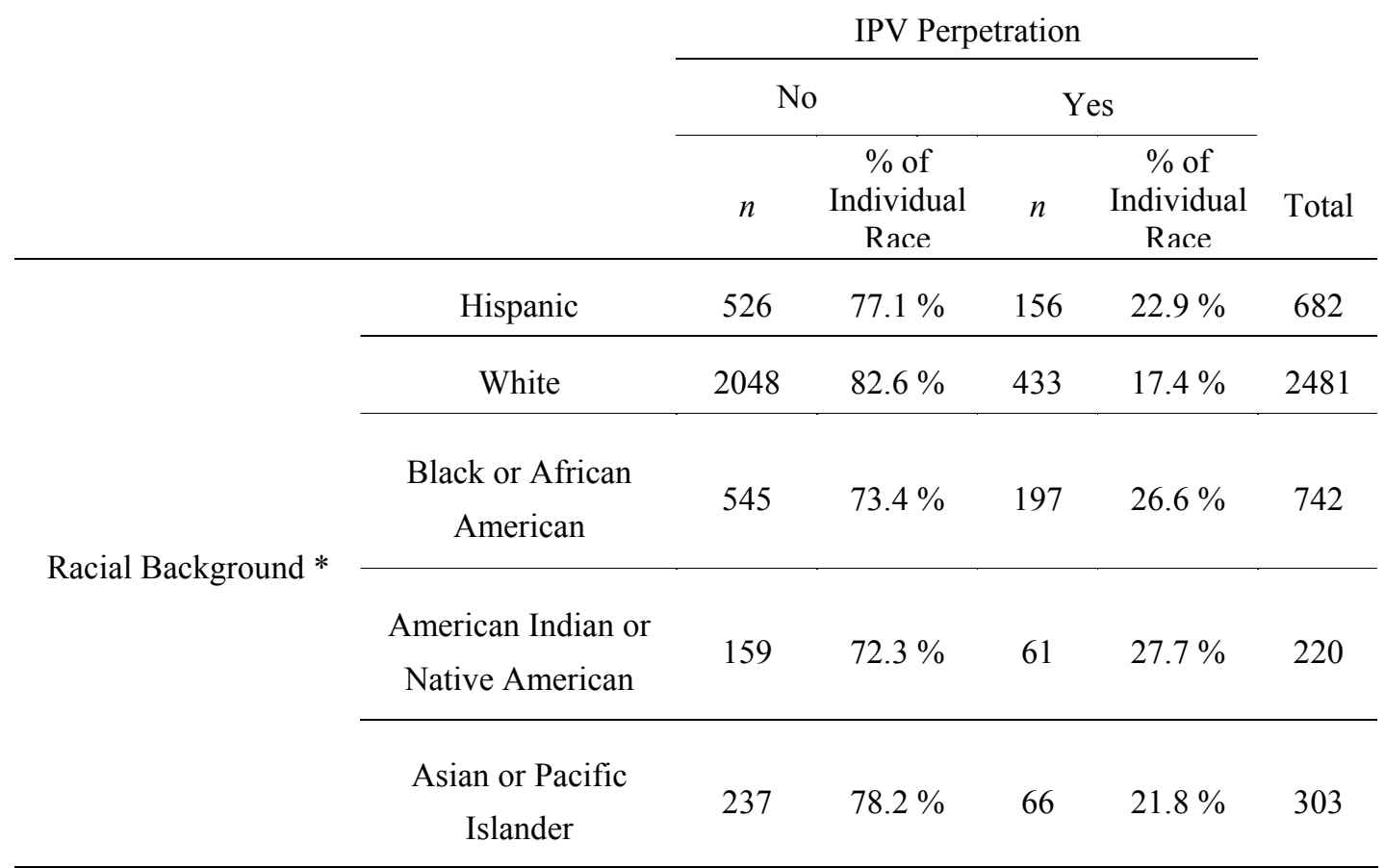

* Respondent could select multiple categories

\section{Education}

The highest education level received by the selected respondents is shown in Table 7. Data from the sixth to the ninth grades were not reported individually because the cross-tabulated row totals were less than allowed by the research data security agreement entered into with the University of North Carolina. A review of the Table 6 
results revealed that across grades levels, the majority of the selected males did not commit IPV. The tabulations also indicate that the percentage of men perpetuating IPV decreased as the level of education achieved increased, until the graduate school level.

Table 7

Education Level of Respondents by Perpetration Occurrence

\begin{tabular}{|c|c|c|c|c|c|c|}
\hline & & & & & & \multirow[b]{4}{*}{ Total $n$} \\
\hline & & \multicolumn{4}{|c|}{ IPV Perpetration } & \\
\hline & & \multicolumn{2}{|c|}{ No } & \multicolumn{2}{|c|}{ Yes } & \\
\hline & & $n$ & $\begin{array}{l}\% \text { of } \\
\text { Grade }\end{array}$ & $n$ & $\begin{array}{l}\% \text { of } \\
\text { Grade }\end{array}$ & \\
\hline \multirow{13}{*}{$\begin{array}{c}\text { Highest } \\
\text { Level of } \\
\text { Education } \\
\text { Received }\end{array}$} & 6 th $-9^{\text {th }}$ grade & 46 & $61.3 \%$ & 29 & $38.7 \%$ & 75 \\
\hline & 10th grade & 100 & $75.8 \%$ & 32 & $24.2 \%$ & 132 \\
\hline & 11 th grade & 175 & $69.2 \%$ & 78 & $30.8 \%$ & 253 \\
\hline & 12th grade & 945 & $77.6 \%$ & 273 & $22.4 \%$ & 1218 \\
\hline & 1 vear of college & 431 & $80.4 \%$ & 105 & $19.6 \%$ & 536 \\
\hline & 2 vears of college & 462 & $81.8 \%$ & 103 & $18.2 \%$ & 565 \\
\hline & 3 vears of college & 321 & $85.8 \%$ & 53 & $14.2 \%$ & 374 \\
\hline & 4 vears of college & 293 & $86.2 \%$ & 47 & $13.8 \%$ & 340 \\
\hline & 5 vears of college & 82 & $85.4 \%$ & 14 & $14.6 \%$ & 96 \\
\hline & 1 vear of graduate school & 28 & $90.3 \%$ & 3 & $9.7 \%$ & 31 \\
\hline & $\begin{array}{l}2 \text { to } 5 \text { or more years graduate } \\
\text { school }\end{array}$ & 20 & $71.4 \%$ & 8 & $28.6 \%$ & 28 \\
\hline & Missing & 2 & - & 1 & - & 3 \\
\hline & Total & 2905 & - & 747 & - & 3652 \\
\hline
\end{tabular}

Similarly, as shown in Table 8 , the percentage of men who perpetuated IPV appeared to decrease as more advanced degrees were achieved, with the exception of the obtaining of a master's degree. This phenomenon could be an artifact of the data set, as it 
appears that some participants answered affirmatively for more than one diploma category. See Appendix C for education related questions. No further detailed testing was attempted and the significance of these group differences was not assessed.

Table 8

Highest Level Diploma Received

\begin{tabular}{cc}
\multicolumn{2}{c}{ IPV Perpetration } \\
\hline No $\quad$ Yes \\
\hline
\end{tabular}

$n \begin{gathered}\% \text { of Individual } \\ \text { Degree }\end{gathered} \quad n \begin{gathered}\% \text { of Individual Total } \\ \text { Degree }\end{gathered}$

\begin{tabular}{|c|c|c|c|c|c|c|}
\hline \multirow{6}{*}{$\begin{array}{l}\text { Highest Level of } \\
\text { Diploma Received }\end{array}$} & $\begin{array}{c}\text { GED or H.S. } \\
\text { Equivalent }\end{array}$ & 226 & $72.7 \%$ & 85 & $27.3 \%$ & 311 \\
\hline & H.S. Diploma & 2453 & $81.5 \%$ & 555 & $18.5 \%$ & 3008 \\
\hline & $\begin{array}{c}\text { Junior College } \\
\text { Degree }\end{array}$ & 235 & $83.0 \%$ & 48 & $17.0 \%$ & 283 \\
\hline & Bachelor Degree & 307 & $86.5 \%$ & 48 & $13.5 \%$ & 355 \\
\hline & Master's Degree & 8 & $80.0 \%$ & 2 & $20.0 \%$ & 10 \\
\hline & Doctoral Degree & 0 & $0 \%$ & 0 & $0 \%$ & 0 \\
\hline
\end{tabular}

Age

The distribution of ages for the respondents is shown in Table 9. The differences in the percentage of men who perpetuate IPV by age were reviewed for representation. 
The overall percentage of men in the sample who were abusive to their partners was approximately $20.5 \%$. Though not unexpected with such a narrow age range, goodness of fit testing of the independence of age and IPV perpetration was not significant $\left(X^{2}=\right.$ 13.908, $d f=8, p=.084)$.

Table 9

Age Distribution by Respondent

\begin{tabular}{|c|c|c|c|c|c|c|c|}
\hline & & \multicolumn{6}{|c|}{ IPV Perpetration } \\
\hline & & \multicolumn{2}{|c|}{ No } & \multicolumn{2}{|c|}{ Yes } & \multicolumn{2}{|c|}{ Total } \\
\hline & & $n$ & $\begin{array}{l}\% \text { Within } \\
\text { Age }\end{array}$ & $n$ & $\begin{array}{c}\% \text { Within } \\
\text { Age }\end{array}$ & $n$ & $\%$ \\
\hline \multirow[t]{10}{*}{ Age } & 18 & 25 & $.9 \%$ & 5 & $.7 \%$ & 30 & $.8 \%$ \\
\hline & 19 & 234 & $8.1 \%$ & 67 & $9 \%$ & 301 & $8.2 \%$ \\
\hline & 20 & 374 & $12.9 \%$ & 75 & $10 \%$ & 449 & $12.3 \%$ \\
\hline & 21 & 453 & $15.6 \%$ & 111 & $14.9 \%$ & 564 & $15.4 \%$ \\
\hline & 22 & 576 & $19.8 \%$ & 134 & $17.9 \%$ & 710 & $19.4 \%$ \\
\hline & 23 & 568 & $19.6 \%$ & 143 & $19.1 \%$ & 711 & $19.5 \%$ \\
\hline & 24 & 492 & $16.9 \%$ & 147 & $19.7 \%$ & 639 & $17.5 \%$ \\
\hline & 25 & 156 & $5.4 \%$ & 54 & $7.2 \%$ & 210 & $5.8 \%$ \\
\hline & 26 & 27 & $.9 \%$ & 11 & $1.5 \%$ & 38 & $1.0 \%$ \\
\hline & Total & 2905 & $100.1 \%$ & 747 & $100 \%$ & 3652 & $99.9 \%$ \\
\hline
\end{tabular}

\section{Religious and Spiritual Factors}

As a contractual data set, the Add Health data analyses may not be readily replicated. For the reader's reference the results of the cross tabulations between the 
violence variable and the religious and spiritual factors are listed in Tables 10 through 13. Several goodness of fit tests were significant, and not surprisingly the variables showing significance were later selected for inclusion in the logistic regression analyses.

Higher ratings on the religious or spiritual factors represented a greater frequency of participation, or a more strongly held belief or attitude. To the degree that any of the religious or spiritual factors serve as proxies to Allport's intrinsic measures, higher ratings would represent more intrinsic actions and attitudes. 


\section{Table 10}

\section{Religious or Spiritual Factor by Perpetration Occurrence - Part 1}

\begin{tabular}{|c|c|c|c|c|c|c|}
\hline \multirow[b]{3}{*}{ Variable } & \multicolumn{6}{|c|}{ Perpetrated IPV } \\
\hline & \multicolumn{3}{|c|}{ No } & \multicolumn{3}{|c|}{ Yes } \\
\hline & $n$ & $\begin{array}{c}\text { \% Within No } \\
\text { Perp. }\end{array}$ & $\begin{array}{c}\% \text { of Grand } \\
\text { Total }\end{array}$ & $n$ & $\begin{array}{l}\text { \% Within } \\
\text { Perp. }\end{array}$ & $\begin{array}{c}\% \text { of Grand } \\
\text { Total }\end{array}$ \\
\hline \multicolumn{7}{|l|}{ Frequency of Attendance } \\
\hline Never & 482 & 16.6 & 13.2 & 145 & 19.4 & 4.0 \\
\hline A few times & 844 & 29.1 & 23.1 & 251 & 33.6 & 6.9 \\
\hline Several times & 409 & 14.1 & 11.2 & 109 & 14.6 & 3.0 \\
\hline Once a month & 274 & 9.4 & 7.5 & 68 & 9.1 & 1.9 \\
\hline 2 or 3 times a month & 359 & 12.4 & 9.8 & 66 & 8.8 & 1.8 \\
\hline Once a week & 399 & 13.7 & 10.9 & 76 & 10.2 & 2.1 \\
\hline More than once a week & 138 & 4.8 & 3.8 & 32 & 4.3 & 0.9 \\
\hline Total & 2905 & 100 & 79.5 & 747 & 100 & 20.5 \\
\hline
\end{tabular}

Participate in Other Corporate Religious Activities

\begin{tabular}{|c|c|c|c|c|c|c|}
\hline Never & 2121 & 73.0 & 58.1 & 549 & 73.5 & 15.0 \\
\hline A few times & 382 & 13.1 & 10.5 & 110 & 14.7 & 3.0 \\
\hline Several times & 135 & 4.6 & 3.7 & 31 & 4.1 & 0.8 \\
\hline Once a month & 48 & 1.7 & 1.3 & 15 & 2.0 & 0.4 \\
\hline 2 or 3 times a month & 69 & 2.4 & 1.9 & 14 & 1.9 & 0.4 \\
\hline Once a week & 93 & 3.2 & 2.5 & 22 & 2.9 & 0.6 \\
\hline More than once a week & 57 & 2.0 & 1.6 & 6 & 0.8 & 0.2 \\
\hline Total & 2905 & 100 & 79.5 & 747 & 100 & 20.5 \\
\hline
\end{tabular}

Hours Participating in Other Private Religious Activities

$\begin{array}{rcccccc}0 & 1065 & 36.7 & 29.2 & 272 & 36.4 & 7.4 \\ 1 & 865 & 29.8 & 23.7 & 241 & 32.3 & 6.6 \\ 2 & 369 & 12.7 & 10.1 & 88 & 11.8 & 2.4 \\ 3 & 131 & 4.5 & 3.6 & 44 & 5.9 & 1.2 \\ 4 & 81 & 2.8 & 2.2 & 20 & 2.7 & 0.5 \\ 5 & 131 & 4.5 & 3.6 & 29 & 3.9 & 0.8 \\ 6 & 36 & 1.2 & 1.0 & 8 & 1.1 & 0.2 \\ 7 & 90 & 3.1 & 2.5 & 25 & 3.3 & 0.7 \\ 7-21 & 137 & 4.7 & 3.8 & 20 & 2.7 & 20.5 \\ \text { Total } & 2905 & 100 & 79.5 & 747 & & \\ \end{array}$




\section{Table 11}

\section{Religious or Spiritual Factor by Perpetration Occurrence - Part 2}

\begin{tabular}{|c|c|c|c|c|c|c|}
\hline \multirow[t]{3}{*}{ Variable } & \multicolumn{6}{|c|}{ Perpetrated IPV } \\
\hline & \multicolumn{3}{|c|}{ No } & \multicolumn{3}{|c|}{ Yes } \\
\hline & $n$ & $\begin{array}{c}\text { \% Within No } \\
\text { Perp. }\end{array}$ & $\begin{array}{l}\% \text { of Grand } \\
\text { Total }\end{array}$ & $n$ & $\begin{array}{l}\text { \% Within } \\
\text { Perp. }\end{array}$ & $\begin{array}{c}\% \text { of Grand } \\
\text { Total }\end{array}$ \\
\hline \multicolumn{7}{|l|}{ Prayed Privately } \\
\hline Never & 465 & 16.0 & 12.7 & 96 & 12.9 & 2.6 \\
\hline Less than once a month & 320 & 11.0 & 8.8 & 94 & 12.6 & 2.6 \\
\hline Once a month & 152 & 5.2 & 4.2 & 50 & 6.7 & 1.4 \\
\hline A few times a month & 336 & 11.6 & 9.2 & 101 & 13.5 & 2.8 \\
\hline Once a week & 188 & 6.5 & 5.1 & 44 & 5.9 & 1.2 \\
\hline A few times a week & 409 & 14.1 & 11.2 & 115 & 15.4 & 3.1 \\
\hline Once a day & 656 & 22.6 & 18.0 & 180 & 24.1 & 4.9 \\
\hline More than once a day & 379 & 13.0 & 10.4 & 67 & 9.0 & 1.8 \\
\hline Total & 2905 & 100 & 79.5 & 747 & 100 & 20.5 \\
\hline \multicolumn{7}{|c|}{$X^{2}=19.048 ; d f=7 ; p=.008$} \\
\hline \multicolumn{7}{|l|}{ Spiritual Life Importance } \\
\hline Not important & 193 & 6.6 & 5.3 & 44 & 5.9 & 1.2 \\
\hline Somewhat important & 1093 & 37.6 & 29.9 & 317 & 42.4 & 8.7 \\
\hline Very Important & 1326 & 45.6 & 36.3 & 340 & 45.5 & 9.3 \\
\hline $\begin{array}{r}\text { More important than anything } \\
\text { else }\end{array}$ & 293 & 10.1 & 8.0 & 46 & 6.2 & 1.3 \\
\hline Total & 2905 & 100 & 79.5 & 747 & 100 & 20.5 \\
\hline \multicolumn{7}{|c|}{$X^{2}=13.962 ; d f=3 ; p=.003$} \\
\hline \multicolumn{7}{|l|}{ Led Spiritually } \\
\hline Strongly disagree & 91 & 3.1 & 2.5 & 13 & 1.7 & 0.4 \\
\hline Disagree & 369 & 12.7 & 10.1 & 102 & 13.7 & 2.8 \\
\hline Neither agree or disagree & 1088 & 37.5 & 29.8 & 262 & 35.1 & 7.2 \\
\hline Agree & 973 & 33.5 & 26.6 & 258 & 34.5 & 7.1 \\
\hline Strongly Agree & 384 & 13.2 & 10.5 & 112 & 15.0 & 3.1 \\
\hline Total & 2905 & 100 & 79.5 & 747 & 100 & 20.5 \\
\hline
\end{tabular}




\section{Table 12}

\section{Religious or Spiritual Factor by Perpetration Occurrence - Part 3}

Variable
Perpetrated IPV

\begin{tabular}{cccccc}
\multicolumn{4}{c}{ No } & \multicolumn{3}{c}{ Yes } \\
\hline \% Within No & \% of Grand & Petal & \% Within & \% of Grand \\
& Perp. & Total & Perp. & Total
\end{tabular}

Religion or Spiritual Beliefs Integrated

\begin{tabular}{|c|c|c|c|c|c|c|}
\hline Strongly Disagree & 66 & 2.3 & 1.8 & 8 & 1.1 & 0.2 \\
\hline Disagree & 347 & 11.9 & 9.5 & 98 & 13.1 & 2.7 \\
\hline Neither agree or disagree & 842 & 29.0 & 23.1 & 244 & 32.7 & 6.7 \\
\hline Agree & 1227 & 42.2 & 33.6 & 282 & 37.8 & 7.7 \\
\hline Strongly Agree & 423 & 14.6 & 11.6 & 115 & 15.4 & 3.1 \\
\hline Total & 2905 & 100 & 79.5 & 747 & 100 & 20.5 \\
\hline
\end{tabular}

Extent Considers Self to be

Religious

\begin{tabular}{|c|c|c|c|c|c|}
\hline Not religious at all & 225 & 7.7 & 6.2 & 55 & 7.4 \\
\hline Slightly religious & 1162 & 40.0 & 31.8 & 335 & 44.8 \\
\hline Moderately religious & 1185 & 40.8 & 32.4 & 286 & 38.3 \\
\hline Very religious & 333 & 11.5 & 9.1 & 71 & 9.5 \\
\hline Total & 2905 & 100 & 79.5 & 747 & 100 \\
\hline
\end{tabular}

Extent Considers Self to be Spiritual

\begin{tabular}{|c|c|c|c|c|c|}
\hline Not spiritual at all & 292 & 10.1 & 8.0 & 77 & 10.3 \\
\hline Slightly Spiritual & 1064 & 36.6 & 29.1 & 298 & 39.9 \\
\hline Moderately Spiritual & 1105 & 38.0 & 30.3 & 264 & 35.3 \\
\hline Very Spiritual & 444 & 15.3 & 12.2 & 108 & 14.5 \\
\hline Total & 2905 & 100 & 79.5 & 747 & 100 \\
\hline
\end{tabular}


Table 13

Percent of Respondents by Level of Religious or Spiritual Factors

$\begin{array}{lc}\text { Religious or Spiritual Factors } & \% \text { of Males } \\ \text { Respondents }\end{array}$

Attended religious services more than once a month

$29.3 \%$

Participated in other corporate religious activities more than once a month

$7.1 \%$

Participated in other private religious activities more than 4 hours a week

$13.0 \%$

Prayed privately more than once a week

$49.4 \%$

Considered spiritual life to be "more important than anything else"

$9.3 \%$

Agrees or Strongly agrees that they feel led spiritually

$47.3 \%$

Agrees or Strongly agrees that religious or spiritual beliefs are employed in life on a daily basis

$56.1 \%$

Considers self very religious

$11.1 \%$

Considers self very spiritual

$15.1 \%$ 


\section{Hypothesis Testing}

To test the main hypothesis a logistic regression analysis using the Forward LR method was performed using both the $\mathrm{BC}$ and $\mathrm{BR}$ data sets.

The results for the $\mathrm{BC}$ analysis (i.e., including multiple relationships for some participants) showed that four variables were entered into the model: imptspirit, ledspirit, freqattend, and integlife. The overall model appeared significant at the conclusion of Step $4\left(X^{2}=60.352, d f=17, p<.001\right)$. The Hosmer and Lemeshow test showed nonsignificance also indicating that the overall model fit of these four predictors was adequate: $X^{2}=9.120(d f=8, p=.332)$. However, at the termination of the estimation at Step 4, the -2 Log likelihood was very high at 4806.761 , indicating a poor fitting model or large unexplained variances. Additionally, at Step 4 both the Nagelkerke $R^{2}$ and the Cox and Snell $R^{2}$ were very low at .018 and .010 respectively. Though the overall fit of the model appeared significant, the overall percentage of cases classified correctly at Step 4 remained exactly the same as the model at Step 0 (constant only) with $86 \%$ correctly classified.

The results of the BR logistic regression analysis again showed four variables selected for the model: imptspirit, ledspirit, freqattend, and prayer. In this model integlife was not selected. As with the by cases analysis, this overall model appeared significant at the conclusion of Step $4\left(X^{2}=62.649, d f=20, p<.001\right)$. The Hosmer and Lemeshow test showed nonsignificance, again indicating that the overall fit of these four predictors was adequate: $X^{2}=2.274(d f=8, p=.971)$. However, at the termination of the estimation the -2 Log likelihood statistic was again high at 3637.847 . At Step 4 both the 
Nagelkerke $R^{2}$ and the Cox and Snell $R^{2}$ were also low at .017 and .027 respectively. Though the overall fit of the model was significant, the overall percentage of cases classified correctly remained the same at Step 4 as the constant only model at Step 0 with $79.5 \%$ correctly classified.

These findings lead this researcher to conclude that though there were conflicting results in each analysis, the overall model fit was poor for both runs, especially with regard to their ability to predict classifications in unknown cases. In sum, the null hypothesis is not rejected.

The power of this logistic regression was expected to be high due to the large number of available cases. Power calculations were completed using NCSS' PASS Software 8.0.8 (Hintze, 2008). Adjustments were made for the estimate of the event occurrence of IPV in the population to $21 \%$. A general estimate for the detection of an odds ratio of 1.5 was selected. The correlation among the independent variables was set at .45. An estimate for the frequency of occurrence of each of the independent variables was assumed to be .50 . To capture the worst-case scenario, the covariates of interest were set to be binary. Using the smaller data set's sample size $(n=3652)$ power was calculated to be $99.9 \%$.

Because the hypothesis that the perpetration IPV is not related to the independent religious or spiritual factors is not rejected, the coefficients associated with the model are deemed to be not practically different than zero. As such, subsequent analyses regarding which religious or spiritual factors are essential to the prediction and the goodness of the model in classifying unknown IPV cases could not be made. Relatedly, all corresponding 
Wald statistics, odds ratios (OR), and OR confidence intervals for the variables cannot be meaningfully reported Field, 2005; Mertler \& Vannatta, 2005, Pallant, 2007).

\section{Partner Data Analysis}

Due to cost constraints, this researcher was unable to meet the level of equipment and office space security required by the contract for the sensitive romantic partner data. Because the use of the romantic partner data was intended for data triangulation purposes only, their analysis has been dropped from the study with approval from the dissertation committee.

\section{Chapter Summary}

The results of the logistic regression analysis indicated that the perpetration of IPV by young adult males who (at least nominally) consider themselves to be Christian, cannot be reliability predicted from certain religious or spiritual factors. The power in this analysis was quite high (99.9\%) and some analyses findings indicated that the model might be significant. However, several other results indicated that the model was a poor fit, especially for classifying unknown cases. Therefore, the null hypothesis was not rejected. The meaning of the conflicting analyses results, as well as greater insight into the Add Health data set, will be discussed in the following chapter. 
CHAPTER 5:

\section{SUMMARY, CONCLUSION, AND RECOMMENDATIONS}

Overview of the Study Problem and Methodology

It seems contradictory that Christian church communities, whose members often profess to embrace doctrines of love, concern for others, parity, and service to one another, do not experience significantly lower rates of partner violence than does the general population (Annis \& Rice, 2001; Brinkerhoff et al., 1992, Nason-Clark, 2000, 2004). At the onset of this research it seemed possible that this paradox reflected a misguided belief that all Christians uniformly hold to the tenets of their faith. To frame this study, this researcher pulled conceptually from Allport's theory of religious orientation and his categorization of Christian churchgoers into those who were: (a) intrinsically or (b) extrinsically motivated to participate in their faith communities. With a better understanding of what relationship, if any, existed between religious factors and violence, this researcher intended to apply the knowledge gained in her efforts to improve faith-based batterer's intervention programs.

The purpose of the study was to determine if there was a predictive relationship between certain religious behaviors, beliefs, and attitudes and the odds of perpetrating IPV by adult, Christian males, aged 18 to 26 years old. The young men isolated for this study fell within an age group (i.e. under 30 years old) that has shown to be at higher risk of committing IPV (Bureau of Justice Statistics, 2005b; O’Leary et al., 1989; Pan et al., 1994). Though useful to understand the relationship between religious and spiritual 
factors and IPV across all age groups, it was this researcher's intention to better understand these relationships within this specific, at risk group.

This study used archival data from Wave III of the National Longitudinal Study of Adolescent Health (Add Health), conducted by the Carolina Population Center at the University of North Carolina. To measure the occurrence of violence, one dichotomous dependent variable was constructed from the Add Health study. One quantitative and nine categorical religious or spiritual factors were constructed as independent variables and served conceptually as proxy measures for religious orientation. A binary logistic regression (LR) analysis was performed to determine to what degree the religious or spiritual factors increased or decreased the odds of committing IPV by young men. The research findings did not confirm a predictable relationship between the religious or spiritual and violence factors. Though the null hypothesis was not rejected in this study, this researcher considered ways these findings might be interpreted, particularly in light of elements that may have masked a true relationship.

\section{Discussion and Interpretation of Findings}

\section{No Evidence of a Predictive Relationship}

Previous studies using both primary and archival data evidenced relationships between several types of religious variables and the occurrence of partner violence (Brinkerhoff et al., 1992; Cunradi et al., 2002a; Ellison \& Anderson, 2001; Ellison et al., 1999). In particular, the frequency of church attendance has been shown to have an inverse relationship to IPV perpetration (Brinkerhoff et al., 1992; Cunradi et al., 2002a; Ellison \& Anderson, 2001; Ellison et al., 1999). However, in this study no clear 
relationship between various faith-based behaviors or attitudes and the occurrence of partner violence was consistently evident. Given the size and the scope of the Add Health study, as well as the power of these analyses, the finding of no evidence of a relationship is quite significant.

As unexpected as this investigation's results were, vis-à-vis the findings in other studies, they also may be understandable in light of the youthful and narrow age range investigated in this study. Though of special interest to this researcher, the Add Health interview responses available from young men 18 to 26 years old represented an age range that was narrower than that of other studies, most of which included participants aged 18 to 65 years and older.

Though the definition of IPV varies among studies, the overall level of $20.5 \%$ of men who perpetrate IPV in this study was consistent with the level of perpetration by young adults (i.e., under 30 years old) found in other research (O'Leary et al., 1989). Also, as shown in Table 12, the levels of various religious or spiritual factors, that Allport would have considered to be evidence of mature or intrinsic religious orientation, were mixed. In some cases the levels of intrinsic-like religious or spiritual behaviors or beliefs were low, which was also consistent with other research. For example, a 2001 national survey conducted by the Barna Research Group revealed that participation in various religious activities (e.g., Bible reading, private meditation) increased with age (Barna Group, 2001). With Christians the degree of commitment to one's faith also increases with age. Barna (2001) reported that only $34 \%$ of 18 to 35 year olds were 'absolutely 
committed to the Christian faith' (Generation Gap, ๆ 1) as compared to $52 \%$ of those aged 37 to $55,63 \%$ of those aged 55 to 73 , and $70 \%$ of those 74 and older.

As the reader may recall one variable, bornagain, was dropped from the study due to a high number of missing cases. The Barna Group (2001) reported that young adults generally are less likely to classify themselves as "born again". In one survey, only $33 \%$ of young adults labeled themselves as such vs. $49 \%$ of the 37 to 55 year olds, and $44 \%$ of the 55 to 73 year olds (Barna, 2001). Other Barna Group (2007) research indicated that the term "born again" is most often associated with Evangelical Christians. Add Health respondents who classified themselves as Protestants were given an opportunity to further categorize themselves. Since only $2.3 \%$ of Protestants selected in this study considered themselves to be Evangelical, it seems possible that this question was legitimately skipped by $38.5 \%$ of the respondents because the alternative, more definitive answers of “yes", "no", “don’t know", and "not applicable” did not seem appropriate either.

Nonetheless, no clear predictive relationship between religious or spiritual factors and the occurrence of IPV points to the idea that the religious orientation of young males is less differentiated than expected. However, it seems more likely considering the variation among the types and levels of religious and spiritual factors (shown in Tables 9 through 12), that the religious orientation of the respondents is not homogeneous, but rather a mix of intrinsic and nonintrinsic behaviors and beliefs.

\section{Statistical Issues That May Mask the Relationship}

For the selected Add Health respondents a few demographic and respondent characteristics generally paralleled patterns of IPV perpetrators found in other studies. 
For example, as shown in Table 6, it appeared that the percentage of white participants who perpetrated IPV $(17.4 \%)$ was less than the percentage of men in other racial groups who perpetrated $(21.8 \%$ to $27.7 \%)$. This observation paralleled findings in other studies regarding partner violence committed by men of color (Cunradi et al., 2002a, Ellison et al., 1999; Riggs \& Caulfield, 2000). Educational patterns regarding IPV were also evident. As shown in Table 7 and Table 8, the commission of partner violence appears to be inversely related to the level of educational attainment, at least until the graduate school level. The reason for the increase in violence at the graduate school level is unknown, but it is important to note that there are less than 30 participants who fell into this category.

With characteristics of IPV perpetrators similar to those found in other studies (e.g., young, less educated, nonwhite) this researcher is led to question the absoluteness of the findings in this research. Though this study's findings indicated that for young adult Christian males, select religious and spiritual factors did not allow for better prediction of the perpetration of IPV, this researcher is concerned that data and statistical elements of the study may have concealed a real relationship between religious and spiritual attitudes or behaviors and partner violence. Potential areas that might have influenced the finding of a true relationship between IPV and religious and spiritual factors include the limitations of using ordinal categorical independent variables, as well as potential multicollinearity problems among the independent variables. 


\section{Limitations of Ordinal Categorical Data}

Religious and spiritual questions, as well as those concerning the perpetration of violence, lend themselves to reporting biases. In order to minimize the influence of social desirability factors that manifest with small-scale, primary data collection, the use of archival data was chosen. Additionally, it was hoped that the breadth of the Add Health study would allow for greater generalization of the results. However, there were significant limitations to using archival data, not the least of which was the construction of the interview questions.

Nine out of 10 of the categorical independent variables in this research were ordinal. While the ordinal scales likely reduced the amount of error caused by overdemanding recall during the Add Health interview, the use of ordinal data limits the ways in which phenomena can be analyzed. Categorical data inherently contains less useful information than comparable interval or ratio measurements, especially when there are small differences to be detected. Berry (1993) recommends that in logistic regression categorical independents be at least at interval level. In other words, the levels of the categorical variable should at least be sensitive to a uniform magnitude of differences between groups, and that there are at least five classifications available. In designing any future studies, this researcher would recommend that an interval scale be used if quantitative independent variables were not possible.

\section{Multicollinearity Issues}

Unlike multiple regression, logistic regression analysis is robust against deviations from the assumptions that the independent variables are normally distributed, 
homoscedastic, or linearly related (Mertler \& Vannatta, 2005). However, LR is highly sensitive to multicollinearity among the independent variables (Mertler \& Vannatta, 2005). In trying to understand the significance of the findings in this study, it is important to consider the possibility that true religion-violence relationships were masked by large standard errors, caused by multicollinearity among the religious or spiritual factors. Because of the excessive standard errors that result when multicollinearity is an issue, it is more difficult to reject the null hypothesis. Such errors increase the likelihood that independent variable coefficients will seem nonsignificant or vary from one sample to the next. Additionally, the model may not result in a good fit, and allow for predictive classification of IPV in unknown cases (Field, 2005).

Though the prescreening VIF and Tolerance values indicated that multicollinearity was not a problem among the independent variables, all of the correlation levels shown in Table 4 and Table 5 were statistically significant $(p<.001)$. Despite the VIF and Tolerance results, a logical assessment of the religious and spiritual factors reflects more the findings among the partialed correlations. It is possible that the religious and spiritual factors used in this study were operationalizations of overlapping religious or spiritual constructs. As seen in the partial correlations in Table 4 and Table 5, higher correlations were found among variables that reflected the less tangible respondents' attitudes or beliefs about their religiosity or spirituality than found among variables that measured observable behaviors. For example, the extent to which a respondent believed himself to be a spiritual or religious person resulted in larger correlations with other variables, than did the frequency of his church attendance. 
Kirkpatrick and Hood's (1990) criticism of Allport's construct of religious orientation could be rendered against the bundle of variables in this study as well. The mixture of self-reported attitudes and behaviors measured by the Add Health questions not only might blur the line between motivations, personality traits, and cognitive styles, as did questions in Allport's Religious Orientation Scale (Gorsuch, 1984, Gorsuch \& McPherson, 1989), they actually might reflect only a single construct.

The results of the Cronbach analysis would also support the single construct supposition, though in the absence of a factor analysis it was not possible to know if there was only one or several separate, but related constructs represented by the Add Health questions. Additionally, interpretations of the Cronbach alpha results in this study should be made cautiously because the potential for inflation due to the larger number of scale items within some of the religious and spiritual factors.

One way of dealing with multicollinearity is to increase sample size (Field, 2005). However, in this study an increase in sample size was not possible with the archival Add Health data set. Moreover, the sample size for both the BR data set $(n=3652)$ and the BC data set $(n=6013)$ analyses were quite large and this researcher is doubtful that any increase in sample size would have improved the model results. Another suggested action for dealing with redundant variables is the combining of or deletion of one or more of the correlated variables. However, there was no obvious reason to delete one variable over another from the model or to combine one variable with another, despite the potential of multicollinearity problems. An improvement in approach for future studies would be to 
perform a factor analysis in order to collapse most appropriately the religious and spiritual factors, if possible.

In sum, despite the statistical findings, it is possible that with the young adult males selected for study, the intrinsic elements of their religious orientation were not developed, but only emerging. Thus the relationship between violence perpetration and religious and spiritual factors was not evident in this study. It is also possible a direct or indirect relationship between religious and spiritual factors and partner violence did exist, but was masked in this study by data and analyses conditions.

\section{Implications for Social Change and Recommended Actions}

Complementing findings in other studies, this research offers new information to researchers and practioners about religious and spiritual factors, as they relate to the perpetration of partner violence by young Christian males. Unlike other studies, which have included a wider range of participant ages, this study was narrowly focused within an age bracket that has been shown to be at higher risk for IPV perpetration. For young males aged 18 to 26 , this researcher concludes that there is no consistent evidence that relates the nine selected religious and spiritual factors to the perpetration of IPV. Fortunately, the religious and spiritual factors examined do not appear to increase IPV perpetration by young men. Unfortunately, it appears that the elements do not moderate IPV either.

Even with mixed results, this research challenges the inclination by ecclesiastical resources to unilaterally include religious and spiritual elements into faith-based batterer's intervention programs (BIP), targeting young male adults. The findings 
illuminate the potential limitations of faith-based BIP efforts that attempt to mitigate partner violence by appealing to intrinsic motivations of batterers. Given the usual time constraints faced when conducting BIP sessions, it may be reasonable in sessions geared toward young men, to exclude some religious teaching and faith-oriented exercises and include elements that address social conformance. The findings keep open the possibility that extrinsic or at least less intrinsic motivations may be key to reducing IPV perpetration in young males. However, church-based BIPs often include more educated, Caucasian men, across a broad age range (Nason-Clark, et al., 2003). Given other research that indicates some intrinsic religious elements may have a mitigating impact on IPV, especially as an abuser ages, this research does nothing to preclude the inclusion of religious elements in the batterer's programs.

The examination of the data patterns of both perpetrating and nonperpetrating respondents revealed a collection of both high and low intrinsic like behaviors, beliefs, and attitudes. This mixture in the level of responses in religious and spiritual factors advances the notion that collaboration between secular and ecclesiastical resources might provide the best, client-tailored approach to batterer's intervention. Motivation to stop the commission of partner abuse might need to come from both within the church and from the larger general community. To this end, it is proposed that the findings of this study be shared in presentation format with community and ecclesiastical resources, followed by a working session to discuss revisions to batterer's intervention programming. Locally, this researcher may be extended an invitation to present her findings to an interfaith community group focused on domestic violence abatement. Further dissemination to 
secular and religious counseling resources could be made through journal publication of this research.

\section{Recommendations for Further Study}

\section{Further Examination the IPV-Religion Relationship}

An examination of the Wave III Add Health partner data may improve the understanding of the findings in this study. Though it was not possible to meet the data security requirements for this study, it is recommended that future studies consider the use of partner information to triangulate the findings of the primary analyses.

Add Health researchers are in the process of completing Wave IV of the longitudinal study, with a focus on respondents who are now 24 to 32 years old. Though the codebook of questions is not yet available to the public, presumably some of the same violence and religious and spiritual questions are being asked of the primary respondents. An examination of the data from Wave IV as compared to Wave III may provide more insight into the relationship between religious or spiritual factors, IPV and age. If the Wave IV questions are predominately ordinal, as in Wave III, this researcher would recommend a factor analysis be completed for both Wave III and Wave IV data in an attempt to reduce problems with multicollinearity before completing logistic regression analyses.

The Add Health data set contains a plethora of information about each respondent include in this study such as personality factors, family situations, friendship and intimate relationship dynamics, motivations, feelings, and substance abuse. Additionally, there is more information about aggression and violence in general, not related to partner 
violence. For researchers the opportunity to explore the dynamics of IPV in light of several other biological, social, and contextual factors is vast.

\section{Addressing Data Set Issues}

As Feagin (1964) modified and improved the operationalization of Allport's religious orientation construct as well as his ROS instrument, a factor analysis of the Add Health religious and spiritual questions might yield a better set of independent factors, with less multicollinearity.

Not surprisingly, there are limitations to using an archival data set. The advantage gained by the national representation within the Add Health data was offset by the inflexibility of the question designs. If primary data collection becomes possible, this researcher would recommend construction of interview questions that included quantitative measurements of both the violence and religious or spiritual factors.

This researcher had hoped to gain a better understanding of the religious or spiritual behaviors, beliefs, and attitudes of young Christian males. Understanding whether males who perpetrated IPV were heterogeneous or homogenous in their religious orientation was key to making recommendations to improve faith-based batterers' intervention programming. While this investigation did not provide clear insight into the intrinsic or extrinsic nature of the religious motivations, actions, and attitudes of young men, it did shed light on the mixed religiosity of both IPV perpetrators and non perpetrators. Though a predictive model for IPV perpetration using religious and spiritual factors was not found, there was some evidence that provides a platform from which this researcher and others can launch new investigations. 


\section{REFERENCES}

Aldarondo, E., \& Sugarman, D. B. (1996). Risk marker analysis of the cessation and persistence of wife assault. Journal of Consulting and Clinical Psychology, 64(5), 1010-1019.

Alker, H. A., \& Gawin, F. (1978). On the intrapsychic specificity of happiness. Journal of Personality, 46(2), 311-322.

Allport, G. W. (1954). The Nature of Prejudice. Cambridge, MA: Addison-Wesley.

Allport, G. W. (1966). Religious context of prejudice. The Journal for the Scientific Study of Religion, 5, 447-457.

Allport, G. W., \& Ross, J. (1967). Personal religious orientation and prejudice. Journal of Personality and Social Psychology, 5(4), 432-443.

Allport, G., \& Ross, J. M. (1999). Religious orientation scale. In P. C. Hill \& R. W. Hood, Jr. (Eds.), Measures of religiosity (pp. 144-153). Birmingham, Alabama: Religious Education Press.

Altemeyer, B., \& Hunsberger, B. (1992). Authoritarianism, religious fundamentalism, quest, and prejudice. The International Journal for the Psychology of Religion, 2(2), 113-133.

Altemeyer, B., \& Hunsberger, B. (1993). Reply to Gorsuch. International Journal for the Psychology of Religion, 3(1), 33-37.

Amaro, H., Fried, L. E., Cabral, H., \& Zuckerman, B. (1990). Violence during pregnancy and substance abuse. American Journal of Public health, 80(5), 575-579.

Annis, A. W., \& Rice, R. R. (2001). A survey of abuse prevalence in the Christian Reformed Church. Journal of Religion \& Abuse, 3(3/4), 7-40.

Ballard, T. J., Saltzman, L. E., Gazmararian, J. A., Spitz, A. M., Lazorick, S., \& Marks, J. S. (1998). Violence during pregnancy: Measurement issue. American Journal of Public Health, 88(2), 274-276.

Barna Group. (2001, March 5). Annual study reveals that America is spiritually stagnant. Barna Update. Retrieved from http://www.barna.org/barna-update/article/5barna-update/37-annual-study-reveals-america-is-spiritually-stagnant 
Barna Group. (2007, January 28). Survey explores who qualifies as an Evangelical. Barna Update. Retrieved from http://www.barna.org/barna-update/article/13culture/111-survey-explores-who-qualifies-as-an-evangelical

Batson, C. (1976). Religion as prosocial: agent or double agent. Journal for the Scientific Study of Religion, 15(1), 29-45.

Batson, C. D., \& Schoenrade, P. A. (1991a). Measuring religion as Quest: 2) Reliability concerns. Journal for the Scientific Study of Religion, 30(4), 430-447.

Batson, C. D., \& Schoenrade, P. A. (1991b). Measuring religion as Quest: 1) Validity concerns. Journal for the Scientific Study of Religion, 30(4), 416-429.

Batson, C. D., \& Ventis, W. L. (1985). Misconception of Quest: A reply to Hood and Morris. Review of Religious Research, 26(4), 398-407.

Batson, C. D., Oleson, K. C., Weeks, J. L., Healy, S. P., Reeves, P. J., Jennings, P., et al. (1989). Religious Prosocial Motivation: Is It Altruistic or Egoistic? Journal of Personality and Social Psychology, 57(5), 873-884. doi:10.1037/00223514.57.5.873

Bennett, L., \& Williams, O. (2001). Controversies and recent studies of batterer intervention program effectiveness. In VAWnet, a Project of the National Resource Center on Domestic Violence/Pennsylvania Coalition Against Domestic Violence. Retrieved from http://www.vawnet.org/

Berry, W. D. (1993). Understanding regression assumptions. Newbury Park, CA: Sage Publications, Inc.

Bevan, E., \& Higgins, D. J. (2002). Is domestic violence learned? The contribution of five forms of child maltreatment to men's violence and adjustment. Journal of Family Violence, 17(3), 223-245.

Brecklin, L. R. (2002). The role of perpetrator alcohol use in the injury outcomes of intimate assaults. Journal of Family Violence, 17(3), 185-197.

Breiding, M. J., Black, M. C., \& Ryan, G. W. (2008). Prevalence and risk factors of intimate partner violence in eighteen U.S. states/territories, 2005. American Journal of Preventive Medicine, 34(2), 112-118. Retrieved from University of Minnesota Libraries \& MINTEX.

Brinkerhoff, M. B., Grandin, E., \& Lupri, E. (1992). Religious involvement and spousal violence: The Canadian case. Journal for the Scientific Study of Religion, 31(1), $15-31$. 
Burch, R. L., \& Gallup, G. G. (1990). Pregnancy as a stimulus for domestic violence. Journal of Family Violence, 19(4), 243-247.

Bureau of Justice Statistics. (1998). Violence by Intimates. Retrieved from US Department of Justice: http://www.ojp.usdoj.gov/bjs

Bureau of Justice Statistics. (2005a). Crime characteristics. Retrieved from http://www.ojp.usdoj.gov/bjs/cvict_c.htm

Bureau of Justice Statistics. (2005b). Offender characteristics. Retrieved from http://www.ojp.gov/bjs/intimate/offender.htm

Burris, C. T. (1994). Curvilinearity and religious types: A second look at intrinsic, extrinsic, and quest relations. The International Journal for the Psychology of Religion, 4(4), 245-260.

Busch, A. L., \& Rosenberg, M. S. (2004). Comparing women and men arrested for domestic violence: A preliminary report. Journal of Family Violence, 19(1), 4957.

Campbell, J. C., Webster, D., Koziol-McLain, J., Block, C. R., Campbell, D., Curry, M. A., et al. (2003). Assessing risk factors for intimate partner homicide: Issue No. 250. Intimate Partner Homicide (pp. 14-19). National Institute of Justice.

Campbell, R., Greeson, M. R., Bybee, D., \& Raja, S. (2008). The co-occurrence of childhood sexual assault, adult sexual assault, intimate partner violence, and sexual harassment: A mediational model of post-traumatic stress disorder and physical health outcomes. Journal of Consulting and Clinical Psychology, 76(2), 194-207.

Cano, A., \& Vivian, D. (2001). Life stressors and husband-to-wife violence. Aggression \& Violent Behavior, 6(5), 459-480.

Carolina Population Center. (2003). Contract for Obtaining Restricted Use Data (chap.) Retrieved from http://www.cpc.unc.edu/projects/addhealth/data/contract

Carolina Population Center. (2004). National longitudinal study of adolescent health: Wave III data documentation.

Cascardi, M., O'Leary, K., \& Schlee, K. (1999). Co-occurrence and correlates of posttraumatic stress disorder and major depression in physically abused women. Journal of Family Violence, 14(3), 227-249. 
Cattaneo, L. B., \& Goodman, L. A. (2003). Victim-reported risk factors for continued abusive behavior: Assessing the dangerousness of arrested batterers. Journal of Community Psychology, 31(4), 349-369.

Centers for Disease Control. (2007). Intimate partner violence prevention scientific information: Risk and protective factors. Retrieved from http://www.cdc.gov/ncipc/dvp/IPV/ipv-risk_protective.htm

Centers for Disease Control and Prevention (CDC), \& National Center for Injury Prevention and Control (NCIPC). (2003, March). Costs of intimate partner violence against women in the United States (pp. 1-55). Atlanta, Georgia: Department of Health and Human Services.

Chang, J., Berg, C. J., Saltzman, L. E., \& Herndon, J. (2005). Homicide: A leading cause of injury deaths among pregnant and postpartum women in the United States, 1991-1999. American Journal of Public Health, 95(3), 471-477.

Chartas, N. D., \& Culbreth, J. R. (2001). Counselor treatment of coexisting domestic violence and substance abuse: A qualitative study. Journal of Addictions \& Offender Counseling, 22(1), 2-11.

Chermack, S. T., Walton, M. A., Fuller, B. E., \& Blow, F. C. (2001). Correlates of expressed and received violence across relationship types among men and women substance abusers. Psychology of Addictive Behaviors, 15(2), 140-151.

Coker, A. L., Smith, P. H., McKeown, R. E., \& King, M. J. (2000). Frequency and correlates of intimate partner violence by type: Physical, sexual, and psychological battering. American Journal of Public Health, 90(4), 245-258.

Collins, K. S., Schoen, C., Joseph, S., Duchon, L., Simantov, E., \& Yellowitz, M. (1999, May). The Commonwealth Fund 1998 Survey of Women's Health. Retrieved from http://www.commonwealthfund.org/publications/publications show.htm?doc id= $\underline{221554}$

Critchlow, B. (1985). The blame in the bottle: Attributions about drunken behavior. Personality and Social Psychology Bulletin, 11(3), 258-274.

Cunradi, C. B., Caetano, R., \& Schafer, J. (2002a). Religious affiliation, denominational homogamy, and intimate partner violence among U.S. couples. Journal for the Scientific Study of Religion, 41(1), 139-151.

Cunradi, C. B., Caetano, R., \& Schafer, J. (2002b). Socioeconomic predictors for intimate partner violence among white, black, and Hispanic couples in the United States. Journal of Family Violence, 17(4), 377-389. 
Dobash, R. E. (2003). Domestic violence: Arrest, prosecution, and reducing violence. Criminology \& Public Policy, 2(2), 313-318.

Donahue, M. J. (1985). Intrinsic and extrinsic religiousness. Journal of Personality and Social Psychology, 48(2), 400-419.

Dutton, D. G., \& Corvo, K. (2006). Transforming a flawed policy: A call to revive psychology and science in domestic violence research and practice. Aggression \& Violent Behavior, 11(5), 453-83.

Dutton, D. G., Bodnarchuk, M., \& Cavanaugh, M. M. (2005). Through a psychological lens: Personality disorder and spouse assault. In D. R. Loseke \& R. J. Gelles (Eds.), Current controversies on family violence (2nd ed., pp. 5-18) Thousand Oaks, CA: Sage Publications.

Dutton, M. A., Kaltman, S., Goodman, L. A., Weinfurt, K., \& Vankos, N. (2005). Patterns of intimate partner violence: Correlates and outcomes. Violence and Victims, 20(5), 483-497.

Eckhardt, C. I. (2007). Effects of alcohol intoxication on anger experience and expression among partner assaultive men. Journal of Consulting and Clinical Psychology, $75(1), 61-71$.

Eckhardt, C. I., Murphy, C., Black, D., \& Shur, L. (2004). Intervention programs for perpetrators of intimate partner violence: Conclusions from a clinical research perspective. Public Health Reports, 121(4), 369-381.

El-Bassel, N., Gilbert, L., Wu, E., Go, H., \& Hill, J. (2005). Relationship between drug abuse and intimate partner violence: A longitudinal study among women receiving Methadone. American Journal of Public Health, 95(3), 465-470.

Ellison, C. G., \& Anderson, K. L. (2001). Religious involvement and domestic violence among U.S. couples. Journal for the Scientific Study of Religion, 40(2), 269-286.

Ellison, C. G., Bartkowski, J. P., \& Anderson, K. L. (1999). Are there religious variations in domestic violence? Journal of Family Issues, 20(1), 87-113.

Ellsberg, M., \& Heise, L. (2005). Researching violence against women: A practical guide for researchers and activists [Brochure]. Washington, DC: World Health Organization, PATH.

Emery, R. E., \& Laumann-Billings, L. (1998). An overview of the nature, causes, and consequences of abusive family relationships : Toward differentiating maltreatment and violence. American Psychologist, 53(2), 121-135. 
Fals-Stewart, W. (2003). The occurrence of partner physical aggression on days of alcohol consumption : A longitudinal diary study. Journal of Consulting and Clinical Psychology, 71(1), 41-52.

Fals-Stewart, W., Leonard, K. E., \& Birchler, G. R. (2005). The occurrence of male-tofemale intimate partner violence on days of men's drinking: The moderating effects of antisocial personality disorder. Journal of Consulting and Clinical Psychology, 73(2), 239-248.

Feagin, J. R. (1964). Prejudice and religious types: A focused study of Southern fundamentalists. The Journal for the Scientific Study of Religion, 4(1), 3-13.

Feder, L., \& Forde, D. (2000). A test of the efficacy of court-mandated counseling for domestic violence offenders: The Broward experiment. In National Institute of Justice (chap.) Retrieved from http://www.ncjrs.gov/pdffiles1/nij/grants/184631.pdf

Feingold, A., Kerr, D. C., \& Capaldi, D. M. (2008). Associations of substance use problems with intimate partner violence for at risk men in long term relationships. Journal of Family Psychology, 22(3), 429-438.

Feld, S. L., \& Straus, M. A. (1989). Escalation and desistance of wife assault in marriage. Criminology, 27(1), 141-141.

Felson, R. B., \& Burchfield, K. B. (2004). Alcohol and the risk of physical and sexual assault victimization. Criminology, 42(4), 837-859.

Field, A. (2005). Discovering statistics using SPSS (2nd ed.) Thousand Oaks, CA: Sage Publications Inc

Field, C. A., Caetano, R., \& Nelson, S. (2004). Alcohol and violence related cognitive risk factors associated with the perpetration of intimate partner violence. Journal of Family Violence, 19(4), 249-253.

Fish, E. W., Faccidomo, S., DeBold, J. F., \& Miczek, K. A.. Alcohol, allopregnanolone and aggression in mice. Psychopharmacology, 153(4), 473-483.

Foss, L. L., \& Warnke, M. A. (2003). Fundamentalist Protestant Christian women: Recognizing cultural and gender influences on domestic violence. Counseling \& Values, 48(1), 14-23.

Fried, L. E., Aschengrau, A., Cabral, H., \& Amaro, H. (2006). A comparison of maternal interview and medical record ascertainment of violence among women who had poor pregnancy outcomes. Maternal and Child Health Journal, 10(5), 451-460. 
Galvani, S. (2004). Responsible disinhibition: Alcohol, men and violence to women. Addiction Research and Theory, 12(4), 357-371.

Gazmararian, J. A., Petersen, R., Spitz, A. M., Goodwin, M. M., Saltzman, L. E., \& Marks, J. S. (2000). Violence and reproductive health: Current knowledge and future research directions. Maternal and Child Health Journal, 4(2), 79-84.

Gelles, R. J. (1987). Family violence. Newbury Park. CA: Sage Publications.

Gelles, R. J., \& Straus, M. A. (1979). Determinants of violence in the family: Toward a theoretical integration. In W. R. Burr, R. Hill, F. Nye, \& I. L. Reiss (Eds.), Contemporary theories about the family: General theories and theoretical orientations (Vol. 1, pp. 549-581). New York: Free Press.

Genia, V. (1993). A Psychometric evaluation of the Allport-Ross I/E scales in a religiously heterogeneous sample. Journal for the Scientific Study of Religion, 32(3), 284-290.

Gerlock, A. A. (2004). Domestic violence and post-traumatic stress disorder severity for participants of a domestic violence rehabilitation program. Military Medicine, 169(6), 470-474.

Gorsuch, R. (1984). Measurement: The boon and bane of investigating religion. American Psychologist, 39(3), 228-236.

Gorsuch, R. L., \& McPherson, S. E. (1989). Intrinsic/extrinsic measurement: I/E-revised and single-item scales. Journal for the Scientific Study of Religion, 28(365), 348.

Gorsuch, R. L., \& Venable, G. (1983). Development of "Age Universal" I-E scale. Journal for the Scientific Study of Religion, 22(2), 181-187.

Grann, M., \& Wedin, I. (2002). Risk factors for recidivism among spousal assault and spousal homicide offenders. Psychology, Crime \& Law, 8(1), 2-23.

Greenfeld, L. C., Rand, M. R., Craven, D., Klaus, P. A., Perkins, C. A., Ringel, C., et al. (1998). Violence by intimates: Analysis of data on crimes by current or former spouses, boyfriends, and girlfriends. Retrieved from http://www.ojp.usdoj.gov/bjs/pub/pdf/vi.pdf

Greenwood, G. L., Relf, M. V., Huang, B., Pollack, L. M., Canchola, J. A., \& Catania, J. A. (2002). Battering victimization among a probability-based sample of men who have sex with men. American Journal of Public Health, 92(12), 1964-1969.

Hadaway, C. K., Marler, P. L., \& Chaves, M. (1993). What the polls don't show: A closer look at U.S. church attendance. Sociological Review, 58(6), 741-752. 
Harris, K. M., Halpern, C. T., Entzel, P., Tabor, J., Bearman, P. S., \& Udry, J. R. (2008). The National Longitudinal Study of Adolescent Health: Research Design. Retrieved from http://www.cpc.unc.edu/projects/addhealth/design

Haugen, R., \& Lund, T. (2000). Achievement motives, incentive values and attribution. Scandinavian Journal of Educational Research, 44(4), 423-432.

Hedin, L. W., \& Janson, P. (2000). Domestic violence during pregnancy. Acta Obstetricia et Gynecologica Scandinavica, 79(8), 625-630.

Heise, L., \& Garcia-Moreno, C. (2002). Violence by intimate partners. World Report on Violence and Health. Retrieved from http://www.who.int/violence_injury prevention/violence/world_report/chapters/e $\underline{\mathrm{n} /}$

Hintze, J. (2008). PASS 2008 (Version 08.0.8) [Computer software]. Kaysville, Utah: NCSS LLC. Retrieved from http://www.ncss.com

Holtzworth-Munroe, A. (2000). A typology of men who are violent toward their female partners: Making sense of the heterogeneity in husband violence. Current Directions in Psychological Science, 9(4), 140-143.

Holtzworth-Munroe, A., \& Stuart, G. L. (1994). Typologies of male batterers : Three subtypes and the differences among them. Psychological Bulletin, 116(3), 476497.

Holtzworth-Munroe, A., Meehan, J. C., Herron, K., Rehman, U., \& Stuart, G. L. (2000). Testing the Holtzworth-Munroe and Stuart (1994) batterer typology. Journal of Consulting and Clinical Psychology, 68(6), 1000-1019.

Holtzworth-Munroe, A., Meehan, J. C., Herron, K., Rehman, U., \& Stuart, G. L. (2003). Do subtypes of maritally violent men continue to differ over time. Journal of Consulting and Clinical Psychology, 71(4), 728-740.

Hood Jr., R. W. (1978). The usefulness of the indiscriminately pro and anti categories of religious orientation. Journal for the Scientific Study of Religion, 17(4), 419-431.

Howard, D. E., Wang, M. Q., \& Yan, F. (2007). Psychosocial factors associated with physical dating violence among U.S. adolescent females. Adolescence, 42(166), 311-324.

Hunt, R. A., \& King, M. (1971). The intrinsic-extrinsic concept. Journal for the Scientific Study of Religion, 10, 339-356. 
Jeyaseelan, L., Sadowski, L. S., Kumar, S., Hassan, F., Ramiro, L., \& Vizcarra, B. (2004). World studies of abuse in the family environment - risk factors for physical intimate partner violence. Injury Control and Safety Promotion, 11(2), 117-124.

Jones, A. S., \& Gondolf, E. W. (2001). Time-varying risk factors for reassault among batterer program participants. Journal of Family Violence, 16(4), 345-359.

Jones, A. S., Fowler, T. S., Farmer, D. F., Anderson, R. T., \& Richmond, D. W. (2005). Description and evaluation of a faith community-based domestic violence pilot program in Forsyth County, NC. Journal of Religion \& Abuse, 7(4), 55-87.

Kahoe, R. D. (1976). Comment on Thompson's "Openmindedness and indiscriminate antireligious orientation. Journal for the Scientific Study of Religion, 15(1), 91-93.

Kahoe, R. D. (1985). The development of intrinsic and extrinsic religious orientations. Journal for the Scientific Study of Religion, 24(4), 408-412.

Kantor, G. K., \& Jasinski, J. L. (1998). Dynamics and risk factors in partner violence. In J. L. Jasinski \& L. M. Williams (Eds.), Partner violence: A comprehensive review of 20 years research (pp. 1-43). Thousand Oaks, CA US: Sage Publications, Inc.

Keenan-Miller, D., Hammen, C., \& Brennan, P. (2007). Adolescent psychosocial risk factors for severe intimate partner violence in young adulthood. Journal of Consulting and Clinical Psychology, 75(3), 456-463.

Kernsmith, P. (2005). Treating perpetrators of domestic violence: Gender differences in the applicability of the theory of planned behavior. Sex Roles, 52(11/12), 757-770.

Kirkpatrick, L. A., \& Hood, R. W., Jr. (1990). Intrinsic-extrinsic religious orientation: The boon or bane of contemporary psychology of religion? Journal for the Scientific Study of Religion, 29(4), 442-462.

Koss, M. P., \& Dinero, T. E. (1989). Discriminant analysis of risk factors for sexual victimization among a national sample of college women. Journal of Consulting and Clinical Psychology, 57(2), 242-250.

Koss, M. P., Bachar, K. J., Hopkins, C. Q., \& Carlson, C. (2004). Expanding a community's justice response to sex crimes through advocacy, prosecutorial, and public health collaboration: Introducing the RESTORE program. Journal of Interpersonal Violence, 19(12), 1435-1463.

Kroop, P. R. (2008). Intimate partner violence risk assessment and management. Violence and Victims, 23(2), 202-219. 
Lee, R. K., Thompson, V. L. S., \& Mechanic, M. B. (2002). Intimate partner violence and women of color: A call for innovations. American Journal of Public Health, 92(4), 530--534.

Leonard, K. E. (2002). Alcohol's role in domestic violence: A contributing cause or an excuse? Acta Psychiatrica Scandinavica, 106(Suppl, 412), 9-14.

Leonard, K. E., \& Senchak, M. (1996). Prospective prediction of husband marital aggression within newlywed couples. Journal of Abnormal Psychology, 105(3), 369-380.

Levendosky, A. A., \& Graham-Bermann, S. A. (2001). Parenting in battered women: The effects of domestic violence on women and their children. Journal of Family Violence, 16(2), 171-192.

Malony, H. (1971). The contribution of Gordon Allport (1897-1967) to the psychology of religion. Journal of the American Scientific Affiliation, 23(3), 99-104.

Maltby, J. (1999). The internal structure of a derived, revised, and amended measure of the Religious Orientation Scale: The 'Age Universal" I-E Scale-12. Social Behavior and Personality, 27(4), 407-412.

Maltby, J. (2002). The Age Universal I-E Scale-12 and orientation toward religion: Confirmatory factor analysis. The Journal of Psychology, 136(5), 555-560.

Marshall, A. D., \& Holtzworth-Munroe, A. (2002). Varying forms of husband sexual aggression: Predictors and subgroup differences. Journal of Family Psychology, 16(3), 286-296.

McClain, E. W. (1978). Personality differences between intrinsically religious and nonreligious students: A factor analytic study. Journal of Personality Assessment, 42(2), 159-166.

McFarlane, J., Soeken, K., Campbell, J., Parker, B., Reel, S., \& Silva, C. (1998). Severity of abuse to pregnant women and associated gun access of the perpetrator. Public Health Nursing, 15(3), 201-206.

McFarlane, J., Wist, W., \& Watson, M. (1998). Characteristics of sexual abuse against pregnant Hispanic women by their male intimates. Journal of Women's Health, $7(6), 739-745$.

Melton, H. C., \& Belknap, J. (2003). He hits, she hits: Assessing gender differences and similarities in officially reported intimate partner violence. Criminal Justice and Behavior, 30, 328-348. 
Mertler, C. A., \& Vannatta, R. A. (2005). Advanced and multivariate statistical methods (3rd ed.) Glendale, CA: Pyrczak Publishing.

Michalski, J. H. (2005). Explaining intimate partner violence: The sociological limitations of victimization studies. Sociological Forum, 20(4), 613-640.

Miller, A. J., Bobner, R. F., \& Zarski, J. J. (2000). Sexual identity development: A base for work with same-sex couple partner abuse. Contemporary Family Therapy: An International Journal, 22(2), 189-200.

Miller, J. (2006). A specification of the types of intimate partner violence experienced by women in the general population12. Violence Against Women, 12(12), 1105-1131.

Murphy, C. M., Meyer, S.-L., \& O'Leary, K. (1994). Dependency characteristics of partner assaultive men. Journal of Abnormal Psychology, 103(4), 729-735.

Nason-Clark, N. (1997). The battered wife: How Christians confront family violence. Louisville, KY: Westminister John Knox Press.

Nason-Clark, N. (2000). Making the sacred safe: Woman abuse and communities of faith. Sociology of Religion, 61(4), 349-368.

Nason-Clark, N. (2004). When terror strikes at home: The interface between religion and domestic violence. Journal for the Scientific Study of Religion, 43(3), 303-310.

Nason-Clark, N., Murphy, N., Fisher-Townsend, B., \& Ruff, L. (2003). An overview of the characteristics of the clients at a faith-based batterers' intervention program. Journal of Religion and Abuse, 5(4), 51-72.

National Institute of Justice (NIJ). (2002). Batterer intervention: Where do we go from here? In Violence Against Women \& Family Violence (Workshop Notes).

National Institute of Justice (NIJ). (2003). Batterer intervention program.

O'Leary, K., Barling, J., Arias, I., Rosenbaum, A., Malone, J., \& Tyree, A. (1989). Prevalence and stability of physical aggression between spouses : A longitudinal analysis. Journal of Consulting and Clinical Psychology, 57(2), 263-268.

Pallant, J. (2007). SPSS survival manual (3rd ed.) New York, NY: McGraw Hill.

Pan, H. S., Neidig, P. H., \& O'Leary, K. (1994). Predicting mild and severe husband-towife physical aggression. Journal of Consulting and Clinical Psychology, 62(5), 975-981. 
Pargament, K. I., Magyar-Russell, G., \& Murray-Swank, N. A. (2005). The sacred and the search for significance: Religion as a unique process. Journal of Social Issues, 61(4), 665-687.

Quigley, B. M., Corbett, A. B., \& Tedeschi, J. T. (2002). Desired image of power, alcohol expectancies, and alcohol related aggression. Psychology of Addictive Behaviors, 16(4), 318-324.

Rand, M. R., \& Saltzman, L. E. (2003). The nature and extent of recurring intimate partner violence against women in the United States. Journal of Comparative Family Studies, 34(1), 137-149.

Reed, E. (2008). Intimate partner violence: A gender based issue? Journal of Public Health, 98(2), 197-198.

Rennison, C. M. (2003, February). Bureau of Justice Statistics Crime Data Brief: Intimate Partner Violence. Retrieved from http://www.ojp.usdoj.gov/bjs/pub/pdf/ipv01.pdf

Rennison, C. M., \& Welchans, S. (2000). Intimate Partner Violence. Bureau of Justice Statistics Special Report. Retrieved from US Department of Justice.

Riggs, D. S., \& Caulfield, M. B. (2000). Risk for domestic violence: Factors associated with perpetration and victimization. Journal of Clinical Psychology, 56(10), 1289-1315.

Salazar, L. F., \& Cook, S. L. (2002). Violence against women: is psychology part of the problem or the solution? A content analysis of psychological research from 1990 through 1999. Journal of Community \& Applied Social Psychology, 12(6), 410421 .

Saltzman, L. E., Johnson, C. H., Gilbert, B. C., \& Goodwin, M. M. (2003). Physical abuse around the time of pregnancy: An examination of prevalence and risk factors in 16 states. Maternal and Child Health Journal, 7(1), 31-47.

Schmaling, K. B., Fonesca, C. A., Stoever, C., Gutierrez, C., Blume, A. W., \& Russell, M. L. (2006). Variables associated with intimate partner violence in a deploying military sample. Military Medicine, 171(7), 627-631.

Sharps, P., Campbell, J. C., Campbell, D., Gary, F., \& Webster, D. (2003). Risky mix: Drinking, drug use, and homicide. In Intimate Partner Homicide (Issue No. 250, pp. 9-13). National Institute of Justice. 
Siegel, J. A., \& Williams, L. M. (2001, July). Risk factors for violent victimization of women: A prospective study, summary. Retrieved from U.S. Department of Justice: http://www.ncjrs.gov/pdffiles1/nij/grants/189160.pdf

Sieving, R., Beuhring, T., Resnick, M. D., Bearinger, L. H., Shew, M., Ireland, M., et al. (2001). Development of adolescent self-report measures from the National Longitudinal Study of Adolescent Health. Journal of Adolescent Health, 28(1), 73-81.

Spanier, G. B. (1976). Measuring dyadic adjustment: New scales for assessing the quality of marriage and similar dyads. Journal of Marriage \& Family, 38(1), 15-28.

Stuart, G. L. (2007, January). The association between drug use and intimate partner violence. The Brown University Digest of Addiction Theory and Application, $26(1), 8$.

Stuart, G. L., Temple, J. R., Follansbee, K. W., Bucossi, M. M., Hellmuth, J. C., \& Moore, T. M. (2008). The role of drug use in a conceptual model of intimate partner violence in men and women arrested for domestic violence. Psychology of Addictive Behaviors, 22(1), 12-24.

Sturgeon, R. S., \& Hamley, R. W. (1979). Religiosity and anxiety. Journal of Social Psychology, 108(2), 137-138.

Sweet, J. A., Bumpass, L. L., \& Call, V. (1988). The Design and Content of The National Survey of Families and Households [NSFH Working Paper \#1, 1988]. Retrieved from http://www.ssc.wisc.edu/nsfh/home.htm

Testa, M., Livingston, J. A., \& Leonard, K. E. (2003, April). Women's substance use and experiences of intimate partner violence: A longitudinal investigation among a community sample. Research In Brief, 04(2), 1.

Tjaden, P., \& Thoennes, N. (2000). Full report of the prevalence, incidence, and consequences of violence against women: Findings from the National Violence Against Women survey (pp. 1-71) [NCJ 183781 funded by the National Institute of Justice and the Centers for Disease Control]. Washington, DC: U.S. Department of Justice.

Torres, S., \& Han, H.-R. (2003). Women's perceptions of their male batterers' characteristics and level of violence. Issues in Mental Health Nursing, 24(6/7), 667-679.

Watson, P. J., Hood Jr., R. W., Morris, R. J., \& Hall, J. R. (1984). Empathy, religious orientation, and social desirability. Journal of Psychology, 117(2), 211-216. 
Watson, P. J., Morris, R. J., Foster, J. E., \& Hood, R. W. (1986). Religiosity and social desirability. Journal for the Scientific Study of Religion, 25(2), 215-232.

Weiner, I. B. (1989). Human motivation. Hillsdale New Jersey: Lawrence Erlbaum Associates.

Weir, E. (2000). Wife assault in Canada. CMAJ: Canadian Medical Association Journal, $163(3), 328$.

White, J. W., \& Smith, P. H (2001). Developmental antecedents of violence against women: A longitudinal approach, executive summary. Retrieved from http://www.ncjrs.gov/pdffiles1/nij/grants/187770.pdf

World Health Organization [WHO]. (2002). World report on violence and health. Retrieved from http://www.who.int/violence injury prevention/violence/world_report/en/full_en. pdf

Yllo, K. A. (2005). Gender, diversity, and violence: Extending the feminist framework. In D. R. Loseke \& R. J. Gelles (Eds.), Current controversies on family violence (2nd ed., pp. 19-34) Thousand Oaks, CA: Sage Publications. 


\section{APPENDIX A:}

\section{ALLPORT'S RELIGIOUS ORIENTATION SCALE QUESTIONS}

Please indicate the extent to which you agree or disagree with each item below by using the following rating scale:

$\begin{array}{ccccc}1 & 2 & 3 & 4 & 5 \\ \begin{array}{c}\text { strongly } \\ \text { disagree }\end{array} & \text { disagree } & \text { neutral } & \text { agree } & \begin{array}{c}\text { strongly } \\ \text { agree }\end{array}\end{array}$

Extrinsic (sub)scale

1. Although I believe in my religion, I feel there are many more important things in my life.

2. It doesn't matter so much what I believe so long as I lead a moral life.

3. The primary purpose of prayer is to gain relief and protection.

4. The church is most important as a place to formulate good social relationships.

5. What religion offers me most is comfort when sorrows and misfortunes strike.

6. I pray chiefly because I have been taught to pray.

7. Although I am a religious person I refuse to let religious considerations influence my everyday affairs.

8. A primary reason for my interest in religion is that my church is a congenial social activity.

9. Occasionally I find it necessary to compromise my religious beliefs in order to protect my social and economic well being.

10. One reason for my being a church member is that such membership helps to establish a person in the community.

11. The purpose of prayer is to secure a happy and peaceful life.

12. Religion helps to keep my life balanced and steady in exactly the same way as my citizenship, friendships, and other memberships do.

\section{Intrinsic (sub)scale}

1. It is important to me to spend periods of time in private religious thought and meditation.

2. If not prevented by unavoidable circumstances, I attend church.

3. I try hard to carry my religion over into all my other dealings in life.

4. The prayers I say when I am alone carry as much meaning and personal emotion as those said by me during services.

5. Quite often I have been keenly aware of the presence of God or the Divine Being.

6. I read literature about my faith (or church). 
7. If I were to join a church group I would prefer to join a Bible study group rather than a social fellowship.

8. My religious beliefs are really what lie behind my whole approach to life.

9. Religion is especially important because it answers many questions about the meaning of life. 
APPENDIX B:

ADD HEALTH QUESTIONS: SECTION 1 - OVERVIEW AND DEMOGRAPHICS

\section{Are you of Hispanic or Latino origin?}

3. What is your Hispanic or Latino background?

You may give more than one answer.

Mexican/Mexican American, Chicano/Chicana, Cuban/Cuban American, Puerto Rican, Central/South, other Hispanic

4. What is your race? You may give more than one answer.

White, black or African American, American Indian or Native, Asian or Pacific

5. What is your Asian background? You may give more than one answer. Chinese, Filipini, Japanese, Asian Indian, Korean, Vietnamese, Other

\section{Which one category best describes your racial background}

1 white; 2 black or African American; 3 American Indian or Native American; 4 Asian or

Pacific Islander; 6 refused; 7 legitimate s kip; 8 don 't know; 9 not applicable 


\section{APPENDIX C:}

\section{ADD HEALTH QUESTIONS: SECTION 7- EDUCATION}

\section{What is the highest grade or year of regular school you have completed?}

6-6th grade; 7-7th grade; 8-8th grade; 9-9th grade; 10-10th grade; 11-11th grade; $12-12$ th grade; 13-1 year of college; 14-2 years of college; 15-3 years of college; $16-4$ years of college; 17-5 or more years of college; 18 -1 year of graduate school; 19-2 years of graduate school; 20-3 years of graduate school; 21-4 years of graduate school; 22-5 or more years of graduate school; 96-refused; 98-don't know; 99-not applicable

What degrees or diplomas have you received? Indicate all that apply.

2. GED or high school equivalency degree

0 not marked; 1 marked; 6 refused; 9 not applicable;! missing

\section{3. high school diploma}

0 not marked; 1 marked; 6 refused; 8 don 't know; 9 not applicable;! missing

\section{4. associate or junior college degree - an AA}

0 not marked; 1 marked; 6 refused; 9 not applicable;! missing

\section{5. bachelor's degree-a BA, AB, or BS}

0 not marked; 1 marked; 6 refused; 9 not applicable;! missing

\section{6. master's degree - an MA or MS}

0 not marked; 1 marked; 6 refused; 9 not applicable;! missing

\section{7. doctoral degree - a PhD, DrPH, and so on}

0 not marked; 1 marked; 6 refused; 9 not applicable;! missing

\section{8. professional degree - a DDS, JD, MD, DVM, and so on}

0 not marked; 1 marked; 6 refused; 9 not applicable;! missing 


\section{CURRICULUM VITAE}

Robbin G. Todhunter

rtodh001@waldenu.edu

\section{EDUCATION}

Doctor of Philosophy - Psychology

2009

Walden University, Minneapolis, Minnesota

Dissertation Topic: The Relationship Between Religious and Spiritual Factors and the Perpetration of Intimate Personal Violence

Master of Science, Psychology

2006

Walden University, Minneapolis, Minnesota

Master of Business Administration

Thomas College, Waterville, Maine

Bachelor of Science, Chemistry

1980

Bates College, Lewiston, Maine

\section{BUSINESS EXPERIENCE}

\section{MESA CONSULTING GROUP, INC.}

VICE PRESIDENT \& PRINCIPAL CONSULTANT Bristol, Connecticut 1996 - Present

Co-founded Mesa Consulting Group, Inc. in 1996. MCG's primary business includes consulting and training in comprehensive quality management system approaches and applied statistical methods for both manufacturing and service industries. Over 450 seminars and workshops have been held to date. Special areas of service include Six Sigma training, statistics training, and consulting, ISO9001 and TS16949 registration consulting/auditing, team building and development, new product development and process analysis and control. Provides strategic direction and implementation plans for a broad range of business improvement initiatives. Additionally, oversee project work, team and employee development and business improvement monitoring as needed. 
INTERNATIONAL PAPER COMPANY

Approximately nineteen years of progressive manufacturing, technical, and quality systems management experience with worldwide forest products company with annual revenues of $\$ 25$ billion and 51,500 employees worldwide

BUSINESS DEVELOPMENT MANAGER Cincinnati, Ohio 1996-1999

Responsible for the building of a charter group charged with creating and proliferating substantial and transformational products across all business units

- Staffed and developed a new group for focus on consumer/customer fundamentals and market assessments

- Acted as a liaison between market research, product development and business unit marketing organizations

- Led group efforts ensuring a stream of innovative products delivering outstanding customer benefits. Conducted consumer research and provided business partners with customer \& consumer insights gained

- Contributed to the development of technology and product strategies by monitoring technology trends/forecasts and blending with newly identified cross divisional markets, products, categories and customers

- Managed staff responsible for development of consumer/customer insights linked with technology platforms to produce substantive and transformational project portfolio for applied research

- Ensured support for business partners in formulating business plans (e.g. Concept of Enterprise, Objectives, Identification of Customers, Distribution Channels, and Product Requirements, Competitive Situations and Reactions, Pro-forma Financials)

- Trained and coached technology and business unit and product development managers in using a disciplined and customer focused process for new product development. Conducted seminars and workshops in customer/consumer research

PLANT MANAGER Knoxville, Tennessee $1992-1996$ Responsible for managing the manufacturing and service aspects of the Industrial Papers plant in an efficient manner while complying with all company procedures and government regulations and ensuring the best possible return. Plant assets totaled $\$ 50$ million including: 120 hourly and 15 management personnel, a polyethylene laminator, a silicon coater, a polyethylene and in-line silicone coater, a wax coating line, a flexographic printing press, asphalt coater and seven rewinders

- Directed the manufacturing of approximately 60 million pounds of product with an approximate value of $\$ 56$ million per year. Achieved favorable mill margin 9 months after startup. Plant was the division low cost producer

- Managed the development and implementation of a unique high performance work system. Maintained facility's union-free position

- Lead the quality improvement effort. Instituted measurement and analysis systems. Reduced claims as a percent of sales by $75 \%$. Plant achieved ISO 9002 certification

- Ensured that all government regulations are met for safety, industrial hygiene and environmental compliance. Improved safety performance by $81 \%$ 
- Manage the corporation's capital through project management, cost management and operations improvements

MANAGER - Corporate Quality Management Memphis, Tennessee $1991-1992$ Responsible for assisting and leading organizations to achieve business results. Provided quality management consulting with senior managers in three divisions and fifteen primary manufacturing facilities (contributing approximately $30 \%$ of corporate sales)

- Assisted business unit managers with the design, utilization, assessment and improvement of quality assurance, communication, measurement, planning and education systems

- Created and helped implement original and innovative strategies for business improvement. Areas included: internal assessments, employee empowerment, benchmarking, supplier/customer partnerships and process control

- Designed and conducted over 40 seminars, presentations and training sessions on topics such as leadership and strategic planning, group process management, employee participation/empowerment, customer satisfaction and process improvement

STATISTICAL CONSULTANT Memphis, Tennessee $1987-1991$

Consulted company-wide on problem solving techniques and applied statistical methods. Worked extensively with both manufacturing and service sectors

- Assisted businesses with the design, implementation, assessment and improvement of measurement, quality assurance and Statistical Process Control (SPC) systems

- Provided direct support to manufacturing facilities on significant product/process problems and provided direct customer interface

- Designed manufacturing trials and experiments, and provided analytical support. Designed and conducted process capability, measurement integrity and SPC studies

- Consulted daily with business managers and lead teams on objective decision making, organizing and training for quality, measurement systems and process improvement methodologies

- Developed and conducted numerous seminars and training sessions in fundamental and intermediate statistical methods, problem solving, process improvement and training methodologies

- Conducted employee focus groups, surveys and interviews for clients

- Designed and conducted over 65 presentations, seminars and training sessions on topics such as process improvement, basic and intermediate statistical methods, specification setting, QFD and customer satisfaction measurement 
ANDROSCOGGIN MILL Jay, Maine $1981-1987$

Held positions of increasing responsibility in the technical department. Participated in mill rotational training program. Project assignments in Pulp (2.5yrs), as well as Paper, Power, Quality Control, Process Control, and Environmental

- Managed laboratory, quality control and technical functions

- Designed and executed process improvement trials and experiments

- Implemented and maintained a real time computer system dedicated to final product quality assurance

- Designed and conducted the first measurement integrity studies for two mill laboratories. Created and executed a plan for achieving and maintaining statistical control of laboratory testing

- Initiated and developed a proactive supplier partnership and testing program

- Developed and conducted SPC training sessions for management and hourly employees

\section{COMMUNITY SERVICE}

- Domestic Violence Counselor, Prudence Crandall Center, New Britain, CT

- Zion Evangelical Lutheran Soup Kitchen Session Coordinator and Volunteer, Bristol, CT

- Batterers' Intervention Program Instructor, Warren County, OH

- Medical Volunteers of Cincinnati, Cincinnati, $\mathrm{OH}$

- Over the Rhine Soup Kitchen Volunteer

- Charter Board of Directors, Sarcoidosis Research Institute, Memphis, TN

\section{LICENSES AND CERTIFICATIONS}

Certified Domestic Violence Counselor, State of Connecticut Certified Quality Engineer, ASQ

\section{HONORS AND AWARDS}

Member, Psi Chi

United Way Volunteer of the Year - 2008

\section{PROFESSIONAL AFFILIATIONS}

Member, American Psychological Association

Senior Member, American Society for Quality 